\title{
Atividade física durante a gestação e baixo peso ao nascer: um estudo de casos e controles.
}

\author{
MONICA YURI TAKITO
}

Tese de Doutorado apresentada ao Departamento de Nutrição da Faculdade de Saúde Pública da Universidade de São Paulo para obtenção do Grau de Doutor. Área de concentração: Nutrição

Orientadora: Profa. Dra.

MARIa Helena D'Aquino Benício

São Paulo

2006 
FICHA CATALOGRAFICA

Takito, Monica Yuri.

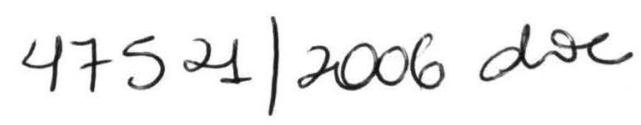

Atividade física durante a gestação e baixo peso ao nascer: um estudo de casos e controles. I Monica Yuri Takito. - 2006.

Tese (doutorado) - FSP- Universidade de São Paulo, 2006. 114.

Palavras-chaves: baixo peso ao nascer, prematuridade, atividade física, gestação 
"O ser humano tem necessidade de movimento, não somente após o nascimento, mas também durante a vida uterina"

(Platão - Leis VI,a) 


\section{Dedicatória}

Este trabalho é dedicado a meus pais, Clarinda e Takito, com os quais aprendo os valores humanos. E a minha pequena familia, Emerson e Isabel, com os quais busco crescer e amadurecer. 


\section{Agradecimentos}

Os meus sinceros agradecimentos à minha orientadora Profa. Dra. Maria Helena D’Aquino Benício, pela competente orientação primando pela qualidade do estudo, com carinho ao indicar o melhor trajeto a ser seguido, estímulo na realização dos diversos projetos e compreensão diante das dificuldades.

Ao grupo do Centro de Pesquisas Epidemiológicas da Universidade Federal de Pelotas, que mediante minha orientadora norteou questōes vitais ao delineamento do estudo. Em especial, ao Prof Aluísio Jardim Dornellas de Barros cuja paciência, questionamentos e respectivas soluções possibilitaram o melhor direcionamento das análises.

À Profa Denise Bergamaschi, pela orientação nas questões estatísticas relativas à reprodutibilidade e validade do questionário.

À Profa Maria Regina Alves Cardoso, pela contribuição na análise do estudo de casos e controles.

Ao Prof Dr Carlos Augusto Monteiro pela preciosa contribuição ao projeto no momento da pré-banca.

Ao Dr Coríntio Mariani Neto pelas valiosas sugestões que precederam as coletas de dados.

À equipe do Hospital Leonor Mendes de Barros pela autorização e receptividade durante as diversas etapas da coleta de dados.

Ao Amparo Maternal e Hospital Santa Marcelina pela autorização e viabilização da coleta de dados. 
Às entrevistadoras e bolsistas de iniciação científica (Juliana e Daniela) pelo dedicado trabalho nas entrevistas, digitação e correção dos questionários.

À Lenycia pela dedicação e por sua amizade durante a execução deste projeto.

Às puérperas que aceitaram participar do estudo, pela paciência para responder os longos questionamentos e interesse em ajudar. $E$ as gestantes que se disponibilizaram ao uso e preenchimento de diversos instrumentos para adequação de um instrumento de medida da atividade física.

Ao CNPq pela disponibilização da verba para a efetivação dessa pesquisa.

Ao meu amor, Emerson, com o qual compartilho inquietações e cujos questionamentos me estimularam a perseverar neste trajeto acadêmico.

Aos meus amados pais, Clarinda e Takito, cujo apoio amoroso é fundamental.

Aos meus queridos irmãos, Daniela, Fabiola e Paulo, que perto ou longe, me apoiaram e incentivaram, e sempre o farão.

À Maria Auxiliadora Borges da Anunciação, a Dora, pelo amor, carinho e dedicação durante meus 31 anos de vida, os quais me fariam muita falta para diversas conquistas profissionais e principalmente pessoais. 


\section{ÍNDICE}

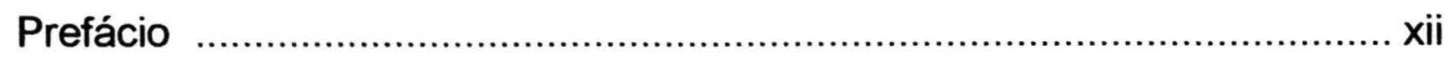

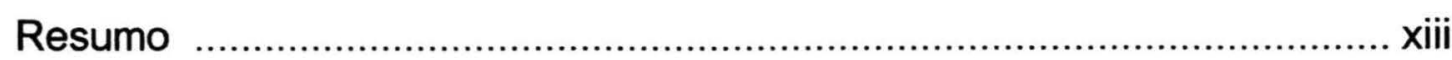

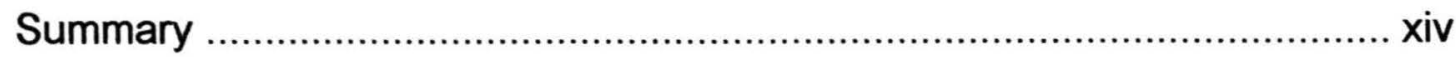

Artigo 1. Atividade física cotidiana em gestantes e baixo peso ao nascer, prematuridade e restrição de crescimento intrauterino: revisão sistemática........................................................ 1

Resumo

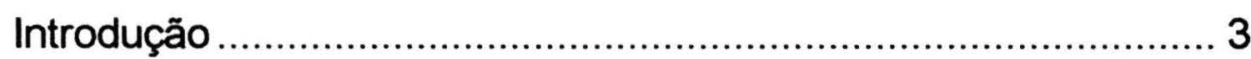

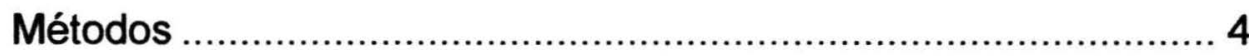

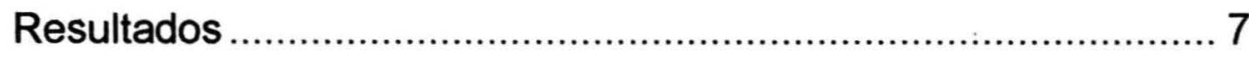

Aspectos metodológicos ………………………………...........

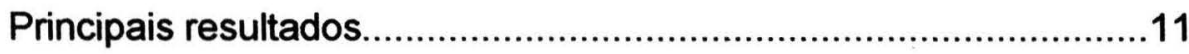

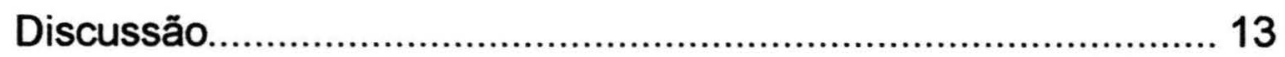

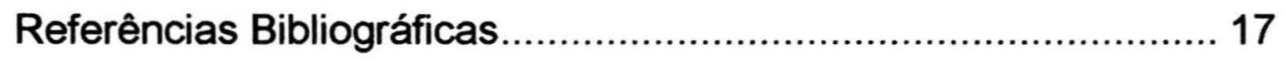

Artigo 2. Avaliação da reprodutibilidade e validade de questionário de atividade física para gestantes.................................................... 33

Resumo

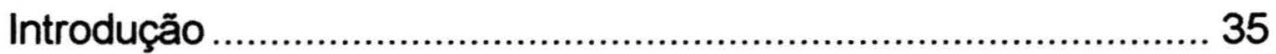

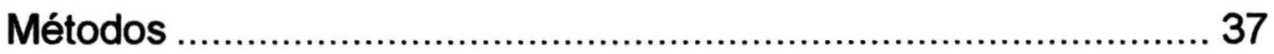

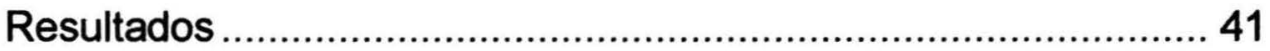

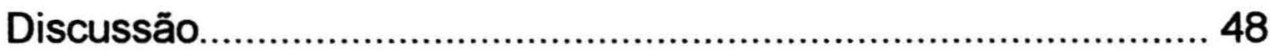

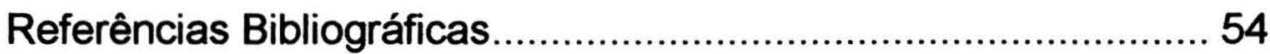

Artigo 3. Atividade física durante a gestação e baixo peso ao nascer: um estudo de casos e controles..................................... 58

Resumo

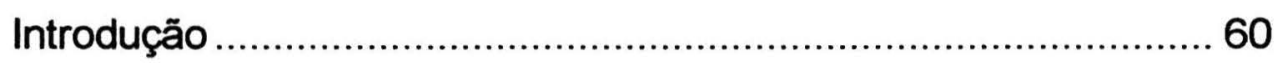




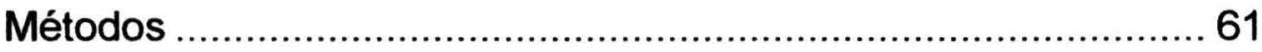

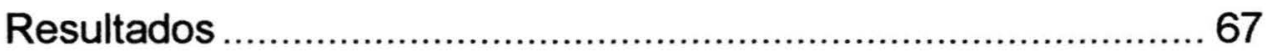

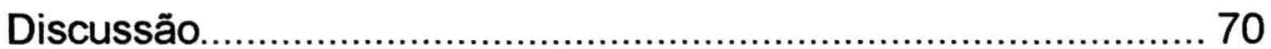

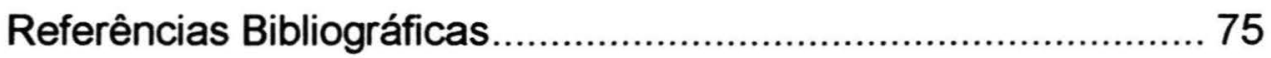

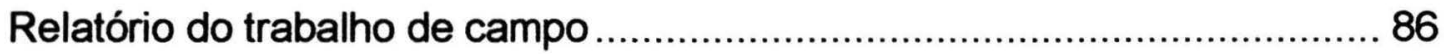

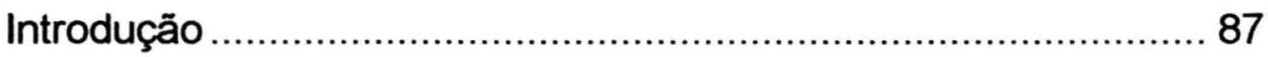

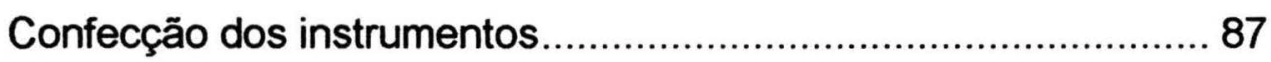

Seleção e treinamento da equipe................................................ 91

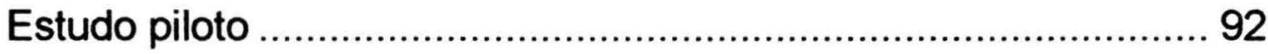

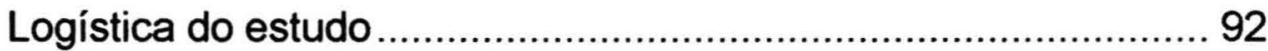

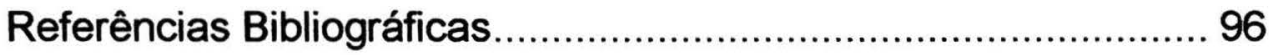

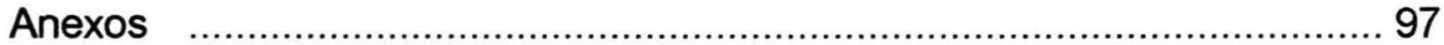

Anexo 1. Comitê de Ética em Pesquisa ........................................ 98

Anexo 2. Termo de consentimento livre e esclarecido.................. 102

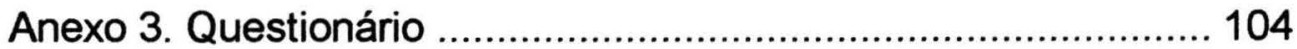

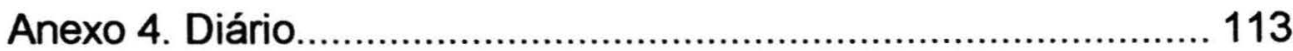




\section{LISTA DE TABELAS}

Artigo 1

Tabela 1. Critérios de avaliação conforme Downs e BLACK (1998). 6

Tabela 2. Revisão bibliográfica da influência da atividade física durante a gestação no peso ao nascer e duração da gestação.

Tabela 3. Síntese dos estudos identificados. 24

Artigo 2

Tabela 1. Características das gestantes estudadas e das perdas

de seguimento. São Paulo, 2004 42

Tabela 2. Valores medianos e quartis do tempo despendido em diferentes dimensões da atividade física. São Paulo, 2004 43

Tabela 3. Análise da reprodutibilidade do questionário de atividade física - variáveis categóricas. São Paulo, 2004 44

Tabela 4. Análise da reprodutibilidade do questionário de atividade física, através do coeficiente de correlação intraclasse $(\mathrm{CCl})$, entre os três questionários. São Paulo, 2004. 45

Tabela 5. Valores medianos e quartis do tempo despendido em diferentes dimensões da atividade física (questionário e frequêncimetro). São Paulo, 2004. 46

Artigo 3

Tabela 1. Distribuição de recém-nascidos de baixo peso (casos) e controles segundo características socioeconômicas, biológicas, reprodutivas, indicadoras de morbidade 
materna, comportamentais e cuidados de pré-natal. São

Paulo, 2005.

Tabela 2. Variáveis de atividade física materna e baixo peso ao nascer, análise bruta. São Paulo, 2005. 82

Tabela 3. Variáveis de atividade física materna e baixo peso ao nascer, análise ajustada. São Paulo, 2005. 83

Tabela 4. Variáveis de atividade física materna e prematuridade, análise bruta. São Paulo, 2005 84

Tabela 5. Variáveis de atividade física materna e prematuridade, análise ajustada. São Paulo, 2005 85 


\section{LISTA DE ABREVIATURAS}

DUM - Data da última menstruação

USG - Ultrassonografia

IG - idade gestacional

BPN - Baixo peso ao nascer

MBP - Muito baixo peso ao nascer

RCIU - Restrição de crescimento intra-uterino

PIG - Pequeno para a idade gestacional

GIG - Grande para a idade gestacional

PREM - prematuros

AF - Atividade física

QAF - Questionário de atividade física

DAF - Diário de atividade física

MET - equivalente metabólico

OMS - Organização Mundial da Saúde

NS - Não significativa

$\mathrm{CCl}$ - coeficiente de correlação intra-classe

OR - odds ratio

IC - Intervalo de confiança

$p$ - nivel de significância

TCLE - Termo de consentimento livre e esclarecido 


\section{PREFÁCIO}

Essa tese foi redigida no formato de três artigos científicos, um relatório técnico e os anexos.

O primeiro artigo apresenta revisão sistemática da literatura utilizando metodologia proposta por Downs e Black (1998).

O segundo artigo estudou a reprodutibilidade e validade de um questionário de atividades físicas durante a gestação, visando adequação da mensuração dessas variáveis.

O terceiro artigo apresentou um estudo de casos e controles para detectar a associação da atividade física materna com o baixo peso ao nascer e a prematuridade.

O relatório técnico, com descrição detalhada da coleta de dados, visa a melhor visualização das ações realizadas não descritas nos artigos. 


\section{RESUMO}

Takito, MY. Atividade fisica durante a gestação e baixo peso ao nascer: um estudo de casos e controles. São Paulo; 2006. [Tese de Doutorado Faculdade de Saúde Pública da USP].

Objetivo: Identificar a magnitude do risco de baixo peso ao nascer (BPN) e prematuridade associados à atividade física durante a gestação. Métodos: $\mathrm{A}$ tese foi apresentada no formato de três artigos cientificos. 1) Revisão sistemática da literatura indexada pelo MEDLINE 2) Validação de questionário de atividade física em amostra de 68 gestantes do segundo trimestre de gestação mediante entrevista para aplicação do questionário repetido com aproximadamente uma semana de intervalo e no puerpério. No periodo entre as duas primeiras entrevistas as mulheres utilizaram monitor de frequeência cardíaca $(n=38)$. 3) Estudo de caso-controle em três hospitais públicos de grande porte do Município de São Paulo: 273 recém-nascidos BPN e 546 controles e sub-amostra dos casos $(n=117)$ com idade gestacional inferior a 37 semanas e controles não prematuros $(n=234)$. As informações foram obtidas mediante entrevistas com as puérperas. Realizou-se análise de regressão logística múltipla pareada e hierarquizada com $p<0,20$ para seleção das variáveis de controle e $p<0,05$ para identificação de associação estatisticamente significativa entre fatores de estudo e desfechos. Resultados: 2) 0 questionário de atividade física apresentou resultados adequados de reprodutibilidade $e$ insatisfatórios de validade quando comparado ao freqüêncímetro. 3) A realização de atividades leves foi identificada como fator de proteção de BPN, com $p$ de tendência linear igual 0,046 . A realização de atividades domésticas associou-se ao $\operatorname{BPN}(p=0,041)$ e à prematuridade ( $p$ de tendência $=0,035$ ). Efeito de proteção da caminhada no lazer mostrou-se significante para a prematuridade. Conclusões: Evidenciou-se que a atividade física durante 0 segundo trimestre de gestação exerce efeito independente sobre o BPN e a prematuridade.

Descritores: peso ao nascer, prematuro, atividade física, gestação. 


\section{SUMMARY}

Takito, MY. Physical activity during pregnancy and low birthweight; a case-control study. São Paulo; 2006. [Doctoral thesis - Faculdade de Saúde Pública da USP].

Objective: To identify the magnitude of the risk of low birthweight (LBW) and preterm birth associated with daily physical activity among pregnant women. Methods: The thesis was presented in the form of three scientific articles. 1) A systematic review of the literature indexed in MEDLINE. 2) Validation of a physical activity questionnaire in a sample of 68 women in the second semester of pregnancy administered during an interview repeated after an approximately one-week interval and during the puerperal period. In the interval between the first two interviews, subjects were evaluated using a hear rate monitor $(n=38)$. 3) Case-control study in three large public hospitals in the Municipality of Sao Paulo, including 273 LBW newborns and 546 controls, and a subsample of cases $(n=117)$ with gestational age below 37 weeks and non-preterm controls $(n=234)$. Information were obtained by interviewing puerperal mothers. We carried out paired, hierarchic multiple logistic regression with a threshold of $p<0.20$ for selection of control variables and significance level of $p<0.05$ for the identification of significant associations between exposures and outcomes. Results: 2) The physical activity questionnaire showed satisfactory reliability but unsatisfactory validity when compared to hear rate monitoring. Light physical activity was identified as a protective factor against LBW, with linear trend $p$-values of 0.046 . The domestic activity was associated with LBW $(p=0.041)$ and preterm birth ( $p$ trend $=0,035)$. Walking for leisure showed a significant protective effect against preterm birth. Conclusions: We found evidence that daily physical activity during the second trimester of pregnancy has an independent effect on LBW and preterm birth.

Key-words: birthweight, preterm birth, physical activity, pregnancy. 
ARTIGO I.

Atividade física cotidiana em gestantes e baixo peso ao nascer, prematuridade e restrição de crescimento intrauterino: revisão sistemática. 


\section{Resumo}

A atividade física vem sendo apontada como um dos múltiplos determinantes do peso ao nascer, prematuridade e restrição de crescimento intra-uterino. $\mathrm{O}$ objetivo deste artigo foi realizar revisão sistemática dirigida aos estudos que envolvem a atividade física cotidiana durante a gestação e os desfechos da gravidez mencionados. Para tanto, realizou-se revisão dos artigos indexados no banco de dados MEDLINE sobre o tema. A qualidade metodológica dos artigos foi mensurada utilizando critérios sugeridos por Downs e Black. Quarenta e quatro artigos que preenchiam os critérios da revisão foram localizados. Há grande variabilidade quanto aos indicadores utilizados para atividade física materna, envolvendo atividades ocupacionais, domésticas, no lazer e para locomoção de maneira global ou parcial. A despeito das diferenças da aferição da exposição, 37 artigos que avaliaram a atividade física na gestação detectaram associação significativa com os desfechos estudados. Dentre os dez artigos que mensuravam a atividade física cotidiana global das mulheres, apenas um não encontrou associação. Esforço deve ser feito para adequada mensuração da atividade física cotidiana durante a gestação. Os resultados da presente revisão indicam que tanto a atividade física excessiva quanto a inatividade física estão associados a desfechos adversos à saúde do recém-nascido.

Descritores: peso ao nascer, prematuro, crescimento intrauterino, atividade física, gestação. 


\section{Introdução}

O baixo peso ao nascer, a prematuridade e a restrição de crescimento intra-uterino (RCIU) têm sido amplamente estudados sob diversos aspectos, em virtude da relevância dos temas para a saúde da população. Dentre os seus múltiplos determinantes (KRAMER 1987, BERKOWITZ e PAPIERNIK 1993, KRAMER et al. 2003), a atividade física tem se destacado pelo potencial de modificação do comportamento na direção de estilo de vida mais ativo que implicaria melhores condições da saúde materno-fetal (ARTAL 2003). Os estudos disponiveis englobam: (1) o dispêndio energético, partindo da suposição de que maior gasto calórico materno poderia suprimir energia do feto; (2) determinadas posturas, por exemplo, a manutenção da postura ereta por tempo prolongado, como capaz de reduzir o fluxo sangüíneo úteroplacentário; (3) atividades ocupacionais ou categorias profissionais (abrangendo aspectos físicos e psicológicos) e (4) atividades de lazer, a prática de exercício regular e as atividades físicas cotidianas, como fatores potencialmente associados ao baixo peso ao nascer, à prematuridade e à RCIU. A literatura conta com diversos estudos de revisão sobre o tema que no entanto, enfocam apenas uma dimensão da atividade física. SIMPSON et al. (1993) apontam as discrepâncias da literatura no tocante à influência da atividade ocupacional sobre o baixo peso ao nascer e a prematuridade. PIRVANIK (1998) analisa apenas o exercício físico materno de moderada e vigorosa intensidade enquanto STERNFELD (1997) direciona sua revisão às recomendações de exercício materno. Detectaram-se, também, quatro metaanálises sobre o exercício físico. LEET e FLICK (2003) apresentam como desfecho o peso ao nascer, LOKEY et al. (1991) analisam os diversos desfechos da gestação, BELL (2002) enfatiza exercícios de vigorosa intensidade e KRAMER (2002) restringe a análise apenas aos exercícios aeróbios. A atividade física ocupacional foi analisada por MOZURKEWICH et al. (2000) em meta-análise que englobou 160.000 mulheres para avaliar a influência desta sobre a prematuridade. 
Como o interesse deste estudo é a atividade física cotidiana, abrangendo suas diferentes dimensões (ocupacional, doméstica, lazer e locomoção) optou-se por realizar revisão sistemática da literatura com o objetivo de organizar o conhecimento atual sobre os desfechos da gestação mencionados. Para assegurar a qualidade metodológica dos estudos a serem incluídos, utilizaram-se os critérios propostos por DownS e BLACK (1998).

\section{Métodos}

Essa revisão bibliográfica foi realizada com base em resumos de artigos indexados na base eletrônica de dados MEDLINE, acessada através da internet, inicialmente sem restrições em termos de tipo de publicações, linguagem ou ano de publicação.

Todos os artigos que estudassem a associação entre atividade física cotidiana durante a gestação e o peso ao nascer, a duração da gestação e a restrição de crescimento intra-uterino foram considerados. Artigos sobre treinamento e exercícios físicos, e acerca de categorias profissionais foram incluídos somente quando envolvessem a atividade física.

A estratégia de busca utilizou palavras-chaves de acordo com o Medical Subject Headings (MeSH) da US National Library of Medicine, responsável pela indexação da base de dados utilizada (MEDLINE). Os seguintes termos foram empregados: "pregnancy" combinadas com "activities of daily living", "motor activity" relacionadas com a exposição, juntamente com "birth weight", "premature infant", "preterm birth", "intrauterine growth", "fetal growth", "pregnancy outcome" para o desfecho. Para assegurar a totalidade de trabalhos, foram incluídas as seguintes palavras chave: "work" e "exercise" que caracterizam outros tipos de exposição, sendo selecionados somente os artigos com o enfoque no tema proposto, ou seja, a atividade física cotidiana. Ainda que "pregnant", "maternal", "physical activity", "preterm delivery", "job", "occupational" não sejam termos de busca do $\mathrm{MeSH}$, foram incluídos por serem observados em 
estudos sobre o tema. Artigos relevantes e que eventualmente não apareceram nas buscas eletrônicas foram avaliados.

Todos os títulos que tinham alguma relação com o tema foram selecionados. Foi realizada leitura inicial dos resumos e posterior dos próprios artigos para eleger os artigos a serem incluídos na presente revisão, independentemente da qualidade metodológica dos mesmos. Não foram incluídos na presente revisão os seguintes tipos de publicações: cartas, comentários, editoriais, revisões, artigos históricos, estudos em animais, outras línguas senão o inglês, português e espanhol.

Os artigos foram então avaliados segundo os critérios propostos por DOWNS e BLACK (1998), em que cada publicação recebe uma pontuação baseada na qualidade metodológica (Tabela 1). Esse escore proposto pelos autores é composto de 27 questões que abordam clareza da redação do artigo, validade externa, validade interna (presença de viés), controle de fatores de confusão e poder estatístico para detecção de efeitos clínicos importantes. Esse instrumento foi adaptado para o presente estudo, conforme proposto por LIMA (2003) e utilizado por MONTEIRO e VICTORA (2005) em sua revisão sistemática sobre o rápido crescimento na infância e obesidade posterior. Essa adaptação foi necessária pelo fato de os critérios terem sido originalmente concebidos para avaliação de ensaios clínicos. Desse modo, as questões $8,13,23$ e 24 que não se aplicavam a estudos observacionais foram excluídas. Houve também a modificação da questão relativa ao poder estatístico, sendo fixado o mínimo de $80 \%$ de poder estatístico para detecção dos desfechos. Cada questão recebia a pontuação de 0 ou 1 (exceto a pergunta 5 que poderia receber até 2 pontos), assim cada artigo poderia receber no máximo 24 pontos. 
Tabela 1. Critérios de avaliação conforme DowNS e BLACK (1998).

\begin{tabular}{|c|c|c|}
\hline \multirow[t]{2}{*}{ Critérios } & \multicolumn{2}{|c|}{ Número de artigos } \\
\hline & Adequado & Inadequado \\
\hline $\begin{array}{l}\text { 1. As hipóteses e/ou objetivos do estudo estão claramente } \\
\text { descritas? }\end{array}$ & 43 & 1 \\
\hline $\begin{array}{l}\text { 2. Os principais desfechos a serem medidos estão claramente } \\
\text { descritos na introducăo ou metodologia? }\end{array}$ & 44 & 0 \\
\hline 3. As características dos entrevistados estão descritas? & 40 & 4 \\
\hline $\begin{array}{l}\text { 4. As exposições de interesse estão claramente descritas? } \\
\text { 5. As distribuiçőes dos principais fatores de confusão estão }\end{array}$ & 41 & 3 \\
\hline $\begin{array}{l}\text { claramente descritas? } \\
\text { 6. Os principais achados/resultados do estudo estão claramente }\end{array}$ & 39 & 5 \\
\hline $\begin{array}{l}\text { descritos? } \\
\text { 7. O estudo fornece dados sobre as estimativas de variabilidade }\end{array}$ & 38 & 6 \\
\hline $\begin{array}{l}\text { aleatória dos principais achados? } \\
\text { 8. Todos os eventos adversos que poderiam ser conseqüência }\end{array}$ & 40 & 4 \\
\hline $\begin{array}{l}\text { da intervenção estão citados? } \\
9 \text {. As características dos sujeitos perdidos durante o } \\
\text { acompanhamento estão citadas? Marcar sim se o estudo não }\end{array}$ & - & - \\
\hline $\begin{array}{l}\text { teve perdas ou as perdas foram muito pequenas. } \\
10 . \text { A probabilidade real está citada (por ex. } 0,035 \mathrm{em} \text { vez de } \\
\text { p<0.05) para os principais desfechos? (exceto quando a }\end{array}$ & 26 & 18 \\
\hline $\begin{array}{l}\text { probabilidade é menor do que } 0,001 \text { ) } \\
11 \text {. Os sujeitos selecionados para o estudo são representativos }\end{array}$ & 29 & 15 \\
\hline $\begin{array}{l}\text { da população onde foram recrutados? } \\
\text { 12. Os sujeitos incluídos no estudo são representativos da }\end{array}$ & 20 & 24 \\
\hline $\begin{array}{l}\text { população de onde foram recrutados? } \\
13 \text {. A equipe, o local e os cuidados onde os pacientes recebiam }\end{array}$ & 15 & 29 \\
\hline o tratamento eram representativos? & - & - \\
\hline $\begin{array}{l}\text { 14. Houve uma tentativa de cegamento dos sujeitos para o.tipo } \\
\text { de exposição? } \\
\text { 15. Houve cegamento dos examinadores dos principais }\end{array}$ & 2 & 42 \\
\hline $\begin{array}{l}\text { desfechos para a exposição? } \\
\text { 16. As análises dos principais resultados foram estabelecidas a }\end{array}$ & 6 & 38 \\
\hline $\begin{array}{l}\text { priori? Ou teve alguma análise de subgrupo? } \\
\text { 17. A análise foi ajustada para diferentes durações de follow-up } \\
\text { em estudos de coorte? O tempo entre intervenção e o desfecho }\end{array}$ & 41 & 3 \\
\hline $\begin{array}{l}\text { foi o mesmo em casos e controles? } \\
\text { 18. Os testes estatisticos utilizados para medir os principais }\end{array}$ & 30 & 14 \\
\hline $\begin{array}{l}\text { desfechos foram adequados? } \\
\text { 19. As exposiçőes foram realísticas (confiáveis), ou seja, sem }\end{array}$ & 41 & 3 \\
\hline $\begin{array}{l}\text { erro de classificação? } \\
20 \text {. As medidas utilizadas para os principais desfechos foram } \\
\text { acuradas? Se o artigo refere outro artigo para demonstrar }\end{array}$ & 30 & 14 \\
\hline $\begin{array}{l}\text { acurácia das medidas, marcar sim. } \\
\text { 21. Os sujeitos dos diferentes grupos de comparação casos e }\end{array}$ & 35 & 9 \\
\hline $\begin{array}{l}\text { controles foram recrutados da mesma população? } \\
\text { 22. Os sujeitos dos diferentes grupos de comparação foram }\end{array}$ & 42 & 2 \\
\hline recrutados ao mesmo tempo? & 42 & 2 \\
\hline 23. Os sujeitos foram randomizados para intervenção? & - & - \\
\hline 24. A randomização foi completa e irrevogável? & - & - \\
\hline $\begin{array}{l}\text { 25. A análise foi ajustada para os principais fatores de confusão? } \\
26 \text {. Os pacientes perdidos durante o acompanhamento foram }\end{array}$ & 38 & 6 \\
\hline $\begin{array}{l}\text { levados em conta? } \\
27 . \text { O poder estatístico do estudo era suficiente para detectar um }\end{array}$ & 13 & 31 \\
\hline efeito importante, com nível de significância de $5 \%$ ? & 2 & 42 \\
\hline
\end{tabular}




\section{Resultados}

As buscas eletrônicas resultaram em mais de 5000 títulos, dos quais foram selecionados 411 títulos relacionados com o tema. Desses foram excluídos 96 artigos de revisão, cinco meta-análises, dois estudos de caso, 16 editoriais, cartas e comentários, 44 artigos em outras línguas. Outros 76 artigos acerca da atividade física que não enfocavam os desfechos propostos, entre os quais destacam-se seis guias de recomendações da prática de atividade física e três sobre validação de questionários. Outros 95 artigos não abordavam a exposição conforme a proposta dessa revisão. Por exemplo: utilização de categorias profissionais sem discriminar as atividades físicas efetivamente realizadas (SANJOSE et al. 1991; SAVITZ et al. 1996).

Foram selecionados para leitura e análise metodológica 77 artigos. Desses foram excluídos 32 após a leitura por não apresentarem os desfechos ou exposição enfocados no presente estudo (Tabela 2).

Tabela 2. Revisão bibliográfica da influência da atividade física durante a gestação no peso ao nascer e duração da gestação.

\begin{tabular}{lc}
\hline & MEDLINE \\
\hline Títulos encontrados & 5083 \\
Resumos avaliados & 411 \\
Resumos potencialmente relevantes & 77 \\
Artigos obtidos & 76 \\
Artigos analisados & 44 \\
\hline
\end{tabular}

\section{Aspectos metodológicos}

Os 44 artigos que envolviam a associação entre a atividade física materna cotidiana e o baixo peso ao nascer, prematuridade e restrição de crescimento intra-uterino ( $\mathrm{RCIU}$ ) foram analisados $e$ as principais características desses estudos são apresentadas na Tabela 3.

De acordo com os dados descritos na Tabela 3 , o valor médio de escore da qualidade metodológica foi 16,7 pontos (desvio padrão $=3,6$ pontos). A Tabela 1 mostra que as deficiências metodológicas mais 
freqüentes nos estudos foram falta de descrição sobre o poder estatístico da análise e não cegamento dos sujeitos e entrevistadores. Adicionalmente, outros problemas metodológicos detectados foram a não consideração das perdas nos resultados ou discussão e a não representatividade da amostra incluída no estudo. Os cinco estudos (AGARWAL et al. 2001; CHIEN e Ko 2004; HENRICH et al. 2003; RodRíguez-Escudero et al. 1980; Rose et al. 1991) com menores valores do escore de qualidade metodológica (abaixo de 15), apresentaram deficiências importantes quanto à validade (interna e externa) e às analises estatísticas.

No tocante à qualidade da aferição da exposição, foram encontrados 14 estudos inadequados. O estudo melhor posicionado nesse item (RAO et al. 2003) apresenta os procedimentos utilizados desde a elaboração e validação do questionário de atividade física cotidiana, até a proposta de escore de atividade a partir do custo energético das atividades realizadas pelas mulheres na Índia rural. Outros estudos (SCHRAMM et al. 1996; HATCH et al. 1993; HENRIKSEN et al. 1995; ALDERMAN et al. 1998; MisRA et al. 1998; TAKITO et al. 2005) ainda que não utilizassem questionários específicos para gestantes, demonstraram cuidado na definição das variáveis relacionadas a cada tipo de atividade física identificadas de forma padronizada e de fácil compreensão pela gestante. Para as análises, duas estratégias foram adotadas: estimativa do gasto energético ou freqüência e/ou duração das atividades. Vinte estudos que abordam atividade ocupacional e doméstica incluíram questões acerca das características do trabalho, tais como, carregar peso, permanecer em pé, e outras posturas extenuantes (curvar, agachar, elevar os braços acima dos ombros). Outros estudos, focados na ocupação principal e no trabalho doméstico realizaram estimativas do tempo e/ou do gasto energético de determinadas posturas e atividades (ZUCKERMAN et al. 1986; BARNES et al. 1991; NiETo et al. 1994; HANKE et al. 1999; ChiEN e Ko 2004). Dois estudos não relataram a metodologia utilizada para mensuração da atividade física (ARMSTRONG et al. 1989; PETRIDOU et al. 2001). 
Dentre os estudos que enfocaram as atividades de lazer, destaca-se a utilização da freqüência, duração e tipo da atividade de lazer (SCHRAMm et al. 1996; CAmpBell e MotTola 2001; MAgANn et al. 2002; LeIfERMAn e EVERSON 2003), tendo como parâmetro a realização de atividade por pelo menos três vezes por semana.

A busca por uma única variável para classificar a atividade física toma direções diferentes. ALDERMAN et al. (1998) utilizaram a percepção da mãe para quantificar sua intensidade, com base em parâmetros objetivos, tais como alterações na sudorese, e nas freqüências cardiaca e/ou respiratória (CAmpbell e Mottola 2001). Por outro lado, estudos como o de Rose et al. (1991), com amostra de 21342 mulheres, utilizaram a auto-classificação da intensidade de esforço físico sem parâmetros objetivos (HERNÁNDEZ-PEÑA et al. 1999; FORTIER et al. 1995).

Quanto às atividades ocupacionais, o escore proposto por MAMELLE et al. (1984) para analisar a fadiga ocupacional foi utilizado por CERóN-MIRELES et al. (1996) e HERNÁNDEZ-PEÑA et al. (1999). Outros estudos englobaram tarefas semelhantes, tais como, permanência em pé, posturas extenuantes, carregar peso, jornada de trabalho, entre outras, para elaboração de escore (SAUREL-Cubizolles e KAMINSKI 1987, 1991; EscribÀ-AgÜIR et al. 2001). SPINILLo et al. (1996) consideraram apenas a intensidade de esforço físico no trabalho (leve ou moderado/vigoroso) para estabelecer escore de atividade física. CHIEN e Ko (2004) utilizaram escore construído com base em sintomas de fadiga ocupacional. TUNTISERANEE et al. (1998) detalharam a mensuração e classificação das mulheres com alta demanda psicológica no trabalho, entretanto, não fazem o mesmo com a demanda física que classificam como leve, moderada e alta.

Verificou-se também que 17 estudos não relataram o período da gestação a que se refere a exposição. Apenas quatro estudos (SAURELCUBizolles e KAMINSKI 1987; LAUNER et al. 1990; KoemeEster et al. 1995; ESCRIBÀ-AGÜIR et al. 2001) restringem a mensuração da exposição ao primeiro trimestre da gestação. Outros quatro estudos analisam apenas o terceiro trimestre da gestação (BARNES et al. 1991; SCHRAMm et al. 1996; 
Cerón-Mireles et al. 1997; Wergeland et al. 1998). Seis estudos de coorte (HATCH et al. 1993, 1997, 1998; HenRIKSEN et al. 1995; MAgÁnN et al. 2002; RABKIN et al. 1990) e um caso-controle (RODRÍGUEZ-Escudero et al. 1980) apresentam os resultados para cada trimestre da gestação. MiSRA et al. (1998), em estudo de coorte, detectaram pequena modificação nas atividades sedentárias e de exercício no lazer. Por outro lado, modificação importante foi encontrada na atividade ocupacional, dormir e subir escadas nos dois primeiros trimestres de gestação. Considerando que as atividades físicas variam no decorrer da gestação, e pautados na maior plausibilidade de exposiçőes durante o segundo trimestre de gestação afetarem mais o crescimento fetal e a duração da gestação, estudos de coorte, ou não, utilizaram medidas referentes ao segundo trimestre (ROSE et al. 1991; Saurel-Cubizolles e Kaminski 1991; Alderman et al. 1998; Chien e Ko 2004; TAKITO et al. 2005) e agrupadas dos primeiros seis meses (MISRA et al. 1998; TUNTISERANEe et al. 1998; KLeBANOFF et al. 1990; Petridou et al. 2001; RAo et al. 2003; TEITELMAN et al. 1990). FLoRACK et al. (1995), por sua vez, realizaram a mensuração das características do trabalho, antes da gestação e acompanharam as modificações no decorrer da gravidez.

Quanto às variáveis de desfecho, 21 estudos abordam o peso ao nascer de forma contínua. Outro grupo de autores analisa a variável de forma categórica, a maioria de maneira dicotômica, classificando como baixo peso ao nascer $(<2500 \mathrm{~g})$. TAKITO et al. (2005) classificaram o grupo de peso inadequado ao nascer, inferior a 3000 gramas. HATCH et al. (1997) também analisaram dessa maneira após detectarem pequena significância estatística com a variável contínua. A duração da gestação é obtida em semanas, geralmente, apresentada de forma dicotômica: prematuridade (<37 semanas) e nascimentos a termo. Três artigos buscaram analisar os nascimentos pós-termo, superiores a 42 semanas (ALDERMAN et al. 1998; MAGANN et al. 2002; LeIfERMAN e EVERSON 2003). A idade gestacional foi obtida a partir da data da última menstruação (DUM), ultrassonografia (USG) precoce e avaliações clínicas (Capurro e Dubowitz). 


\section{Principais resultados}

Os resultados dos estudos, apresentados na Tabela 3, demonstram discrepâncias nos principais achados. Dentre os estudos considerados inadequados, na mensuração da exposição ou dos desfechos, seis não encontraram associação da atividade física com o crescimento fetal e/ou duração da gestação (ZUCKERMAN et al. 1986; PEOPLES-SHEPS et al.1991; Rose et al. 1991; Florack et al. 1995; HenRich et al. 2003; Chien e Ko 2004). Outros seis encontraram associação com todos os desfechos estudados (Rodríguez-Escudero et al. 1980; LAUNER et al. 1990; Nieto et al. 1994; HANKE et al. 1999; Petridou et al. 2001; HA et al.2002) e os nove estudos restantes encontraram associação apenas com um dos desfechos estudados.

Dentre os estudos com menos problemas na mensuração de exposição e desfecho, a média de escore de qualidade foi igual a 18,2 (desvio padrão=1,9), todos com 15 ou mais pontos de escore. A maioria detectou associação da atividade física com pelo menos um desfecho da gestação: peso ao nascer de forma contínua (BARNES et al. 1991; HATCH et al. 1993, 1997; HeNRIKSEN et al. 1995; MAGANN et al. 1996, 2002) ou categórica (SAURel-Cubizolles e Kaminski 1987; Fortier et al. 1995; Cerón-Mireles et al. 1996; Schramm et al. 1996; SPINILlo et al. 1996; TUNTISERANEe et al. 1998; Wergeland et al. 1998; CAMPBELl e MotTOLA 2001; RAO et al. 2003; TAKITO et al. 2005), idade gestacional contínua (BARNes et al. 1991; Koemeester et al. 1995) ou categórica (MAMelle et al. 1984; SAUREL-CubIzolles e KAMINSKI 1987, 1991; MAGANN et al. 1996; HATCH et al. 1998; MISRA et al. 1998; ESCRIBÀ-AgÜIR et al. 2001).

HATCH et al. (1997) detectaram redução de 351 gramas nos recémnascidos das mulheres que trabalhavam mais de $\mathbf{4 0}$ horas semanais com alto escore de esforço (em pé, andando e carregando objetos). RABKIN et al. (1990), entretanto, não confirmam essa tendência após ajuste por variáveis de confusão. BARNES et al. (1991) e MAGANN et al. (1996) detectaram associação positiva do gasto energético total com peso ao nascer. Estresse físico intenso (segundo o gasto energético) associou-se negativamente ao 
peso ao nascer (BARNES et al. 1991). Contrariamente, HATCH et al. (1993) detectaram aumento do peso ao nascer em bebês de mulheres que se exercitaram tanto em intensidades baixa-moderada quanto vigorosa. MAGANN et al. (2002), em estudo de coorte, com 750 trabalhadoras das forças armadas, observaram redução do peso ao nascer de 86,5 gramas com a manutenção de exercício vigoroso e obrigatório do treinamento além da $28^{\mathrm{a}}$ semana de gestação $(p=0,048)$.

SAUREL-CUBIZOLLES e KAMINSKI (1987) encontraram associação positiva das condições extenuantes no trabalho tanto para baixo peso ao nascer como prematuridade. SPINILLO et al. (1996), analisando a RCIU, também verificaram risco com esforço físico moderado-vigoroso aumentado ao excluir as gestantes hipertensas da análise (OR ajustado=2,54;

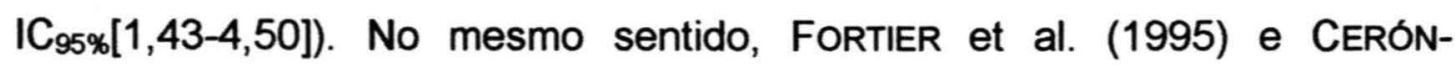
MIRELLES et al. (1996) encontraram associação com a permanência em pé por mais de 6 horas por dia (OR =1,4; IC $\left.\mathrm{C}_{95 \%}[1,03-1,91]\right)$. TAKITO et al. (2005), analisando também as atividades que compunham a permanência em pé, detectaram entre as atividades domésticas, a prática de lavar roupa como risco de peso inadequado ao nascer. WERGELAND et al. (1998) verificaram aumento do risco, para baixo peso ao nascer nas mulheres que carregavam peso. Resultado similar ao obtido por TuntISERANeE et al. (1998) que também identificaram influência de outras caracteristicas do trabalho, como aumento do risco para restrição de crescimento com a permanência na postura agachada e a elevação da prematuridade com realização de caminhada.

SCHRAMM et al. (1996) detectaram proteção significativa para as mulheres que se exercitaram pelo menos três vezes por semana durante, no mínimo, 15 minutos. CAMPBell e Mottola (2001), em seu estudo de casocontrole sobre a prática de exercício estruturado, detectaram aumento do risco de baixo peso ao nascer quando as 401 mulheres, sem restrição à prática de atividade física, realizavam exercício menos de três vezes por semana (OR ajustado=4,54; IC $95 \%[1,63-12,62]$ ) e também quando realizavam cinco ou mais dias (OR ajustado=2,37; IC S5\% $_{95}[1,14-4,91]$ ), 
comparadas aquelas mulheres que realizavam exercícios 3 ou 4 dias por semana.

A associação negativa da duração de tarefas de maior sobrecarga física no trabalho com a idade gestacional (KoEEMESTER et al. 1995), confirma-se em outros estudos (SAUREL-CuBIzolles e KAMINSKI 1987, 1991; EscribÀ-AgüIR et al. 2001) que, assim como MAMElle et al. (1984), analisaram a elevação de escore de fadiga ou condições adversas no trabalho. Por outro lado, MAGANn et al. (1996) detectaram aumento do risco da prematuridade $\left(\mathrm{OR}=1,61 ; \mathrm{IC}_{95 \%}[1,15-2,26]\right)$ com gasto energético diário inferior a $2500 \mathrm{kcal}$. BARNES et al. (1991) detectaram associação positiva entre o gasto energético e a idade gestacional. HATCH et al. (1998), denominando exercício vigoroso a realização de atividades de lazer que implicassem em gasto energético semanal igual ou superior a $1000 \mathrm{kcal}$, identificaram proteção da prematuridade nas mulheres previamente ativas que praticaram exercício vigoroso na gestação. MiSRA et al. (1998), analisando as atividades cotidianas, identificaram aumento de risco da prematuridade tanto para atividades vigorosas como subir escada mais de 10 vezes por dia, quanto para mulheres menos ativas utilizando o fato de assistir televisão por mais de $\mathbf{4 2}$ horas semanais como um indicativo de sedentarismo.

\section{Discussão}

A utilização dos critérios propostos por Downs e BLACK (1998) facilitou a avaliação dos artigos revisados, possibilitando maior objetividade e homogeneidade. Tais aspectos foram fundamentais, visto que os artigos são bastante heterogêneos quanto aos delineamentos de estudos, tamanhos amostrais, mensuração da exposição, definição de desfechos, análises estatísticas e potenciais variáveis de confusão.

Nota-se nos artigos selecionados que os cinco artigos mais antigos, publicados na década de 1980, têm como foco a dimensão ocupacional (SAurel-Cubizolles e KAminski 1987, MAmelle et al. 1984, ARMStrong et al. 1989, RodRíguez-Escudero et al. 1980, ZuCKERMAN et al. 1986). Em 
meados da década de 90 surgiram estudos que buscaram analisar também outras dimensões da atividade física realizada pelas mulheres, tais como atividades no lazer, exercícios, atividades domésticas e para locomoção. Ainda assim, mantém-se o predomínio do enfoque unicamente na dimensão ocupacional. Dentre os 12 artigos analisados na década atual, quatro restringiram a análise à atividade ocupacional e três abordaram, unicamente, atividades físicas de lazer ou exercício físico (CAMPBELL e MOtTOLA 2001; Leiferman e EVERSON 2003; MAgANn et al. 2002). Merecem destaque dez estudos que mensuraram as diferentes dimensões da atividade física cotidiana das gestantes, tais como ocupacional, doméstica, no lazer e de locomoção (HATCH et al. 1993; FoRTIER et al. 1995; HENRIKSEN et al. 1995; MAGANN et al. 1996; SCHRAMm et al. 1996; ALDERMAN et al. 1998; MISRA et al. 1998; CAVAlli e TANAKA 2001; RAO et al. 2003; TAKITO et al. 2005).

Nos países desenvolvidos, nota-se maior número de estudos relacionados à prática regular de atividade física (exercício). Nos países em desenvolvimento, o menor envolvimento das mulheres com a prática de exercícios direciona a atenção às atividades domésticas e ocupacionais, cujas demandas físicas e psicológicas são específicas de cada país ou região, o que dificulta a padronização metodológica.

A qualidade da mensuração da exposição foi inadequada em 14 estudos. No entanto, apenas quatro desses apresentaram escore inferior a 15 , atributo de estudos com baixa qualidade metodológica. A maioria dos estudos utilizou entrevistas ou questionários auto-preenchidos, sem adequada verificação da validade, podendo ser fonte de viés de aferição (SCHLESSMAN 1982). RAO et al. (2003), cujo elevado escore de qualidade metodológica reflete trabalho aprimorado, elaboraram e apresentaram resultados de validação do questionário utilizado. Entretanto, a especificidade do grupo estudado, mulheres na Índia rural, inviabiliza a utilização desse mesmo instrumento por pesquisadores de outros locais com características muito distintas.

Outro aspecto a ser discutido com relação à mensuração da exposição é a utilização de variáveis subjetivas baseadas na percepção 
materna do esforço físico. HANKE et al. (1999) ao analisarem a estimativa do gasto energético com a percepção da mulher ao elevado esforço físico detectaram associação positiva $\left(\chi^{2}=153 ; p=0,01\right)$ e defendem a utilização de variáveis subjetivas de esforço para descrever o trabalho materno.

Com relação aos aspectos fisiológicos relacionados a realização de exercício/esforço físico vigoroso durante a gestação, verifica-se paralelamente à redução do fluxo sanguíneo útero-placentário (HERNÁNDEZPEÑA et al. 1999, HATCH et al. 1993), ocorrem mecanismos compensatórios tais como diminuição da pressão parcial de oxigênio $\left(\mathrm{pO}_{2}\right)$, discreta redução do $\mathrm{pH}$ fetal (no período de recuperação do exercício). No sentido de proteção efetiva ao feto, ocorre aumento de concentração materna e fetal de hemoglobina que eleva a capacidade de transporte e difusão de oxigênio mantendo o suprimento de oxigênio ao feto. A manutenção de intensidade elevada do exercício por tempo prolongado, elevando inclusive a temperatura corporal poderia suprimir tais mecanismos (CLAPP 2003). É plausível supor então que a realização de atividade física adequada ao condicionamento físico da gestante seria benéfica ao crescimento fetal, sendo os extremos, a inatividade/sedentarismo e a duração prolongada, em intensidades vigorosas, potencialmente prejudiciais ao suprimento das necessidades para o crescimento fetal adequado.

DYE et al. (2003), atualizando uma versão anterior (DYE et al. 1996), em revisão de estudos epidemiológicos com objetivo de analisar o exercício físico e a prematuridade, abarcaram também a atividade física ocupacional. Verifica-se que a maioria dos estudos tinha delineamento observacional, diversos com pequeno tamanho amostral ou baixa prevalência da prematuridade e falha no controle por potenciais fatores de confusão. Seus resultados sugerem a associação de esforço físico vigoroso no trabalho e exercício, com resultados negativos e intensidades leves e moderadas com resultados positivos. Como conclusão, os autores recomendam a realização de estudos que avaliem a atividade física de forma global e não apenas as atividades ocupacionais e exercício físico. 
Verifica-se a confirmação dos efeitos deletérios do esforço físico excessivo sobre os produtos da gestação tanto no trabalho (SAURELCubizolles e Kaminski 1991; Koeemester 1995; Spinillo et al. 1996; TUNTISERANEE et al. 1998; WERGELAND et al. 1998) quanto na realização de exercícios físicos (CAMPBell e Mottola 2001; MAgANN et al. 2002). De forma concomitante, diversos estudos apontam efeito igualmente prejudicial no grupo de mulheres menos ativas, seja analisando o gasto energético diário das atividades cotidianas inferior a $2500 \mathrm{kcal}$ (MAGANN et al. 1996), a freqüência de exercícios inferior a três vezes por semana (ScHRAmm et al. 1996; CAMPBell e Mottola 2001) ou o tempo despendido assistindo televisão superior a seis horas diárias (MISRA et al. 1998). Ainda que existam fatores limitantes, tais como a análise fracionada da atividade física, considerando apenas uma ou outra dimensão e as divergências quanto às classificações da exposição, esses resultados falam a favor da hipótese da influência da atividade física sobre os desfechos negativos da gestação como sendo uma curva em $\mathrm{U}$.

A mensuração da atividade física cotidiana, abrangendo as diferentes dimensões (ocupacional, doméstica, lazer, locomoção) faz-se necessária para apreciação adequada de sua influência sobre os desfechos de interesse. As diferenças sócio-econômicas e culturais restringem a utilização dos questionários de atividade física durante a gestação, recentemente publicados, os quais foram elaborados em países desenvolvidos e abarcam as atividades físicas e esportivas de lazer, pouco realizadas em mulheres de baixo nível sócio-econômico, que por sua vez apresentam predomínio das atividades domésticas (CHASAN-TABER et al. 2004; SCHMIDT et al. 2006).

Nota-se deficiências para a verificação da hipótese da curva em $U$ mesmo entre os estudos que consideraram o conjunto das atividades físicas cotidianas. Apenas MISRA et al. (1998) mostraram que tanto atividades que requerem esforço vigoroso quanto inatividade física são fatores de risco para prematuridade. Dessa maneira, torna-se importante, a realização de estudos planejados para testar esta hipótese, os quais devem abranger as quatro dimensões da atividade física cotidiana e fazer uso de instrumento que 
permita aferição confiável das variáveis de exposição. Estudos dessa natureza trarão informações de grande valia para orientações sobre atividade física durante a gestação.

\section{Referências Bibliográficas}

Agarwal S, Agarwal A, Agarwal kn agarwal DK Bansal A. Physical activity and pregnancy outcome in rural undernourished women. Indian Pediatrics 2001;38:1017-22.

Alderman BW, ZhaO H, HOLt VL, Watts DH, Beresford SAA. Maternal physical activity in pregnancy and infant size for gestational age. Ann Epidemiol 1998; 8:513-9.

ARMSTRONg BG, NOLIN AD, MCDONALD AD. Work in pregnancy and birth weigth for gestational age. Br J Ind Med 1989; 46:196-9.

ARTAL R. Exercise and pregnancy. Clin Obst Gynecol 2003; 46(2):377-8.

BARNES DL, ADAIR LS, POPKIN BM. Women's physical activity and pregnancy outcome: a longitudinal analysis from the philippines. Int J Epidemiol $1991 ; 20(1)$ 162-72.

BELL R. The effects of vigorous exercise during pregnancy on birth weight. $J$ Sci Med Sport 2002 Mar;5(1):32-6.

BERKOWITZ GS e PAPIERNIK E. Epidemiology of preterm birth. Epidemiol Rev 1993; 15(2): 414-43.

CAMPBELL MK, MotTOLA MF. Recreational exercise and ocupational activity during pregnancy and birth weight: a case-control study. Am J Obstet Gynecol 2001; 184:403-8.

CAVALLI AS, TANAKA T. Relationship between maternal physical actiities and preterm birth. Environmental Health and Preventive Medicine 2001; 6:74-81.

Cerón-Mireles P, HaRlow SD, SÁnChes-CARRILo CI. The risk of prematurity and small-for-gestational-age birth in Mexico City: the effects of working conditions and antenatal leave. Am J Public Health 1996;86:825-31. 
Cerón-Mireles P, Sánches-Carrilo Cl, harlow SD, núñez-Urquiza RM. Salud Pública Mex 1997;39(1):2-10.

CHIEN LY, Ko YL. Fatigue during pregnancy predicts caesarean deliveries. J Adv Nurs 2004; 45(5):487-94.

CLAPP JF. The effects of maternal exercise on fetal oxygenation and fetoplacental growth. Eur J Obstet Gynecol Reprod Biol 2003; 110:S80-5.

Chasan-Taber L, Schmidt MD, Roberts DE, Hosmer D, Markenson G, FREEDSON PS. Development and validation os a pregnancy physical activity questionnaire. Med Sci Sports Exerc 2004; 36(10): 1750-60.

Dye TD, Fernandez ID, Rains A, Fershteyn $Z$. Recent studies in epidemiologic assessment of physical activity, fetal growth, and pretem delivery: a narrative review. Clin Obstet Gynecol 2003;46(2):415-22.

Dye TD, Oldenettel D. Physical activity and the risk of preterm labor: an epidemiological review and syntesis of recent literature. Semin Perinatol 1996; 20(4):334-9.

DOWNS SH, BLACK $\mathbf{N}$. The feasibility of creating a checklist for the assesment of the methodological quality both of randomised and non-randomised studies of health care interventions. J Epidemiol Community Health $1998,52: 377-84$.

EscribÀ-AgüIR V, Perez-Hoyos S, SAURel-Cubizolles MJ. Physical load and psychological demand at work during pregnancy and preterm birth. Int Arch Occup Environ Health 2001;74:583-8.

Florack eim, Pellegrino aemc, Zielhuis GA, Rolland R. Influence of occupational physical activity on pregnancy duration and birthweight. Scan J Work Environ Health 1995;21:199-207.

FORTIER I, MARCOUX S, BRISSON J. Maternal work during pregnancy and the risks of delivering a small-for-gestacional-age or preterm infant. Scand $\mathbf{J}$ Work Environ Health 1995; 21(6): 412-8. 
Ha E, Cho Si, Chen D, Chen C, Wang L, Xu X, Christiani DC. Does standing at work during pregnancy result in reduced infant birth weight? J Occup Environ Med 2002;44(9): 815-21.

Hanke W, Kalinka J, Makowiec-Dabrowska T. Heavy physical work during pregnancy - a risk factor for small-for-gestational-age babies in poland. Am J Ind Med 1999; 36:200-5.

Hatch MC, Shu Xo, Mclean dE, Levin B, Begg M, Reuss L, Susser M. Maternal exercise during pregnancy, physical fitness, and fetal growth. Am J Epidemiol 1993; 137(10):1105-14.

НАTCH M, Jı BT, SHU XO, Susser M. Do standing, lifting, climbing, or long hours of work during pregnancy have an effect on fetal growth? Epidemiology 1997;8:530-6.

HATCh M, LeVIN B, Shu XO, Susser M. Maternal leisure-time exercise and timely delivery. Am J Public Health 1998; 88:1528-33.

HeNRICH W, Schmider A, Fuchs I, Schmidt F, Dudenhausen JW. The effects of working conditions and antenatal leave for the risk of premature birth in berlin. Arch Gynecol Obstet 2003;269:37-9.

HenRIKsen TB, HedegaARd M, SECHEN NJ. Standing and walking at work and birthweight. Acta Obstet Gynecol Scand 1995; 74:509-16.

Hernández-Peña P, Kageyama ML, Coria I, Hernández B, harlow S. Condiciones de trabajo, fatiga laboral y bajo peso al nacer en vendedoras ambulantes. Salud Publica Mex 1999; 41(2):101-9.

KLEBANOFF MA, ShIONO PH, CAREY JC. The effect of physical activity during pregnancy on preterm delivery and birth weight. Am J Obstet Gynecol 1990; 163(5 Pt1):1450-6.

Koemeester AP, Broesen JPJ, Treffers PE. Physical work load and gestational age at delivery. Occup Envirom Med 1995; 52:313-5.

KRAMER MS. Determinants of low birth weight: methodological assessment and meta-analysis. Bull World Health Organ 1987;65(5):663-737. 
KRAMER MS. Aerobic exercise for women during pregnancy (Cochrane review). The Cochrane Library, Issue 4, 2002. Chichester; UK: John Wiley e Sons.

KRAMER MS. The Epidemiology of Adverse Pregnancy Outcomes: An Overview. J Nutr 2003; 133(suppl):1592-6.

Launer LJ, Villar J, Kestler E, De Onis M. The effect of maternal work on fetal growth and duration of pregnancy: a prospective study. Br J Obstet Gynaecol 1990;97:62-70.

LeET T, Flick L. Effect of exercise on birthweigth. Clinical Obstetric and Gynecology 2003; 46(2):423-31.

LEIFERMAN JA, EVERSON KR. The effect of regular leisure physical activity on birth outcomes. Matern Child Health J 2003; 7(1):59-64.

LIMA RC. Efeito do peso ao nascer sobre a função pulmonar de adolescentes nascido em Pelotas, RS, em 1982. Pelotas (RS); 2003. [Tese de Doutorado - Universidade Federal de Pelotas]

Lokey EA, Tran ZV, Wells CL, Myers BC, Tran AC. Effects of physical exercise on pregnancy outcomes: a meta-analytic reviem. Med Sci Sports Exerc 1991; 23(11):1234-9.

Magann E, Evans SF, Weitz B, Newnham JP. Antepartum, intrapartum and neonatal significance of exercise on healthy low-risk pregnant working women. Obstet Gynecol 2002; 99:466-72.

Magann EF, Evans SF, NeWNham JP. Employment, exertion, and pregnancy outcome: assessment by kilocalories expended each day. Am J Obstet Gynecol 1996; 175:182-7.

Mamelle N, LAUmon B, LAzAR P. Prematurity and ocupational activity during pregnancy. Am J Epidemiol 1984; 119:309-22.

MisRa DP, Strobino DM, Stashinko EE, NAgey DA E NANDA J. Effects of physical activity on preterm birth. Am J Epidemiol 1998; 147:628-35.

MONTEIRO POA, VICTORA CG. Rapid growth in infancy and childhood and obesity in later life - a systematic review. Obes Rev 2005;6:143-54. 
MoZURKEWICH E, LUKE B, AVNI M, Wolf F. Working conditions and adverse pregnancy outcome: a meta-analysis. Obstet Gynecol 2000; 95:623-35.

Nieto A, Matorras R, Serra M, Valenzuela P, Molero J. Multivariate analysis of determinants of fetal growth retardation. Eur J Obstet Gynecol Reprod Biol 1994; 53:107-13.

Peoples-Sheps mD, Siegel E, Suchindran CM, Origasa h, Ware A, BARAKAT A. Characteristics of maternal employment during pregnancy: effects on low birthweight. Am J Public Health 1991; 841:1007-12.

Petridou e, Salvanos h, Skalkidou a, Dessypris $N$, Moustaki $M$, TRICHOPOULOS $\mathrm{D}$. Are there common triggers of preterm deliveries? $\mathrm{Br} \mathbf{J}$ Obstet Gynecol 2001; 108:598-604.

PIRVANIK JM. Potencial effects of maternal physical activity on birth weight: brief review. Med Sci Sports Exerc 1998; 30(3): 400-6.

Rabkin CS, Anderson HR, Bland JM, Chamberlain G, Peacock JL. Maternal activity and birth weight: a prospective, population-based study. Am J Epidemiol 1990; 131(3):522-31.

Rao S, Kanade A, margetts bM, Yajnik CS, lubree h, Rege S, Desal B. JACKSON A, FALL CHD. Maternal activity in relation to birth size in rural India. The Pune Maternal Nutrition Study. Eur J Clin Nutr 2003; 57:53142.

Rodríguez-Escudero FJ, Belausteguigoitia-Abando FJ, GutiérRez MARTINEZ S. Implicaciones perinatales del trabajo y el descanso en la gestante. Ann Esp Pediat 1980; 13(6):465-76.

Rose NC, HADDOW JE, PALOMAKI GE, KNIGHT GJ. Self-rated physical activity level during the second trimester and pregnancy outcome. Obstet Gynecol 1991; 78:1078-80.

SANJose S, Roman E, Beral V. Low birthweight and preterm delivery, Scotland, 1981-84: effect of parents' occupation. Lancet 1991; 338: 42831 
Saurel-Cubizolles MJ, Kaminski M. Pregnant women's working conditions and their changes during pregnancy: a national study in France. $\mathrm{Br} \mathbf{J}$ Ind Med 1987; 44: 236-43.

SaURel-Cubizolles MJ, KAminskI M. Is preterm delivery still related to physical working conditions in pregnancy? J Epidemiol Community Health 1991; 45: 29-34.

SAvitz, D. A.; Olsham, A. F. e Gallagher K. Maternal occupation and pregnancy outcome. Epidemiology 1996; 7(3): 269-74.

Schmidt MD, Freedson PS, Pekow P, Roberts D, Sternfeld B, ChasanTABER L. Validation of the Kaiser physical activity survey in pregnant women. Med Sci Sports Exerc 2006; 38(1):42-50.

SChlesselman JJ. Case-control studies: design, conduct, analysis. Monographs in epidemiology and biostatistics. New York: Oxford University Press, 1982.

SCHRAmm WF, Stockbauer JW, Hoffman HJ. Exercise, employment, other daily activities, and adverse pregnancy outcomes. Am J Epidemiol 1996;143(3):211-8.

SIMPSON JL. Are physical activity and employment related to preterm birth and low birthweight? Am J Obstet Gynecol 1993; 168:1231-8.

Spinillo, A.; Capuzzo, E.; Baltaro, F.; Piazzi, G.; Nicola, S. e lasci, A. The effect of work activity in pregnancy on the risk of fetal growth retardation. Acta Obstet Gynecol Scand 1996; 75:531-6.

SteRnfELD B. Physical activity and pregnancy outcome: review and recommendations. Sports Med 1997; 23 (1):33-47.

TAKITO MY, BENÍcIO MHDA, LATORRE MRD. Postura materna durante a gestação e sua influência sobre o peso ao nascer. Rev Saude Publica 2005; 39(3): 325-32.

Teitelman am, Welch ls, Hellenbrand kg e Bracken mB. Effect of maternal work activity on preterm birth and low birth weight. Am J Epidemiol 1990; 131(1):104-13. 
Tuntiseranee P, Geater A, Chongsuvivatwong $V$ e Kor-anantakul 0. Effect of heavy maternal workload on fetal growth retardation and preterm delivery. JOEM 1998; 40(11): 1013-21.

Wergeland E. StRand K, Bordahl PE. Strenuous working conditions and birthweight, Norway 1989. Acta Obstet Gynecol Scand 1998; 77:26371.

Zuckerman BS, Frank DA, Hingson R, MoRelock S, Kayne HL. Impact of maternal work outside the home during pregnancy on neonatal outcome. Pediatrics 1986;77(4):459-64. 
Tabela 3. Sintese dos estudos identificados.

\begin{tabular}{|c|c|c|c|c|c|c|}
\hline Autor/País/ano & Delineamento & Amostra Exposiçōes & Desfechos & Resultados & Comentários & Escore" \\
\hline $\begin{array}{l}\text { Agarwal et al. } \\
2001 \\
\text { India }\end{array}$ & $\begin{array}{l}\text { coorte } \\
\text { prospectiva }\end{array}$ & $\begin{array}{l}2331 \text { AF Doméstica } \\
\text { Gasto energético: leve, moderada e } \\
\text { vigorosa }\end{array}$ & $\begin{array}{l}\text { Peso ao nascer } \\
\text { (48h poss-parto) }\end{array}$ & $\begin{array}{l}\text { Análise multivariada (coeficiente e } p \text { ) } \\
\text { AF pesada com } 28 \text { sem aumenta o peso ao nascer }(2,25 ; p=0,01) \\
\text { AF pesada com } 36 \text { sem diminui o peso ao nascer }(-1,7 ; p=0,02) \text { e } \\
\text { comprimento ao nascer }(-0,0047 ; p=0,001) \\
\text { Repouso, atividade leve/moderada NS }\end{array}$ & & 7 \\
\hline $\begin{array}{l}\text { Alderman et al. } \\
1998 \\
\text { EUA }\end{array}$ & $\begin{array}{l}\text { observacional } \\
\text { retrospectivo a } \\
\text { partir de outro } \\
\text { estudo matriz }\end{array}$ & $\begin{array}{l}291 \text { Atlvidade fisica cotidiana } \\
\text { (CARDIA PAH Adaptado) } \\
\text { Demanda fisica auto-percebida } \\
\text { (moderada/Nigorosa) }\end{array}$ & $\begin{array}{l}\text { Peso ao nascer } \\
\text { (certificados de nascimento) } \\
\text { Idade gestacional (exame } \\
\text { cllinico) }\end{array}$ & $\begin{array}{l}\text { Maior escore de atividade fisica indica proteçáo de GIG, Odds Ratio=0,3 } \\
\left(I C_{96 \%}[0,2-0,7]\right) \text { na analise univariada, năo permanecendo a significancia } \\
\text { na análise ajustada. } \\
\text { PIG năo afetado (amostra pequena) } \\
\text { Prematuridade NS }\end{array}$ & $\begin{array}{l}\text { Amostra pequena } \\
P I G=22 \text { e } G \mid G=37 \\
\text { pretermo }=24 \text { e } \\
\text { postermo }=9\end{array}$ & 17 \\
\hline $\begin{array}{l}\text { Armstrong et al. } \\
1989 \\
\text { Canadá }\end{array}$ & retrospectivo & $\begin{array}{l}22404 \text { AF Ocupacional } \\
\text { Nao cita as exposiçøes (levantar pesos; } \\
\text { turno de trabalho; Indice de Mamelle; } \\
\text { horas de trabalho semanais) }\end{array}$ & $\begin{array}{l}\text { Peso ao nascer } \\
\text { Peso ao nascer ajustado } \\
\text { pela idade gestacional }\end{array}$ & $\begin{array}{l}\text { Carregar peso mais de } 15 \text { vezes por dia: } \\
\text { \% predito do peso ao nascer }=98,8(98-99,6) \\
\text { Peso para idade: } 99,1(98,3-99,9) \\
\text { Trabalhar } 246 \text { horas/semana: } \\
\% \text { predito do peso ao nascer }=(99,1 ; 98,2-100) \\
\text { peso ajustado para idade gestacional NS } \\
\text { indice de fadiga Mamele: } \\
\text { Peso ao nascer }(p=0,03)\end{array}$ & & 15 \\
\hline $\begin{array}{l}\text { Barnes et al. } \\
1991 \\
\text { Filipinas }\end{array}$ & $\begin{array}{l}\text { coorte } \\
\text { prospectiva }\end{array}$ & $\begin{array}{l}2741 \text { AF ocupacional e doméstica } \\
\text { Agrupadas: } \\
\text { Gl: năo economicamente ativas, } \\
\text { Gll: trabalho doméstico remunerado, } \\
\text { Glll: outras atvidades remuneradas }\end{array}$ & $\begin{array}{l}\text { Peso ao nascer } \\
\text { Idade gestacional } \\
\text { (variáveis contínuas) }\end{array}$ & 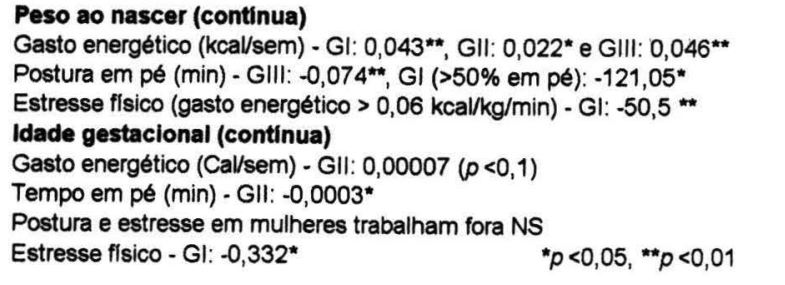 & $\begin{array}{l}\text { Autores apontam } \\
\text { para pequeno } \\
\text { tamanho amostral } \\
\text { nos sub-grupos ao } \\
\text { nâo detectar outras } \\
\text { associaçoes com a } \\
\text { idade gestacional. }\end{array}$ & 15 \\
\hline $\begin{array}{l}\text { Campbell e } \\
\text { Mottola, } 2001 \\
\text { Canadá }\end{array}$ & caso-controle & $\begin{array}{l}529 \text { AF Lazer } \\
\text { Exercicio estruturado e recreacional } \\
\text { Recomendaça: } 3 \text { ou mais vezes por } \\
\text { semana por no minimo } 15 \text { minutos }\end{array}$ & $\begin{array}{l}\text { Pequeno para a Idade } \\
\text { Gestacional (< percentil } 15 \\
\text { da curva de crescimento) }\end{array}$ & $\begin{array}{l}\text { Exercício no } 3^{\circ} \text { trimestre (referéncia: } 3-4 \text { vezes por semana) } \\
\left.\text { menos de } 3 \text { vezes por semana - OR=2,64 (IC } C_{96 \%}[1,29-5,39]\right) \\
5 \text { ou mais vezes por semana - OR= } 4,61\left(I_{96 \%}[1,73 ; 12,32]\right) \\
\text { AF recreacional e ocupacional NS }\end{array}$ & $\begin{array}{l}164 \text { casos } \\
365 \text { controles }\end{array}$ & 17 \\
\hline
\end{tabular}




\begin{tabular}{llc}
\hline Cavalli e Tanaka, transversal & 1714 AF Lazer (praticante/nåo) \\
2001 & retrospectivo (3- & AF Domestica (100\%, mais de 50\%, \\
Japâo & 4 meses pós- & menos de 50\%) \\
& parto) & AF Ocupacional (escore de fadiga \\
& & Mamelle)
\end{tabular}

Cerón-Mireles et coorte

al. 1996 prospectiva

México

2623 AF Ocupacional

ocupaçăo, $n^{\circ}$ empregos; horas/sem

horas em pé; esforço fisico e

temperatura; área; tarefas; reduçáo

jornada; stress; uso da licença:

Indice de Mamelle

Cerón-Mireles et retrospectivo

al. 1997

2623 AF Ocupacional

Tipo de ocupacto; jornada semana; em pé/dia; esforço fisico; modif de

Aarefas; estresse; toxicos

AF Doméstica

pessoas na casa; crianças; tarefas

pesadas; descanso (intervalos)

\section{Chien, 2004 coorte}

Taiwan prospectiva

Escriba-Agair et caso-controle

al. 2001

633 AF Ocupacional (Escore de fadiga)

Grupos: nâo-trabalhadora, trabalho

sedentário, trabalho ativo (andando / em

pé >3 horas/dia)

AF Doméstica (ajuda no trabalho de

casa e cuidado crianças)

\section{AF Ocupacional}

carga fisica do trabalho (em pe;

posturas extenuantes; carregar peso

(

demanda psicologica;

tempo de transporte
Prematuridade

mulheres que tiveram AF Ocupacional; que realizaram menos da metade

da AF Domestica e nâo exercitaram na gestaçâo maior risco de

prematuridade ( $p=0,024 ; p=0,015$ e $p=0,044$ respectivamente)

Realizaram menos da metade das atividades domésticas ( 3 ou mais

doenças) Hospitalizadas antes de $37 \mathrm{sem} O R=4,7\left(\mathrm{IC}_{95 \%}[2,67 ; 8,26]\right)$

AF Ocupacional - $O R=1,66\left(I C_{96} \times[1,07 ; 2,58]\right) p<0,05$ (postura; carregar

peso; fadiga entre outros NS)

Nullparas AF Ocupacional - OR= 4,16 $\left(\mathrm{IC}_{96 \%}[1,59 ; 10,83]\right)$

Multiparas Toda AF Doméstica - OR= $0,23\left(I C_{95 \%}[0,07 ; 0,74]\right)$

Mais da metade da AF Doméstica - OR $=0,31\left(I C_{0}, 0,11 \cdot 0,88\right)$

AF Lazer - exercitar-se durante a gestaçăo $O R=0,65\left(I_{95 \%}[0,25 ; 1,67]\right)$

Pequeno para a ldade PIG

Gestacional (percentil< 10 ) trabalhar $>50$ horas/sem OR= $1,59\left(I C_{96 \times}[1,14 ; 2,22]\right)$

Prematuridade

37 em pe $>7 \mathrm{~h} / \mathrm{d}: \mathrm{OR}=1,4\left(I \mathrm{C}_{95 \times}[1,03 ; 1,91]\right)$

semanas, USG e DUM) sem licença OR=1,55 $\left(\mathrm{IC}_{95 \times}[1,12 ; 2,14]\right)$

Prematuridade NS

PIG: 261

Prematuros: 288

PIG: 2417

PREM: 242

Baixo peso ao Nascer Ocupaçâa; carregar peso; turno; esforço físico NS

5 ou + h/sem $O R=1,6\left(I C_{95 \%}[1,17 ; 2,28]\right)$

em pé>7h/d $O R=1,4\left(I_{96 \%}[1,1 ; 1,9]\right)$ NS apos ajuste

Descanso entre jornada doméstica $x$ sem descanso $(10,8 \%$ e $15,9 \%$ de

Baixo peso ao nascer)

Sem licença maternidade $O R=2,2\left(I_{95 \%}[1,7 ; 2,9]\right)$

Interrupģáo do trabalho por doença ou incapacidade

$O R=1,7\left(I C_{96 x}[1,3 ; 2,3]\right)$

Năo trabalha e trabalho sedentário diferenças sócio-económicas.

Escore de fadiga e partos cesáreas $O R=1,04\left(\mid C_{95 \%}[1,01 ; 1,07)\right)$

Escore de fadiga e prematuridade $O R=1,05\left(\operatorname{IC}_{96 \times}[0,99 ; 1,11]\right) p=0,08$

Prematuridade (DUM)

Carregar peso $(+5 \mathrm{~kg}) \mathrm{OR}=1,73\left(\mathrm{I} \mathrm{C}_{95 \%}[1,17 ; 2,57]\right)$

Muito pretermo (22-32 sem) Carga fisica de trabalho (escore médio $O R=1,59\left(I C_{964}[1,05 ; 2,39]\right)$

Moderado $(33-36$ sem)

escore alto $O R=2,31\left(I_{95 \%}[1,43 ; 3,73)\right.$

Prematuridade moderada e muito prematuros mesma tendencia:

carga trabalho media OR=1,73 (IC $96 \%[1,11 ; 2,68])$, carga de trabalh

alta $O R=2,35\left(I C_{96 *}[1,41 ; 3,94]\right)$

Prematuros induzidos maiores $O R$ que espontâneos para carga $+5 \mathrm{~kg}$ 


\begin{tabular}{ll}
\hline Florack et al. & coorte \\
1995 & prospectiva \\
Holanda &
\end{tabular}

Holanda

128 AF Ocupacional

"gasto energético (escore de fadiga

tempo $x$ peso de gasto energético o

escore de intensidade)

" carga biomecanica= pressáo

Duraçăo da gestaçăo Entre $30-40^{\prime}$ sem:

(diferença em dias da data alto escore de intensidade e velocidade alta: -18dias

abdominal segun

Peso ao nascer ajustado

pela diferença da duraçấo BPN: NS

pressâo crónica)

AF Doméstica: tempo; tamanho da

famllia e ajuda em casa

Fortier et al. retrospectivo

1995

4390 AF Ocupaciona

Tipo, interrupçáo, em pé $(<3 ; 3-5 ;>=0)$ carregando objetos pesados $(0 ; 1-9$; $>=10 \mathrm{~kg}$; desconhecido).

AF Lazer/AF Doméstica (19 questóes abertas)

$\begin{array}{ll}\text { Ha et al. } 2002 & \text { coorte } \\ \text { China } & \text { prospectiva }\end{array}$

1222 AF Ocupacional

trabalho doméstico ou nâo (em pé,

agachada, sentada, inclinada, esforço

fisico e carregar peso)

\section{Hanke et al. retrospectivo}

1999

Polonia parto

1064 AF Ocupacional Medida objetiva: gasto energético no trabalho (METs)

Sentada maior peso ao nascer NS

Esforço fisico; em pé ou postura

sedentária (medida subjetiva)

Ambiente (estresse; temp etc), linha de

produçăo, duraçăo do trabalho,

exposiçáo a cada fator

AF Doméstica

(leve/moderada/pesada)

Hatch et al. 1993 coorte

EUA

prospectiva

462 AF Lazer (Minesota LTPAQ)

"Nenhum exercicio

Exercicio de intensidade baix

moderada ( $<=1000 \mathrm{Cal} / \mathrm{sem}$ )

Exercicio vigoroso(>1000 Cal/sem)

Considerou-se condicionada se o gasto

energético de lazer no trimestre anterio

fosse maior $1000 \mathrm{kcal} / \mathrm{sem}$
Pequeno para a Idade Pequeno para idade gestacional

23

Trabalhar em pe: $3-5$ horas $O R=1,13\left({ }_{1} C_{95 \%}(0,83 ; 1,55]\right) ; 6$ ou mais horas

prematuridade (DUM e US) por dia OR=1,42 (IC

semana de gestaçăo $O R=1,91\left(I C_{05 \%}[1,12 \cdot 3,25)\right)$

Prematuridade

Trabalhar em pé 6 ou mais horas por dia $O R=1,45\left(I C_{96 \%}[0,84 ; 2,49]\right)$

Parar de

Trarar de trable

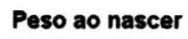

Peso ao nascer

Em pé menor peso ao nascer NS

Ajustada para fatores de confusato:

Em pé 3 ou mais horas por dia: $-16,8$ g/hora $(p=0,01)$

Em pé e ldade gestacional ( $n=27$ pretermo e $n=27$ pós-termo):

incremento de 0,05 semanas/hora $(1-1,11) p=0,058$

Outras atividades NS

Pequeno para a Idade

Duraçăo do trabalho NS

Gestacional (< percentil 10 Gasto energético NS

da curva de referéncia) Elevado esforço físico (relatado) $O R=3,51\left({ }_{195 \%}[1,32-9,14]\right)$

Em pé/sentada NS

Tempo descansando em casa NS

Associaçăo entre a medida objetiva (gasto energético) e a subjetiva

$\left(x^{2}=153 ; p=0,001\right)$

rabalhadoras de

ndústria

petroquimica

\section{Crescimento fetal}

Mulheres que realizaram exercicios de baixa-moderada intensidade

78 PIG

comparadas com quem nấo se exercitou em cada trimestre:

pela idade gestacional: USG $1^{0} ;+60\left(\mid \mathrm{C}_{95 \%}[-30 ;+151]\right) ; 2^{0} ;+97\left(\mid \mathrm{C}_{95 \times}[+10 ;+184]\right)$ e $3^{\circ}: 86\left(I \mathrm{C}_{96 \times}[-1,+174]\right)$

$<18$ semanas e DUM) Com aumento da significancia estatistica no $2^{\circ} \mathrm{e} 3^{\circ}$ trimestres apos

exclusấo de mulheres com desfechos adversos prévios.

Exercicio moderado durante a gestaçăo: $+124\left(\mid C_{95 \%}[-6 ;+255]\right)$

Exercicio vigoroso durante a gestaçăa: $+276 \mathrm{~g}\left(\mathrm{IC}_{95 x[}[+54 ;+497]\right)$

(n) 


\begin{tabular}{|c|c|c|c|c|c|c|c|}
\hline $\begin{array}{l}\text { Hatch et al. } 1997 \\
\text { EUA }\end{array}$ & $\begin{array}{l}\text { coorte } \\
\text { prospectiva }\end{array}$ & $\begin{array}{l}717 \text { AF Ocupacional } \\
\text { "Trabalhar até } 20, \text { mais de } 20 \text { a } 40 \text { ou } \\
\text { mais de } 40 \text { horas por semana) } \\
\text { "Escore (em pé, carregar objetos } \\
\text { pesados e andando): elevado ou baixo } \\
\text { 13/1/28//36 semanas }\end{array}$ & $\begin{array}{l}\text { Peso ao nascer (variável } \\
\text { continua e dicotómica: peso } \\
\text { inadequado inferior a } 3000 \\
\text { gramas) } \\
\text { Prematuridade (idade } \\
\text { gestacional: USG <18 } \\
\text { semanas e DUM) }\end{array}$ & \multicolumn{2}{|c|}{ 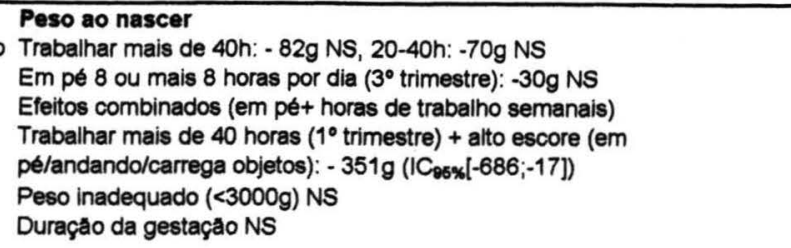 } & & $\overline{17}$ \\
\hline $\begin{array}{l}\text { Hatch et al. } 1998 \\
\text { EUA }\end{array}$ & $\begin{array}{l}\text { coorte } \\
\text { prospectiva }\end{array}$ & $\begin{array}{l}557 \text { AF Lazer (Minesota MLTPAQ) } \\
\text { "Nenhum exercicio } \\
\text { "Exercicio de intensidade baixa- } \\
\text { moderada ( }<=1000 \mathrm{kcal} / \mathrm{semana}) \\
\text { "Exercicio vigoroso(>1000 kcalsem) } \\
\text { Condicionada : gasto energético de } \\
\text { lazer no trimestre anterior superior a } \\
1000 \mathrm{kcal} / \mathrm{sem} \text {. }\end{array}$ & $\begin{array}{l}\text { Prematuridade (IG: USG } \\
\text { <18 semanas e DUM) } \\
\text { PRE32: } 32 \text {, PRE34: } 34 \text { e } \\
\text { PRE36: } 36 \text { semanas. } \\
\text { Postermo } \\
\text { POS42: } 42 \text { e POS } 43: 43 \\
\text { semanas. }\end{array}$ & \multicolumn{2}{|c|}{ 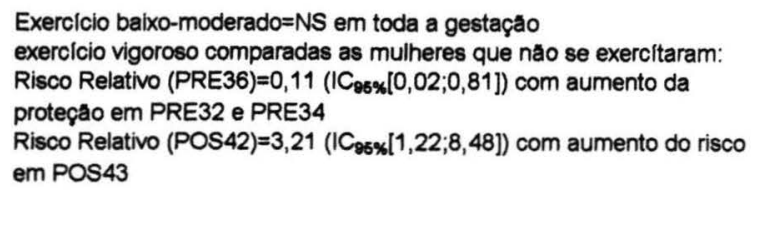 } & $\begin{array}{l}\text { exercicio vigoros } \\
\text { proteçao pretermo e } \\
\text { risco posparto. }\end{array}$ & 19 \\
\hline $\begin{array}{l}\text { Henrich et al. } \\
2003 \\
\text { Alemanha }\end{array}$ & caso-controle & $\begin{array}{l}707 \text { AF Ocupacional } \\
\text { trabalhou/ tipo de trabalho } \\
\text { Condiçoes de trabalho }\end{array}$ & Prematuridade & \multicolumn{2}{|c|}{$\begin{array}{l}\text { tipo de ocupaçăo NS } \\
\text { em pé; curvada; máos acima do ombro; virada; ajoelhada; NS } \\
\text { carregar peso NS } \\
\text { dona de casa e trab NS }\end{array}$} & 237 prematuros & 6 \\
\hline $\begin{array}{l}\text { Henriksen et al. } \\
1995 \\
\text { Dinamarca }\end{array}$ & $\begin{array}{l}\text { coorte } \\
\text { prospectiva }\end{array}$ & $\begin{array}{l}4249 \text { AF Doméstica, AFLazer } \\
\text { AF Ocupacional } \\
\text { permanéncia em pé ou caminhada } \\
\text { categorias estabelecidas a priori. }\end{array}$ & $\begin{array}{l}\text { Peso ao nascer ajustado } \\
\text { para idade gestacional } \\
\text { (USG }<21 \text { semanas) }\end{array}$ & $\begin{array}{l}\text { Análise bruta } \\
\text { Em pé ( }>5 \mathrm{~h} / \mathrm{dia}):-68 \mathrm{~g}(p=0,04) \\
\text { Andando }(2-5 \mathrm{~h} / \mathrm{dia}):+22 \mathrm{~g}(p=0,14) \\
\text { Ambos pé (>4h/dia): }-151 \mathrm{~g}(p=0,04) \\
\text { Exposiçăa ininterrupta: }\end{array}$ & 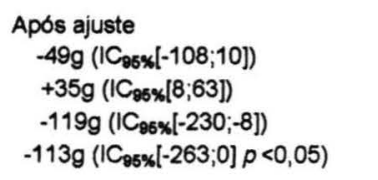 & & 19 \\
\hline $\begin{array}{l}\text { Hernandez-Peña } \\
\text { et al. } 1999 \\
\text { México }\end{array}$ & $\begin{array}{l}\text { retrospectivo } \\
\text { (últimos } 3 \text { anos) }\end{array}$ & $\begin{array}{l}\text { 426 AF Ocupacional (Mamelle) } \\
\text { esforço fisico (levantar peso/cansaço) } \\
\text { ambiente físico, jornada de trabalho } \\
\text { (h/sem; transporte; trabalho doméstico) } \\
\text { posturas }\end{array}$ & $\begin{array}{l}\text { Baixo peso ao nascer } \\
\text { (relatado) }\end{array}$ & \multicolumn{2}{|c|}{$\begin{array}{l}\text { Transporte >90minutos/dia }=O R=23,0\left(I C_{95 \%}[1,1 ; 468,0]\right) \\
\text { Năo ter infraestrutura: OR= } 7,7\left(I C_{96 \%}[1,8 ; 33,0]\right) \\
\text { Esforģo fisico NS; jornada NS }\end{array}$} & $\begin{array}{l}\text { amostra: vendedoras } \\
\text { ambulantes } \\
55 \text { BPN } \\
90 \text { trabalharam na } \\
\text { gestaçăo }\end{array}$ & 16 \\
\hline $\begin{array}{l}\text { Klebanoff et al. } \\
1990 \\
\text { EUA }\end{array}$ & $\begin{array}{l}\text { coorte } \\
\text { prospectiva }\end{array}$ & $\begin{array}{l}7100 \text { AF Ocupacional e Lazer } \\
\text { primeiros } 5 \text { meses da gestaçâo } \\
\text { permanénncia em pé (longo } \\
\text { periodo);rabalho/exerclio pesado } \\
\text { /suando;trabalho/exercicio leve }\end{array}$ & $\begin{array}{l}\text { Prematuridade } \\
\text { Peso ao nascer (ajustado } \\
\text { para idade gestacional: } \\
\text { DUM) }\end{array}$ & \multicolumn{3}{|c|}{$\begin{array}{l}\text { Prematuridade } \\
\text { Em pé }>=8 \mathrm{~h} / \mathrm{dia} \text { OR= } 1,31\left(\left(\mathrm{IC}_{95 \%} \times[1,01 ; 1,71]\right)(p \text { tendéncia }=0,06)\right. \\
\text { Trabalho leve }>=8 \mathrm{~h} / \mathrm{dia} O R=0,59\left(\left(\mathrm{I}_{96 \times}[0,38 ; 0,93]\right)(p \text { tendéncia }=0,019)\right. \\
\text { Trabalho pesado NS } \\
\text { Peso ao nascer NS }\end{array}$} & 15 \\
\hline $\begin{array}{l}\text { Koemeester et } \\
\text { al. } 1995 \\
\text { Holanda }\end{array}$ & $\begin{array}{l}\text { coorte } \\
\text { prospectiva }\end{array}$ & $\begin{array}{l}116 \text { AF Ocupacional } \\
\text { (caminhar, em pé, carregar peso, } \\
\text { agachada, sentada, horas trabalho, } \\
\text { alta carga de esforço fisico) }\end{array}$ & $\begin{array}{l}\text { Idade Gestacional (USG } \\
\text { em } 80 \% \text { e DUM em } 20 \% \text { ) }\end{array}$ & \multicolumn{2}{|c|}{$\begin{array}{l}\text { Duraçăo de tarefas de alta carga de trabalho fisico nas mulheres sem } \\
\text { indicaçáo de parto prematuro (coeficiente }=-0,49 \text { e } p=0,004 \text { ) }\end{array}$} & amostra: enfermeiras & 15 \\
\hline
\end{tabular}

Nenhum exercicio - Exercicio de intensidade baixa (c) $1000 \mathrm{kcal} / \mathrm{semana})$ Condicionada : gasto energético de azer no trimestre anterior superior

Henrich et al. caso-controle

AF Ocupacion

trabalhou/ tipo de trabalno

AF Doméstica, AFLazer

AF Ocupacional

caminhad

Ocupacional (Mamelle)

estorço físico (levantar peso/cansaço)

(h/sem; transporte; trabalho doméstico)

Peso ao nascer (ajustad

DUM)

(n)




\begin{tabular}{|c|c|c|c|c|c|c|}
\hline $\begin{array}{l}\text { Launer et al. } \\
1990 \\
\text { Guatemala }\end{array}$ & $\begin{array}{l}\text { coorte } \\
\text { prospectiva }\end{array}$ & $\begin{array}{l}15786 \text { AF Domestlca } \\
\text { ajuda; } n^{\circ} \text { crianças } \\
\text { Ocupaclonal } \\
\text { tipo (manual, escrituraria), postura } \\
\text { (sentada, em pe, andando), nivel de } \\
\text { intensidade fisica, horas de trabalho, } \\
\text { escore (alto: trabalhar }>=40 \text { horas / } \\
\text { semana; em pé ou caminhando, em } \\
\text { trabalho manual com intensidade } \\
\text { moderada-intensa) }\end{array}$ & $\begin{array}{l}\text { Pequeno para a Idade } \\
\text { Gestaclonal (PIG) } \\
\text { Parto prematuro } \\
\text { PIG/Pretermo: <37sem e } \\
<=\text { percentil } 10 \\
\text { Pretermo: }<37 \text { sem e } \\
\text { >percentil } 10 \\
\text { PIG: }>=37 \text { sem e <=percentil } \\
10\end{array}$ & 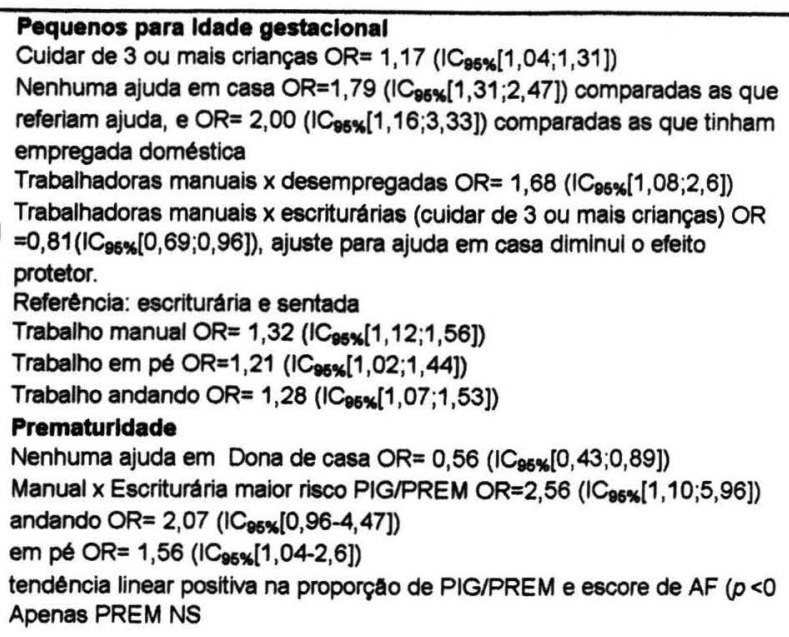 & & $\overline{18}$ \\
\hline $\begin{array}{l}\text { Leiferman e } \\
\text { Everson, } 2003 \\
\text { EUA }\end{array}$ & $\begin{array}{l}\text { retrospectivo (17 } \\
\text { semanas apos o } \\
\text { parto) }\end{array}$ & $\begin{array}{l}9089 \text { AF Lazer } \\
\text { GI (referéncia): Praticantes AF Lazer } \\
\text { condicionadas (AF antes da gestaçăo) } \\
\text { GII: Nao praticantes condicionadas } \\
\text { GIII: Praticantes nâo condicionadas } \\
\text { GIV: Năo praticantes nâo condicionadas }\end{array}$ & $\begin{array}{l}\text { Duraçăo da gestaçáo } \\
\text { (pré/pós e termo) } \\
\text { Peso ao nascer (Baixo } \\
\text { peso: <2500g e Muito Baixo } \\
\text { peso : }<1500 \mathrm{~g} \text { ) }\end{array}$ & 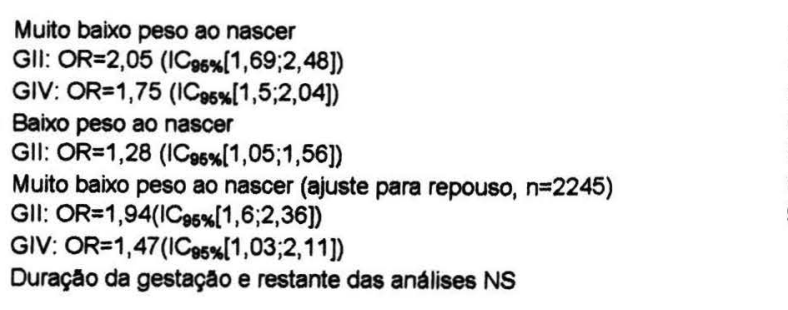 & $\begin{array}{l}\text { Questoes do } \\
\text { estudo:Voce se } \\
\text { exercitou ou praticou } \\
\text { esportes pelo menos } \\
3 \text { vezes por semana } \\
\text { antes (depois) da } \\
\text { gravidez? }\end{array}$ & 22 \\
\hline $\begin{array}{l}\text { Magann et al. } \\
2002 \\
\text { Australia }\end{array}$ & $\begin{array}{l}\text { coorte } \\
\text { prospectiva }\end{array}$ & 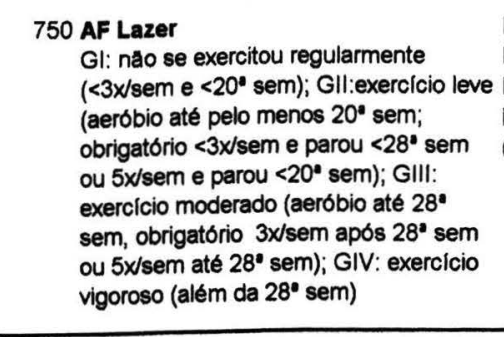 & $\begin{array}{l}\text { Peso ao nascer } \\
\text { Parto prematuro } \\
\text { Restriçäo de crescimento } \\
\text { intra uterino } \\
\text { (< percentil 10) }\end{array}$ & 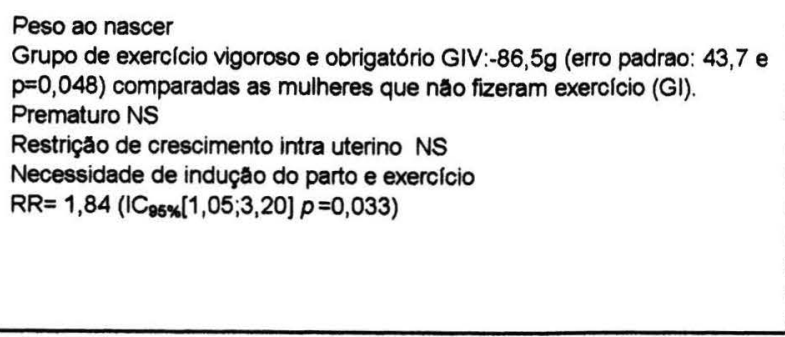 & $\begin{array}{l}\text { Obrigatório (pelo } \\
\text { menos } 3 \times 30 \text { minutos } \\
\text { no treinamento), } \\
\text { voluntário }(3 \times 30 \mathrm{~min}) \\
\text { e aeróbio }(60-80 \% \text { da } \\
\text { frequéncia cardiaca } \\
\text { máxima). GI } \\
(n=217) \\
\text { GII }(n=222) \\
G I I I(n=73) \\
G I V(n=238)\end{array}$ & 19 \\
\hline
\end{tabular}




\begin{tabular}{|c|c|c|c|c|c|c|}
\hline $\begin{array}{l}\text { Maggan et al. } \\
1996 \\
\text { Austrália }\end{array}$ & $\begin{array}{l}\text { Observacional } \\
\text { prospectivo }\end{array}$ & $\begin{array}{l}2743 \text { AF Ocupacional (gasto energético) } \\
\text { horas/semana; descriçáo } \\
\text { AF lazer (gasto energético) } \\
\text { G1: : }=2300 \text { kcal/dia, GII: } 2301 \text { a } 2500, \\
\text { GIII: } 2501 \text { a 2700, GIV: } 2701 \text { a } 2900 \text { e } \\
\text { GV: >2900 kcal/dia }\end{array}$ & $\begin{array}{l}\text { Peso ao nascer } \\
\text { Parto prematuro } \\
\text { Restriçăo de crescimento } \\
\text { Intra uterino }\end{array}$ & $\begin{array}{l}\text { Peso ao nascer como variavel continua, tendo o GIII como referencia } \\
\text { Gl:-73g(p=0,011), GIIl:-60g(p=0,017), GIV:-23g(p=0,33) e GV:-22g(0,515) } \\
\text { Prematuridade (<37 semanas) } \\
\text { Gl: ORajustado=2,66 (IC95\%[1,20;5,90]) comparado ao GIII. } \\
\text { Agrupando GI+GII: ORa }=1,61(I C 95 \%[1,15 ; 2,26]) \text { comparado aos demais } \\
\text { RCIU NS }\end{array}$ & $\begin{array}{l}\text { Segundo os autores } \\
\text { as diferenģas no } \\
\text { peso ao nascer têm } \\
\text { pequena alteraçăo } \\
\text { quanto aos aspectos } \\
\text { clinicos }\end{array}$ & 17 \\
\hline $\begin{array}{l}\text { Mamelle et al. } \\
1984 \\
\text { França }\end{array}$ & $\begin{array}{l}\text { retrospectivo } \\
\text { (pos-parto } \\
\text { imediato) } \\
\text { e sub-estudo } \\
\text { caso controle }\end{array}$ & $\begin{array}{l}1928 \text { Fadiga Ocupacional } \\
\text { Escore de fontes de fadiga:postura, } \\
\text { esforço fisico, ambiente, trabalhar em } \\
\text { máquinas, estresse, categoria, tarefas } \\
\text { repetitivas, modificaçoes com a } \\
\text { gestaçấo. }\end{array}$ & $\begin{array}{l}\text { Prematuridade } \\
\text { (<37 semanas: DUM } \\
\text { checado com Dubowitz) }\end{array}$ & 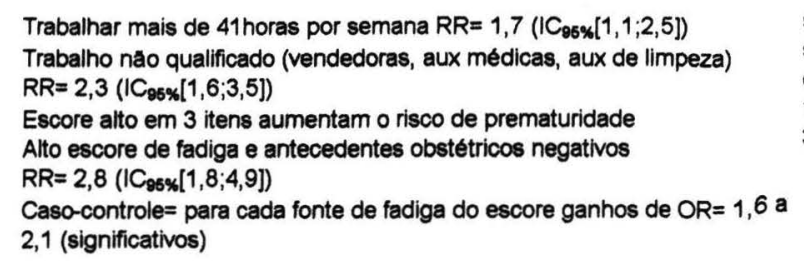 & $\begin{array}{l}\text { selecionados para } \\
\text { sub-estudo de caso } \\
\text { controle: } \\
112 \text { prematuros } \\
336 \text { controles }\end{array}$ & 15 \\
\hline $\begin{array}{l}\text { Misra et al. } \\
1998 \\
\text { EUA }\end{array}$ & $\begin{array}{l}\text { coorte } \\
\text { prospectiva e } \\
\text { retrospectiva }\end{array}$ & $\begin{array}{l}1172 \text { AF Ocupacional } \\
\text { carregar objetos pesados; horas em pe; } \\
\text { caminhar } \\
\text { AF Doméstica } \\
\text { subir escadas; andar para um proposito; } \\
\text { carregar objetos pesados; dormir } \\
\text { AF Lazer } \\
\text { frequencia e duraçăo dos exercicios; } \\
\left.\text { horas assistindo televisăo ( } 2^{\circ} \text { trimestre }\right)\end{array}$ & $\begin{array}{l}\text { Prematuridade } \\
\text { ( }<37 \text { semanas pela melhor } \\
\text { medida obstétrica) }\end{array}$ & 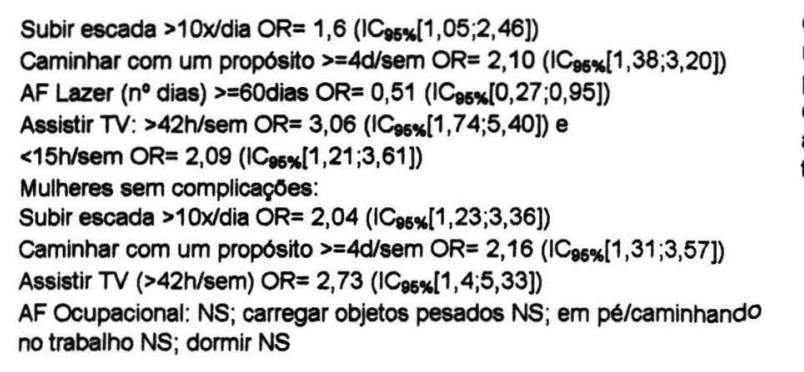 & $\begin{array}{l}\text { estudo prospectivo } \\
\mathrm{n}=719 \text { (198 } \\
\text { prematuros) } \\
\text { estudo retrospectivo } \\
\text { acrescimo de } 469 \text { no } \\
\text { tamanho amostral }\end{array}$ & 18 \\
\hline $\begin{array}{l}\text { Nieto et al. } 1994 \\
\text { Espanha }\end{array}$ & 4 caso-controle & $\begin{array}{l}37025 \text { fatores de risco (agrupados Kramer) } \\
\text { Fatores constitucionais e nutricionais } \\
\text { Fatores demográficos e psicossociais: } \\
\text { ^trabalho materno; } \\
\text { " attividade fisica na gestaçăo (AF } \\
\text { excessiva/ moderada) } \\
\text { Fatores ginecológicos e obstétricos } \\
\text { Morbidade materna durante gestaçăo } \\
\text { Exposiçăo a tóxicos }\end{array}$ & $\begin{array}{l}\text { Restriçăo de crescimento } \\
\text { intra uterino } \\
\text { (< percentil 10) } \\
\text { (idade gestacional: DUM, } \\
\text { USG e avaliaçåo clínica) }\end{array}$ & $\begin{array}{l}\text { Atividade flsica excessiva durante a gestaģăo (trabalho manual, } \\
\text { empregada doméstica, dona de casa com } 3 \text { ou mais crianģas e sem } \\
\text { ajuda, trabalho em pé ou com longa duraçao) } \\
\left.\text { OR= } 1,75 \text { (IC } C_{95 \%}[1,05 ; 2,92]\right) p<0,05 \\
\text { Mais frequente no grupo } R C l U \text { desproporcional } 75,4 \% \times 60,3 \%(p<0,05)\end{array}$ & $\begin{array}{l}185 \text { casos } \\
185 \text { controles }\end{array}$ & 17 \\
\hline $\begin{array}{l}\text { Peoples-Sheps } \\
\text { et al. } 1991 \\
\text { EUA }\end{array}$ & $\begin{array}{l}\text { retrospectivo ( } 1 \\
\text { ano pós-parto) }\end{array}$ & $\begin{array}{l}7601 \text { AF Ocupacional } \\
\text { Caractisticas fisicas } \\
\text { (intensidade/postura) e ambientais: ao } \\
\text { ar livre; frio; calor; barulho; perigos; } \\
\text { elementos da atmosfera) }\end{array}$ & $\begin{array}{l}\text { Restriçăo de crescimento } \\
\text { intra uterino }(<2500 \text { a } \\
\text { termo) } \\
\text { Prematuridade }(<37 \mathrm{sem})\end{array}$ & $\begin{array}{l}\text { Trabalhar } 21 \text { a } 39 \mathrm{~h} / \mathrm{sem}: \text { OR bruto: } 1,4\left(\mathrm{IC}_{96 \%}[0,8 ; 2,36]\right),>=40 \mathrm{~h} / \mathrm{sem}: \mathrm{OR} \\
\text { bruto: } 1,7\left(\mathrm{IC}_{95 \%}[1,03 ; 2,68]\right) \\
\text { Caracteristicas do trabalho NS } \\
\text { Prematuridade NS }\end{array}$ & $\begin{array}{l}2379 \text { BPN a termo } \\
2511 \text { prematuros }\end{array}$ & 16 \\
\hline
\end{tabular}




\begin{tabular}{|c|c|c|c|c|c|}
\hline $\begin{array}{l}\text { Petridou et al. } \\
2001 \\
\text { Grécia }\end{array}$ & caso-controle & $\begin{array}{l}245 \text { AF Ocupacional (estresse psicológico) } \\
\text { AF Doméstica (limpeza pesada da } \\
\text { casa) } \\
\text { Esforço fisico } \\
\text { Atividade sexual }\end{array}$ & $\begin{array}{l}\text { Prematuridade (idade } \\
\text { gestacional: DUM/USG) } \\
\text { casos } n=92 \text { (ig<33 sem) } \\
\text { casos } n=95 \text { ( } 33-35 \text { sem) } \\
\text { controles } n=58(36-37 \text { sem) }\end{array}$ & 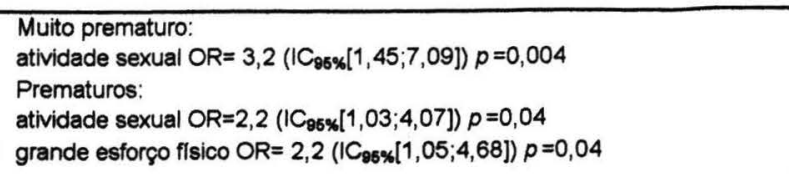 & $\begin{array}{l}\text { controles săo } \\
\text { boardlines para } \\
\text { reduzir o viés de } \\
\text { informaçáo (máes de } \\
\text { termos diferem das } \\
\text { de pretermos) }\end{array}$ \\
\hline $\begin{array}{l}\text { Rabkin et al. } \\
1990 \\
\text { Inglaterra }\end{array}$ & $\begin{array}{l}\text { coorte } \\
\text { prospectiva }\end{array}$ & $\begin{array}{l}1507 \text { AF ocupacional e doméstica } \\
\text { Tempo, esforģo e postura }\end{array}$ & Peso ao nascer & 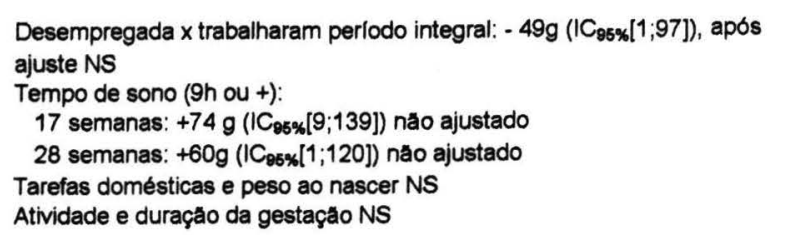 & \\
\hline $\begin{array}{l}\text { Rao et al. } 2003 \\
\text { India }\end{array}$ & prospectivo & $\begin{array}{l}797 \text { AF cotidiana } \\
\text { Leve/moderada/pesada } \\
18 / 28 \text { semanas } \\
\text { Descanso; } \\
\text { AF Doméstica; } \\
\text { Outras atividades (trabalho no sítio) }\end{array}$ & $\begin{array}{l}\text { Prematuridade } \\
\text { peso ao nascer } \\
\text { Ganho de peso } \\
\text { Circunferéncia da cabeça } \\
\text { Dobras cutâneas }\end{array}$ & 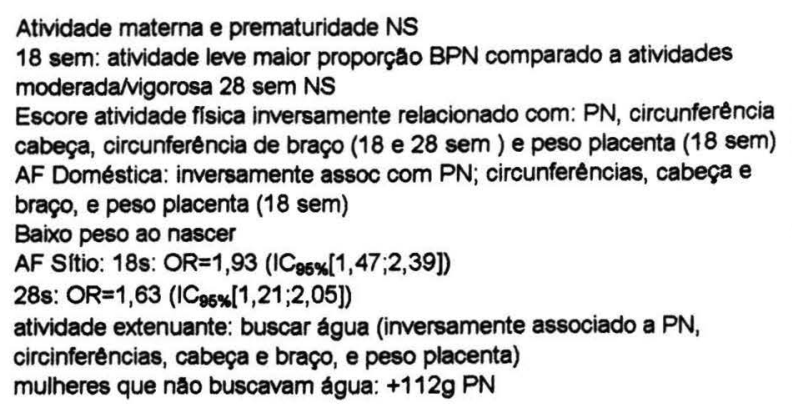 & $\begin{array}{l}\text { GERAL: Atividade } \\
\text { materna foi } \\
\text { inversamente } \\
\text { relacionada com } \\
\text { ganho de peso } \\
\text { materno até } 28 \text { sem, } \\
\text { peso ao nascer, circ } \\
\text { cabeça e circ de } \\
\text { braço do RN }\end{array}$ \\
\hline $\begin{array}{l}\text { Rodriguez- } \\
\text { Escudero et al. } \\
1980 \\
\text { Espanha }\end{array}$ & caso-controle & $\begin{array}{l}871 \text { AF Ocupacional (postura) } \\
\text { AF Domestica } \\
\text { AF Transporte } \\
\text { Sono }\end{array}$ & $\begin{array}{l}\text { Dois grupos de recém } \\
\text { nascidos com peso ao } \\
\text { nascer inferior a } 2500 \mathrm{~g} \\
\text { foram analisados: } \\
\text { " prematuros } \\
37 \text { semanas) } \\
\text { " Restriçăo de } \\
\text { crescimento intra uterino }\end{array}$ & $\begin{array}{l}\text { RCIU associado com trabalho no } 1^{\circ} \text { e } 2^{\circ} \text { trimestres }(p<0,05 \text { e } p<0,01 \text {, } \\
\text { respectivamente), permanencia em pé nos tress trimestres }(p<0,01) \\
\text { Prematuros associados com caminhada no } 2^{\circ} \text { trimestre }(p<0,05) \\
\text { Dormir, menos de } 7 \text { h ou mais de } 10 \mathrm{~h} \text {, apresentaram associaça com } \\
\text { prematuridade }(p<0,05) \text { e RCIU }(p<0,01)\end{array}$ & $\begin{array}{l}\text { Amostra: } \\
124 \text { trabalhadoras } \\
175 \text { Prematuros } \\
139 \text { RCIU }\end{array}$ \\
\hline $\begin{array}{l}\text { Rose et al. } 1991 \\
\text { EUA }\end{array}$ & $\begin{array}{l}\text { coorte (estudo } \\
\text { matriz) }\end{array}$ & $\begin{array}{l}21342 \text { Intensidade AF auto-relatada:leve, } \\
\text { moderada, vigorosa }\end{array}$ & Peso ao nascer & $\begin{array}{l}\text { Referência: AF moderada } \\
\text { Vigorosa - } 31 \mathrm{~g} \text { NS } \\
\text { Leve }-11 \mathrm{~g} \text { NS } \\
\text { Após ajuste por variaveis de confusăo permanece NS } \\
\text { Taxa de BPN semelhante nos } 3 \text { grupos } \\
\text { Prematuridade NS (nấo estabelecida a priori) }\end{array}$ & $\begin{array}{l}\text { Atividade fisica classif } \\
\text { segundo percepçăo } \\
\text { materna; questionário } \\
\text { e registros de } \\
\text { estatisticas vitais }\end{array}$ \\
\hline
\end{tabular}




\begin{tabular}{|c|c|c|c|c|c|c|c|c|}
\hline $\begin{array}{l}\text { Saurel- } \\
\text { Cubizolles e } \\
\text { Kaminski, } 1987 \\
\text { França }\end{array}$ & retrospectivo & $\begin{array}{l}2387 \text { AF Ocupaclonal } \\
\text { condiçoes de trabalho (escore): } \\
\text { em pé, carregar peso, demanda fisica, } \\
\text { linha de produçá } \\
\text { Abstenç̧es e interrupçáo do trabalho }\end{array}$ & $\begin{array}{l}\text { Baixo peso ao nascer } \\
\text { Prematuridade }\end{array}$ & & $\begin{array}{l}\text { Balxo peso ao nascer } \\
\text { Condiçoes adversas de trabalho (nenhuma: } 4,5 \%, 1 \text { ou duas: } 3,2 \% 3 \text { ou } \\
\text { mais: } 8,5 \%)^{*} \\
\text { Prematuridade } \\
\text { Condiçoes adversas de trabalho (nenhuma: } 4,0 \%, 1 \text { ou duas: } 5,1 \% 3 \text { ou } \\
\text { mais: } 8,2 \%)^{* *+} \\
{ }^{*} p<0,001{ }^{* *} p<0,01\end{array}$ & \multirow[t]{2}{*}{$\begin{array}{l}18 \\
18\end{array}$} \\
\hline $\begin{array}{l}\text { Saurel- } \\
\text { Cubizolles e } \\
\text { Kaminski, } 1991 \\
\text { França }\end{array}$ & retrospectivo & $\begin{array}{l}875 \text { AF Ocupacional } \\
\text { Tipo, condiç̧es, horas/sem. Modificaçáo } \\
\text { (aumento permanência sentada; } \\
\text { reduçăo carregar peso; etc), esforço } \\
\text { fisico e interrupçao do trabalho }\end{array}$ & $\begin{array}{l}\text { Prematuridade } \\
\text { (idade gestacional }<37 \\
\text { semanas: DUM) } \\
\text { Parto espontâneo ou năo }\end{array}$ & $\begin{array}{l}\text { Prematuridade } \\
\text { Condiçoes adversas no trabalho } \\
\text { - ocupaçoes mais qualificadas \% pretermo } \\
\text { - ocupaçoes menos qualificadas } \\
\text { Ocupaçoes menos qualificadas } O R=2,6(1,1-6,1)\end{array}$ & $\begin{array}{c}(0 \text { a } 1) \\
3,8 \\
8,1^{*} \\
1)^{*}\end{array}$ & $\begin{array}{l}(2 \text { a } 3) \\
3,8 \\
7,9 \\
{ }^{*} p<0,05\end{array}$ & & \\
\hline $\begin{array}{l}\text { Schramm et al. } \\
1996 \quad \text { EUA }\end{array}$ & Caso-controle & $\begin{array}{l}2378 \text { AF Lazer } \\
\text { Exercicio: tipo, frequencia e duraçăo por } \\
\text { trimestre da gestaçăo } \\
\text { AF Ocupacional } \\
\text { interrupçáo, tipo e ambiente do trabalho } \\
\text { (destaque para cuidar de crianças e } \\
\text { atividades domésticas) }\end{array}$ & $\begin{array}{l}\text { Peso ao Nascer } \\
\text { Multo baixo peso (<1500 } \\
\text { gramas) e Bailxo peso ao } \\
\text { nascer (1500-2499 gramas) }\end{array}$ & 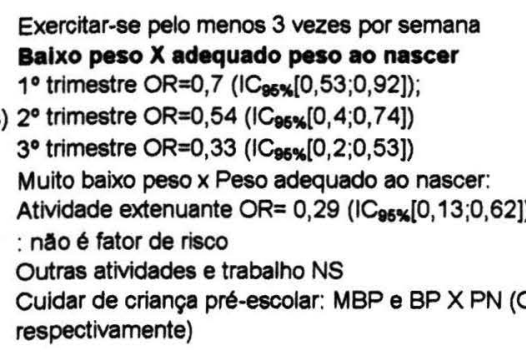 & (OR $=0,7$ & e 0,81 , & $\begin{array}{l}\text { Muito baixo peso } \\
\text { (<1500g): } 782 \\
\text { Baixo peso (1500- } \\
2499 \mathrm{~g}): 802 \\
\text { Peso } \\
\text { normal((22500g): } 794\end{array}$ & 1 \\
\hline $\begin{array}{l}\text { Spinillo et al. } \\
1996 \\
\text { Itália }\end{array}$ & caso-controle & $\begin{array}{l}1047 \text { AF Ocupacional } \\
\text { Tipo de ocupaçá, horas/semana, } \\
\text { postura, nivel de atividade fisica, indice } \\
\text { de fadiga ocupacional }\end{array}$ & $\begin{array}{l}\text { Restriçăo de crescimento } \\
\text { intra uterino } \\
\text { (idade gestacional: USG, } \\
\text { medidas de circunferencias } \\
\text { abdominal e craniana e } \\
\text { peso ao nascer inferiores ao } \\
\text { percentil 10) }\end{array}$ & $\begin{array}{l}\text { Tipo de ocupaçăo (referéncia náo empregada forn } \\
\text { Trabalhadoras de serviços de saúde - OR:1,73 (IC } \\
\text { Trabalhadoras manuais - OR:1,81 (IC } \mathrm{C}_{95 \%[}[1,15 ; 2,8 \\
\text { Esforço moderado-vigoroso: OR=2,4 (IC } 95 \%[1,36 ; \\
\text { Trabalhar mais de 30horas/semana OR bruto= } 1,\end{array}$ & $\begin{array}{l}\text { malmer } \\
\text { I } C_{95 \%[}[1, \\
85]) \\
; 4,21]) \\
64\left(I C_{8}\right.\end{array}$ & e) & $\begin{array}{l}349 \text { casos } \\
698 \text { controles }\end{array}$ & 21 \\
\hline $\begin{array}{l}\text { Takito et al. } \\
2005 \\
\text { Brasil }\end{array}$ & $\begin{array}{l}\text { coorte } \\
\text { prospectiva }\end{array}$ & $\begin{array}{l}152 \text { AF Lazer, Doméstica, Ocupacional e } \\
\text { Locomoçao } \\
\text { Postura (em pé/caminhada) } \\
\text { Frequência e duraçáo das atividades }\end{array}$ & $\begin{array}{l}\text { Peso ao nascer } \\
\text { Inadequado }(<3000 \mathrm{~g})\end{array}$ & $\begin{array}{l}\text { Caminhada até } 50 \text { min/dia ( } 1^{\circ} \text { trimestre) } O R=0,44 \\
\text { Em pé parada } 2,5 \text { horas por dia ou mais }\left(2^{\circ} \text { trime }\right. \\
\left(I C_{96 x}[1,3 ; 7,99]\right) \\
\text { Lavar roupa } 3 \text { ou mais }\left(2^{\circ} \text { trimestre) } O R=3,49(I C\right.\end{array}$ & $\begin{array}{l}4\left(1 C_{96 \times}\right. \\
\text { lestre }) C \\
{ }_{95 \%}[1,5\end{array}$ & $\begin{array}{l}0,20 ; 0,98]) \\
R=3,23 \\
; 7,64])\end{array}$ & & 18 \\
\hline $\begin{array}{l}\text { Teitelman et al. } \\
1990 \\
\text { EUA }\end{array}$ & prospectivo & $\begin{array}{l}1206 \text { AF Ocupacional } \\
\text { Tipo/profissão, classificados em } 3 \\
\text { categorias: } \\
\text { "em pé (>3h/dia); } \\
\text { "ativas (caminhando); } \\
\text { "sedentárias (<1h/dia em pe e ativa) } \\
\text { duraçăo do trabalho }\end{array}$ & $\begin{array}{l}\text { Prematuridade } \quad(<37 \\
\text { semanas: DUM) } \\
\text { Baixo peso ao nascer } \\
(<2500 \mathrm{~g})\end{array}$ & $\begin{array}{l}\text { Prematuridade (referéncia ativas) } \\
\text { Em pé: } R R=2,84\left(\mid C_{95 *}[1,34 ; 6,0]\right) \\
\text { IG média }=37,9 \times 38,2 \text { (ativo/sedentario) } p=0,184 \\
\text { Após ajuste }=O R=2,72\left(\mid C_{95 \%}[1,24 ; 5,95]\right) \\
\text { em pé }-0,37 \text { semanas }(p=0,054) \\
\text { BPN NS para tipo de trabalho; } \\
\text { PN médio }=3364 \times 3412 \text { (sedentário) } \times 3412 \text { (ativo } \\
\text { Indice de Rohrer (crescimento fetal) NS }\end{array}$ & 4 & & $\begin{array}{l}\text { Năo sabe o quanto a } \\
\text { mulher trabalhou } \\
15,1 \% \text { em pé } \\
43,7 \% \text { ativas } \\
41,2 \% \text { sedentárias }\end{array}$ & 18 \\
\hline
\end{tabular}




\begin{tabular}{|c|c|c|c|c|c|c|}
\hline $\begin{array}{l}\text { Tuntiseranee et } \\
\text { al. } 1998 \\
\text { Tailandia }\end{array}$ & $\begin{array}{l}\text { coorte } \\
\text { prospectiva }\end{array}$ & $\begin{array}{l}1797 \text { AF Ocupacional } \\
\text { agachada, em pé, mudanças de } \\
\text { ambiente, caminhada rápida, } \\
\text { carregando peso, demanda fisica, } \\
\text { psicológica. }\end{array}$ & $\begin{array}{l}\text { Baixo peso ao nascer } \\
\text { (ajustado pela IG) } \\
\text { Pequeno para a Idade } \\
\text { Gestacional } \\
\text { (<percentil } 10 \text { e Dubowitz) } \\
\text { Prematuridade } \\
\text { (<37semanas) }\end{array}$ & 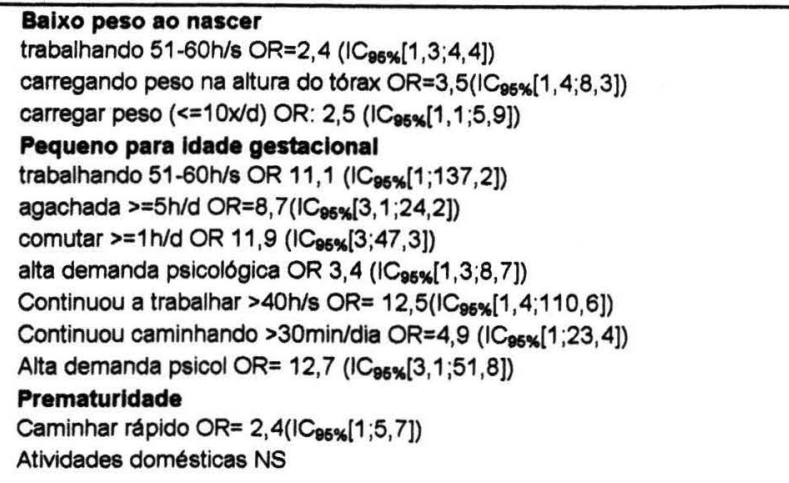 & & $\overline{19}$ \\
\hline $\begin{array}{l}\text { Wergeland et al. } \\
1998 \\
\text { Noruega }\end{array}$ & retrospectivo & $\begin{array}{l}5388 \text { AF Ocupacional } \\
\text { Postura extenuante (em pe; curvada; } \\
\text { trabalhar com máo acima do nivel dos } \\
\text { ombros; caminhando; carregando peso } \\
\text { de } 10 \text { a } 20 \mathrm{~kg} \text { mais de } 10 \text { vezes por dia) } \\
\text { Horas trabalho por semana } \\
\text { Escore de trabalho extenuante }\end{array}$ & $\begin{array}{l}\text { Baixo peso ao nascer } \\
(<2500 \mathrm{~g})\end{array}$ & $\begin{array}{l}\text { Maior em donas de casa } \\
\text { Trabalhar } 35 \text { ou mais horas por semana e trabalhar curvada reduz o peso } \\
\text { ao nascer médio } \\
\text { Carregar peso }\left(10-20 \mathrm{~kg} / 10-20 \text { vezes por dia) } \mathrm{OR}=4\left(\mathrm{IC}_{95 \%}[1,5 ; 10,1]\right)\right. \\
\text { Escore AF NS } \\
\text { Andando e em pé so quando dura mais que metade do dia implica em } \\
\text { risco }\end{array}$ & $\begin{array}{l}\text { Amostra: } 3321 \\
\text { trabalhadoras }\end{array}$ & 19 \\
\hline $\begin{array}{l}\text { Zuckerman et al. } \\
1986 \\
\text { EUA }\end{array}$ & retrospectivo & $\begin{array}{l}1507 \text { AF Ocupacional } \\
\text { năo trabalha fora/estuda ( } 55 \%) \\
\text { trabalha fora (em pé no } 3^{\circ} \text { trim) }(7 \%) \\
\text { trabalha foralestuda (outras condiçoes) }\end{array}$ & $\begin{array}{l}\text { Duraçăo da gestaçáo } \\
\text { (Dubowitz) } \\
\text { Comprimento do bebê }\end{array}$ & $\begin{array}{l}\text { Duraçăo da gestaçăo, peso ao nascer e circunferencia de cabeça NS } \\
\text { Comprimento ao nascer associado positivamente as mulheres que } \\
\text { trabalhavam em pé. }\end{array}$ & & 17 \\
\hline
\end{tabular}


ARTIGO II.

Avaliação da reprodutibilidade e validade de questionário de atividade física para gestantes 


\section{Resumo}

Objetivo: Analisar a reprodutibilidade e validade concorrente de um questionário de atividades físicas para gestantes. Métodos: Em amostra de 68 gestantes, no segundo trimestre de gestação foi realizada entrevista para aplicação do questionário, que foi repetida com aproximadamente uma semana de intervalo e no puerpério. No período entre as duas primeiras entrevistas, as mulheres utilizaram monitor de freqüência cardíaca $(n=38)$. Resultados: As análises de reprodutibilidade foram adequadas com coeficientes de correlação intraclasse variando de 0,54 a 0,85. A análise das variáveis categóricas, com questões subjetivas e de auto-percepção da atividade física, resultou em maior intervalo de coeficiente kappa com valores entre 0,29 e 0,76 entre a aplicação do questionário com uma semana de intervalo, e 0,08 a 0,70 comparado ao puerpério. As análises de validade conduziram a resultado satisfatório quanto à média das diferenças encontrada por intermédio do gráfico de BLAND e ALTMAN (1986) entre o questionário e o freqüencímetro. Entretanto, o intervalo da dispersão não apresentou-se adequado, visto que variou em mais de sete horas para atividades leves e em quase onze horas por dia para atividades moderadas.

As análises do presente estudo parecem assegurar a reprodutibilidade do questionário de atividade física para gestantes. No entanto, com relação à validação, a comparação com os resultados obtidos pelo freqüêncímetro - instrumento disponível na época da coleta de dados - não mostrou graus de concordância adequados.

Descritores: atividade física, validação, questionário, gestação 


\section{Introdução}

A prática de atividade física vem sendo incentivada por vários organismos internacionais e pelo Ministério da Saúde para promoção da saúde e melhoria da qualidade de vida da população (WHO 2002; PATE et al. 1995). Dentre as iniciativas nacionais, destaca-se o Programa Agita São Paulo considerado pela OMS um modelo para os demais países (MATSUdo et al. 2003). A Organização Mundial da Saúde (WHO 2002) define como inatividade física ter pouca ou nenhuma atividade física (não atingir 150 minutos semanais) nas situações de trabalho, transporte, tarefas domésticas ou horas de lazer. A prevalência de inatividade física entre mulheres do Município de São Paulo é igual a 40,6\%, tendo como ponto de corte menos de 150 minutos semanais de atividade moderada ou vigorosa (BRASIL 2004).

ARTAL (2003) enfatiza a importância da promoção da atividade física no período gestacional dada a maior possibilidade de modificação para um estilo de vida mais ativo que implicaria melhores condições de saúde da população feminina. No entanto, não existe consenso acerca da intensidade ótima da atividade física durante a gestação. Questionamentos feitos às recomendações de 1984 do Colégio Americano de Obstetras e Ginecologistas (HATCH et al. 1993; PIRVANIK 1998) ocasionaram modificações que resultaram em recomendação diferenciada, segundo o condicionamento físico anterior à gestação. Assim, as mulheres menos condicionadas devem realizar atividades de menor intensidade $e$ as mulheres fisicamente mais ativas podem manter 0 exercício físico, com segurança, numa intensidade superior às demais. A maior parte dos estudos foi conduzida em países desenvolvidos, em que a mulher mantém a prática de exercícios físicos e atividades esportivas durante a gestação. São poucos os estudos que enfocam a atividade física praticada por gestantes de baixo nível socioeconômico (MISRA et al. 1998; KRAMER 2003).

Em virtude disso, torna-se importante a adequada identificação dos niveis da prática habitual de atividade física nesse segmento da 
população, e posterior associação de seu efeito sobre a saúde maternofetal.

Vários métodos visando obter indicadores associados à prática de atividade física adequados à estimativa do gasto energético individual, tais como, calorimetria direta ou indireta, água duplamente marcada, freqüência cardíaca, sensores de movimento e observação direta, podem ser inviabilizados quando a análise envolve grande número de sujeitos. Quando a preocupação é avaliar grandes grupos populacionais, são fundamentais instrumentos com boa precisão, fácil aplicação e baixo custo. Dentre os instrumentos de avaliação da atividade física que utilizam informaçōes fornecidas pelas pessoas (questionários, entrevistas e diários), destaca-se o questionário como instrumento que oferece dados de duração, frequêencia, intensidade e tipo da atividade. Nesse sentido, vários estudos têm sido desenvolvidos procurando validar questionários de atividade física em diferentes grupos populacionais (crianças, adultos e idosos) (WASHBURN et al. 1999, 2003; BOREHAM e RIDDOCH 2001; PARDINI et al. 2002; FLORINDO e LATORRE 2003).

Identificou-se na literatura, três estudos que propōem questionários de atividade física em gestantes. WILDSHUT et al. (1993), em estudo exploratório com 100 gestantes inglesas, avaliaram a atividade física, incluindo atividade doméstica, durante o lazer e no trabalho, bem como a percepção do esforço. CHASAN-TABER et al. (2004) validaram um questionário auto-preenchido (Pregnancy Physical Activity Questionnaire) com 54 gestantes norte-americanas. Como critério de validação concorrente utilizaram o sensor de movimento (acelerômetro uniaxial). Um terceiro instrumento, Kaiser Physical Activity Questionnaire para mulheres foi adaptado e validado com 61 gestantes, propondo classificar as gestantes segundo um escore de atividade física. A proposta de ScHMiDT et al. (2006) tem como intuito utilizar um mesmo instrumento para avaliar a atividade física antes e durante a gestação.

No Brasil, não foram encontrados estudos de validação de questionário de atividade física para gestantes. $\mathrm{O}$ objetivo do presente 
estudo é analisar a reprodutibilidade e validade concorrente de um questionário que permita quantificar a atividade física de gestantes usuárias de serviços públicos de saúde do Município de São Paulo.

\section{Metodologia}

Foram incluídas no estudo gestantes do segundo trimestre de gestação, em decorrência do fato de que nesse período já são conhecidos os fatores de risco da mulher e ainda não houve um aumento de peso que impossibilite a realização de atividades físicas. $A$ idade gestacional foi avaliada pela data da última menstruação (DUM), confirmada por ultrassonografia anterior a $20^{\mathrm{a}}$ semana. Foram critérios de exclusão do estudo: gestantes com idade inferior a 18 anos, com morbidade potencialmente associada à alteração da atividade física habitual e não alfabetizadas.

Ainda que o tamanho da amostra tenha variado de acordo com tipo de análise, o menor valor $(n=34)$ permite um poder de teste de $90 \%$ para detectar um coeficiente de correlação de 0,50, com nível de significância de 5\% (Hulley e Cummings 1998).

As informações foram obtidas mediante entrevistas com duração média de 31 minutos, realizadas em duas ocasiōes, sendo a segunda entrevista (reteste) efetuada para verificação da reprodutibilidade do questionário. Após o período de cinco dias foi realizada a segunda entrevista.

As gestantes foram informadas sobre os procedimentos e objetivos do estudo e quando concordavam em participar, assinavam o termo de consentimento livre e esclarecido, aprovado no Comitê de Ética (Anexo 1).

O questionário avaliado (Anexo 3 ) foi elaborado com base nos questionários mencionados a seguir:

- Questionário de WiLDSchut et al (1993), modificado segundo sugestão dos próprios autores incluindo questões relacionadas às atividades domésticas; 
- Suplemento do Minnesota Leisure-Time Physical Activity Questionnaire (LPTA) / Household Activities (TAYLOR et al. 1978): engloba atividades domésticas;

- International Physical Activity Questionnaire (IPAQ) versão longa (CraIG et al. 2003), desenvolvido com o apoio da Organização Mundial da Saúde por representantes de 25 países, para estimar a prática habitual de atividade física de populações de diferentes países e contextos sócio-culturais. Incluiu-se no questionário duas questōes visando a verificar a percepção das gestantes quanto à intensidade de atividades físicas vigorosas e moderadas.

Após a entrevista, a gestante foi instruída quanto à utilização do monitor de freqüência cardíaca (durante quatro dias) e ao preenchimento do diário de atividades físicas (Anexo 4). Esse foi proposto para melhor compreensão da relação entre a freqüência cardíaca e as atividades realizadas. As gestantes foram orientadas a não alterar as rotinas diárias. $O$ freqüêncímetro Polar® foi utilizado para mensuração da freqüência cardíaca minuto a minuto. A freqüência cardíaca é considerada indicador fisiológico da atividade física, pois possui relação linear com o consumo de oxigênio para muitas atividades (TREMBLAY et al. 2001). Ainda que a freqüência cardíaca não seja um método preciso de estimativa do gasto energético para todas as atividades diárias, ela pode proporcionar boa indicação da intensidade relativa da atividade física. A orientação quanto ao uso incluiu a colocação da cinta, a ligação e verificação da efetiva gravação, bem como a retirada do equipamento para dormir e tomar banho.

O estudo foi planejado visando facilitar ao máximo a participação das gestantes. Como muitas não poderiam retornar ao serviço de saúde para devolução dos aparelhos, optou-se por visitas domiciliares para realização dos questionários e monitoração do uso do aparelho e preenchimento do diário, minimizando assim, falhas na coleta de dados. Mesmo quando detectou-se falhas no preenchimento do diário de 
atividades físicas ou mau uso do equipamento, o questionário foi reaplicado e as gestantes permaneceram no estudo de reprodutibilidade.

O diagrama a seguir expressa as ações realizadas para a coleta de dados deste estudo:

Informação dos procedimentos e concordância em participar (TCLE).

$1^{\mathrm{a}}$ Entrevista

- Questionário de Atividades Físicas (QAF1)

- Explicação do uso do freqüencímetro

- Explicação e início do preenchimento do Diário de Atividades Físicas (DAF)

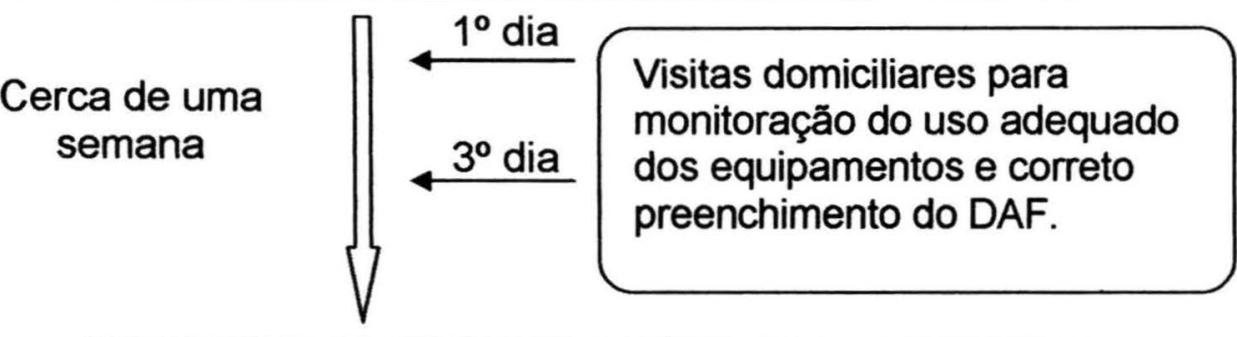

$2^{\mathrm{a}}$ Entrevista

- Reteste QAF2

- Devolução dos equipamentos e do DAF

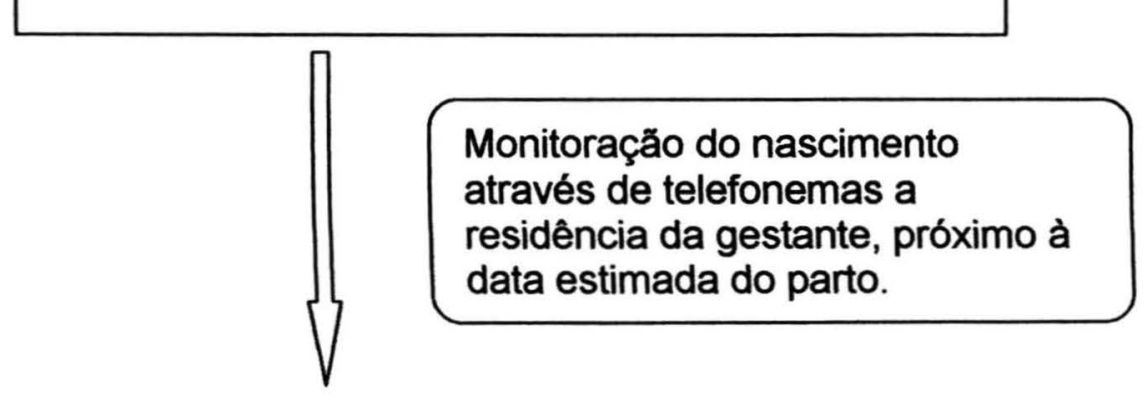

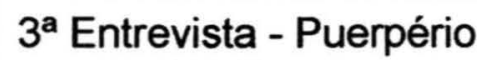

- QAF3

- MAQ adaptado

No questionário foram avaliadas as atividades físicas desenvolvidas no trabalho doméstico, no trabalho fora de casa, no lazer e 
para a locomoção. O tempo despendido em cada atividade foi obtido através da multiplicação da freqüência e duração, expresso em minutos ou horas por dia. Foi utilizado o Compêndio de Atividades Físicas (AINSWORTH et al. 2000) para quantificar o esforço em MET (equivalente metabólico de repouso) em cada atividade questionada. Inicialmente, as atividades foram agrupadas segundo a intensidade: sedentárias $(<1,5$ METs), leves (1,5-2,9 METs), moderadas (3,0-6,0 METs) e vigorosas $(>6,0$ METs). As atividades também foram agrupadas pelo tipo: ocupacional, domésticas, locomoção e lazer e sedentárias (CHASANTABER et al. 2004). E ainda pelas posturas predominantes: permanência na postura ereta e agachada. $O$ tempo e os METs despendidos diariamente foram calculados. Para os dados mensurados da freqüência cardíaca a cada minuto, a estimativa do MET foi obtida por intermédio de equação específica para gestantes, no segundo trimestre, apresentada por PIRVANIK et al. (2002).

O questionário foi duplamente digitado e corrigido, utilizando o programa Epi Info versão 6.04. A transcrição dos diários de atividades físicas foi duplamente conduzida e comparada para efetiva codificação e classificação das atividades.

Para as análises estatísticas utilizou-se o programa estatístico Stata versão 7.0. A análise de reprodutibilidade foi conduzida utilizandose o coeficiente de concordância Kappa para variáveis qualitativas nominais (FLEISS 1981) e o coeficiente de correlação intraclasse para variáveis quantitativas pela análise de variância (ANOVA) com dois fatores (aleatório: gestante e fixo: momento). A seguir foi efetuada a plotagem em diagrama de dispersão segundo proposto por BLAND e ALTMAN (1986) para a verificação da concordância entre as medidas obtidas pelos dois métodos: questionário de atividade física e frequencímetro. 


\section{Resultados}

\section{Características da população estudada e comparação com as perdas}

Foram contatadas 115 mulheres no segundo trimestre de gestação seguindo os critérios de seleção, tendo ocorrido 32 recusas $(28 \%)$. Iniciaram o estudo 83 gestantes, no entanto 15 mulheres (18\%) desistiram. Os principais motivos apresentados para desistência foram o incômodo causado pelo uso do frequencímetro e/ou falta de tempo para anotar o diário de atividades físicas. Quando as mulheres desistiam da participação do estudo em um intervalo da aplicação do primeiro questionário muito pequeno (inferior a 24h) o questionário não era reaplicado e estas mulheres foram consideradas perdas.

Houve variação no tamanho amostral nas análises estatísticas. A análise de reprodutibilidade do primeiro e segundo questionários abrangeu 68 mulheres, e entre o primeiro questionário e o questionário aplicado no pós-parto, 34 gestantes. Devido a falha e mau uso do equipamento (freqüêncimetro) a avaliação da validade foi realizada com dados de 38 gestantes.

A Tabela 1 mostra 0 perfil das mulheres estudadas em comparação com as perdas de seguimento. 
Tabela 1. Características das gestantes estudadas e das perdas de seguimento. São Paulo, 2004.

\begin{tabular}{|c|c|c|c|}
\hline Características das gestantes & $\begin{array}{c}\text { Amostra } \\
\text { estudada }(n=68)\end{array}$ & $\begin{array}{l}\text { Perdas } \\
(n=15)\end{array}$ & \\
\hline Variáveis contínuas & $\begin{array}{l}\text { Média e desvio } \\
\text { padrão }\end{array}$ & $\begin{array}{l}\text { Média e desvio } \\
\text { padrão }\end{array}$ & $p^{a}$ \\
\hline Idade (anos) & $26,9 \pm 6,1$ & $24,1 \pm 5,4$ & 0,11 \\
\hline $\begin{array}{l}\text { Escolaridade (anos completos de } \\
\text { estudo) }\end{array}$ & $9,5 \pm 3,1$ & $8,3 \pm 2,7$ & 0,17 \\
\hline Número de pessoas no domicílio & $3,7 \pm 1,6$ & $4,0 \pm 2,3$ & 0,61 \\
\hline Peso pré-gestacional (kg) & $63,2 \pm 12,5$ & $62,0 \pm 17,1$ & 0,78 \\
\hline Altura $(\mathrm{cm})$ & $162,7 \pm 6,0$ & $162,1 \pm 6,8$ & 0,75 \\
\hline Peso $(\mathrm{kg})$ no momento da entrevista & $69,5 \pm 13,1$ & $66,8 \pm 16,3$ & 0,51 \\
\hline Renda total familiar & $1327,2 \pm 1924,3$ & $1104,6 \pm 831,0$ & 0,71 \\
\hline IMC pré-gestacional $\left(\mathrm{kg} / \mathrm{m}^{2}\right)$ & $23,6 \pm 6,5$ & $24,0 \pm 4,4$ & 0,75 \\
\hline Variáveis categóricas & $\%$ & $\%$ & $p^{b}$ \\
\hline Planejaram a gravidez & 32,4 & 26,7 & 0,53 \\
\hline Queriam ter o filho & 58,8 & 60,0 & 0,63 \\
\hline Primíparas & 44,1 & 33,3 & 0,63 \\
\hline Fumavam durante a gravidez & 9,2 & 18,2 & 0,34 \\
\hline $\begin{array}{l}\text { Trabalharam fora de casa durante a } \\
\text { gravidez }\end{array}$ & 52,9 & 46,2 & 0,88 \\
\hline
\end{tabular}

Nas mulheres estudadas a idade variou de 18 a 33 anos. A escolaridade média foi de nove anos. Do total de mulheres estudadas, $22,1 \%$ moravam sem companheiro. Dentre aquelas com companheiro cerca de um terço estava nesta situação a menos de dois anos.

Mais da metade das gestantes trabalhava fora de casa e dois terços dessas estava satisfeita com o trabalho. Quando indagadas sobre a modificação da atividade física no segundo trimestre de gestação, a maioria das gestantes $(70,6 \%)$ informou ter diminuído sua atividade física. Apenas quatro gestantes $(5,8 \%)$ referiram aumento da atividade física e um quarto da amostra referiu não ter alterado a atividade física. Com 
relação ao trabalho doméstico, mais da metade das mulheres contava com auxílio nessas tarefas.

\section{Análise de reprodutibilidade do questionário}

As informações quanto ao tempo despendido nas diferentes dimensões de atividade física estimado pelo questionário, nos três momentos, são apresentadas na Tabela 2.

Tabela 2. Valores medianos e quartis do tempo despendido em diferentes dimensões da atividade física. São Paulo, 2004.

\begin{tabular}{lccc}
\hline \multicolumn{1}{c}{ VARIÁVEIS } & $\begin{array}{c}\text { Questionário 1 } \\
(n=68)\end{array}$ & $\begin{array}{c}\text { Questionário 2 } \\
(n=68)\end{array}$ & $\begin{array}{c}\text { Questionário 3 } \\
(n=34)\end{array}$ \\
\hline Atividades sedentárias & 743,8 & 756,4 & 707,1 \\
(min/dia) & $(606,4 ; 929,4)$ & $(621,6 ; 941,1)$ & $(645,0 ; 926,3)$ \\
Atividades leves & 284,21 & 218,6 & 185,7 \\
(min/dia) & $(141,1 ; 417,3)$ & $(130,2 ; 378,3)$ & $(116,4 ; 359,5)$ \\
Atividades moderadas & 231,9 & 230,4 & 132,0 \\
(min/dia) & $(107,0 ; 480,7)$ & $(106,1 ; 476,0)$ & $(61,2 ; 432,7)$ \\
Caminhada & 57,1 & 51,7 & 79,8 \\
(min/dia) & $(25,6 ; 117,1)$ & $(28,7 ; 145,8)$ & $(44,0 ; 121,8)$ \\
Permanência em pé & 114,5 & 95,5 & 75,3 \\
parada (min/dia) & $(65,9 ; 180,0)$ & $(58,04 ; 158,9)$ & $(34,5 ; 143,8)$ \\
Postura agachada & 7,1 & 5,4 & 4,3 \\
(min/dia) & $(0,5 ; 17,1)$ & $(1,0 ; 17,14)$ & $(0,4 ; 8,6)$ \\
\hline
\end{tabular}

A aparente redução no tempo despendido após o parto nas três intensidades agrupadas e a elevação da caminhada, no período pós-parto não se confirmou quando a comparação foi feita para as 34 gestantes que responderam os três instrumentos.

Os resultados da análise de reprodutibilidade para as variáveis categóricas com uma semana de intervalo (Questionário $1 \times 2$ ) e no pósparto imediato (Questionário 1x3) são apresentadas na Tabela 3. 
Tabela 3. Análise da reprodutibilidade do questionário de atividade física - variáveis categóricas. São Paulo, 2004.

\begin{tabular}{|c|c|c|c|c|c|}
\hline \multicolumn{2}{|c|}{ Questões: } & \multicolumn{2}{|c|}{$\begin{array}{l}\text { Questionário 1×2 } \\
\qquad(n=68)\end{array}$} & \multicolumn{2}{|c|}{$\begin{array}{l}\text { Questionário 1x3 } \\
\qquad(n=34)\end{array}$} \\
\hline & & Kappa* & $I_{95 \%}$ & Kappa* & $I_{C_{95 \%}}$ \\
\hline \multirow{5}{*}{$\begin{array}{c}\text { Você } \\
\text { pratica } \\
\text { alguma } \\
\text { atividade } \\
\text { física: }\end{array}$} & Na qual transpire & 0,56 & $0,32-0,79$ & 0,46 & $0,18-0,74$ \\
\hline & $\begin{array}{l}\text { Carregando } \\
\text { objetos pesados }\end{array}$ & 0,63 & $0,40-0,87$ & 0,66 & $0,32-0,99$ \\
\hline & Esportiva & 0,41 & $0,17-0,64$ & - & \\
\hline & Vigorosa & 0,32 & $0,09-0,55$ & 0,53 & $0,19-0,86$ \\
\hline & Moderada & 0,29 & $0,07-0,52$ & 0,08 & $-0,02-0,39$ \\
\hline \multirow{2}{*}{$\begin{array}{c}\text { Quão } \\
\text { ativa você } \\
\text { se } \\
\text { considera: }\end{array}$} & $\begin{array}{l}\text { Comparando com } \\
\text { outras gestantes }\end{array}$ & $0,64^{\S}$ & $0,40-0,88$ & $0,64^{\S}$ & $0,30-0,98$ \\
\hline & $\begin{array}{l}\text { Antes de } \\
\text { engravidar }\end{array}$ & $0,43^{\S}$ & $0,19-0,66$ & $0,42^{\S}$ & $0,09-0,76$ \\
\hline $\begin{array}{l}\text { Alguém a } \\
\text { domésticas }\end{array}$ & ajuda nas tarefas & 0,76 & $0,52-0,99$ & 0,70 & $0,36-1,00$ \\
\hline
\end{tabular}

${ }^{8}$ Kappa ponderado

A percepção subjetiva do nível de atividade física abrangeu cinco respostas: muito mais ativa, mais ativa, tão ativa quanto, menos ativa, muito menos ativa comparando com outras gestantes. A concordância foi boa quando a comparação foi feita durante a gestação e menor antes de engravidar. Resultados satisfatórios foram também verificados para ajuda nas tarefas domésticas, realização de atividade física que aumente a transpiração ou carregando objetos.

As questões referentes à prática de atividade física esportiva, vigorosa e moderada, adaptadas do IPAQ versão longa, apresentaram valores abaixo do esperado, demonstrando dificuldade de compreensão pelas gestantes estudadas.

Quanto à avaliação das variáveis de atividade física segundo intensidades de esforço diário, a análise de reprodutibilidade também demonstrou bons resultados com uma semana de intervalo $(n=68)$ e no 
pós-parto imediato $(n=34)$, conforme pode ser observado na Tabela 4. Entretanto, a postura, identificada como a permanência em pé e agachada obteve valores baixos de correlação intraclasse.

Tabela 4. Análise da reprodutibilidade do questionário de atividade física, mediante o coeficiente de correlação intraclasse (CCl), entre os três questionários. São Paulo, 2004.

\begin{tabular}{lcccc}
\hline \multicolumn{1}{c}{ VARIÁVEIS } & \multicolumn{2}{c}{ Questionários $1 \times 2$} & \multicolumn{2}{c}{ Questionários $1 \times 3$} \\
& CCI & IC $(95 \%)$ & CCI & IC $(95 \%)$ \\
\hline $\begin{array}{l}\text { Tempo gasto em atividades } \\
\text { sedentárias (min/dia) }\end{array}$ & 0,81 & $0,70-0,88$ & 0,84 & $0,71-0,91$ \\
\hline $\begin{array}{l}\text { Tempo gasto em atividades } \\
\text { leves (min/dia) }\end{array}$ & 0,85 & $0,76-0,91$ & 0,83 & $0,70-0,91$ \\
\hline $\begin{array}{l}\text { Tempo gasto em atividades } \\
\text { moderadas (min/dia) }\end{array}$ & 0,75 & $0,60-0,85$ & 0,73 & $0,52-0,84$ \\
\hline $\begin{array}{l}\text { Tempo em atividades em } \\
\text { postura agachada (min/dia) }\end{array}$ & 0,54 & $0,20-0,74$ & 0,71 & $0,65-0,90$ \\
\hline $\begin{array}{l}\text { Tempo gasto em caminhada } \\
\text { (min/dia) }\end{array}$ & 0,80 & $0,67-0,88$ & 0,80 & $0,65-0,90$ \\
\hline $\begin{array}{l}\text { Tempo em atividades em } \\
\text { postura em pé parada (min/dia) }\end{array}$ & 0,56 & $0,29-0,73$ & 0,74 & $0,54-0,86$ \\
\hline
\end{tabular}

Os resultados da reprodutibilidade do questionário foram melhores na avaliação das variáveis quantitativas quando comparados aos obtidos para as variáveis qualitativas nas quais há maior dependência da percepção subjetiva.

\section{Análise de validade do questionário}

As informações quanto ao tempo despendido nas diferentes dimensões de atividade física, estimado pelos dois instrumentos questionário e freqüencimetro são apresentadas na Tabela 5 . 
Tabela 5. Valores medianos e quartis do tempo despendido em diferentes dimensões da atividade física (questionário e frequêncimetro). São Paulo, 2004.

\begin{tabular}{lcc}
\hline \multicolumn{1}{c}{ VARIÁVEIS } & $\begin{array}{c}\text { Questionário 1 } \\
(\mathrm{n}=68)\end{array}$ & $\begin{array}{c}\text { Freqüencímetro } \\
(\mathrm{n}=38)\end{array}$ \\
\hline Atividades leves (min/dia) & $284,21(141,07 ; 417,32)$ & $333,30(268,55 ; 454,74)$ \\
\hline Atividades moderadas (min/dia) $)$ & $231,93(106,98 ; 480,71)$ & $214,75(148,50 ; 340,21)$ \\
\hline
\end{tabular}

As estimativas de atividades sedentárias não foram adequadas quando se comparou o questionário e o freqüencímetro como medida padrão, visto que o equipamento apresenta falhas de registro quando a mulher está em decúbito lateral, conforme relatado pelas gestantes e constatado no trabalho de campo.

Não houve diferença significativa entre os valores obtidos pelo questionário e freqüencímetro tanto para atividades leves quanto para moderadas.

Os diagramas de dispersão com a plotagem dos valores médios (abscissa) de tempo despendido em atividades leves (Figura 1) e moderadas (Figura 2), pelas diferenças individuais dos instrumentos (ordenadas) são ilustrados a seguir. Esse procedimento de análise proposto por BLAND e ALTMAN (1986) permite visualizar as diferenças médias e os limites extremos de concordância ( \pm 2 DP da diferença) apresentados na comparação dos instrumentos. 


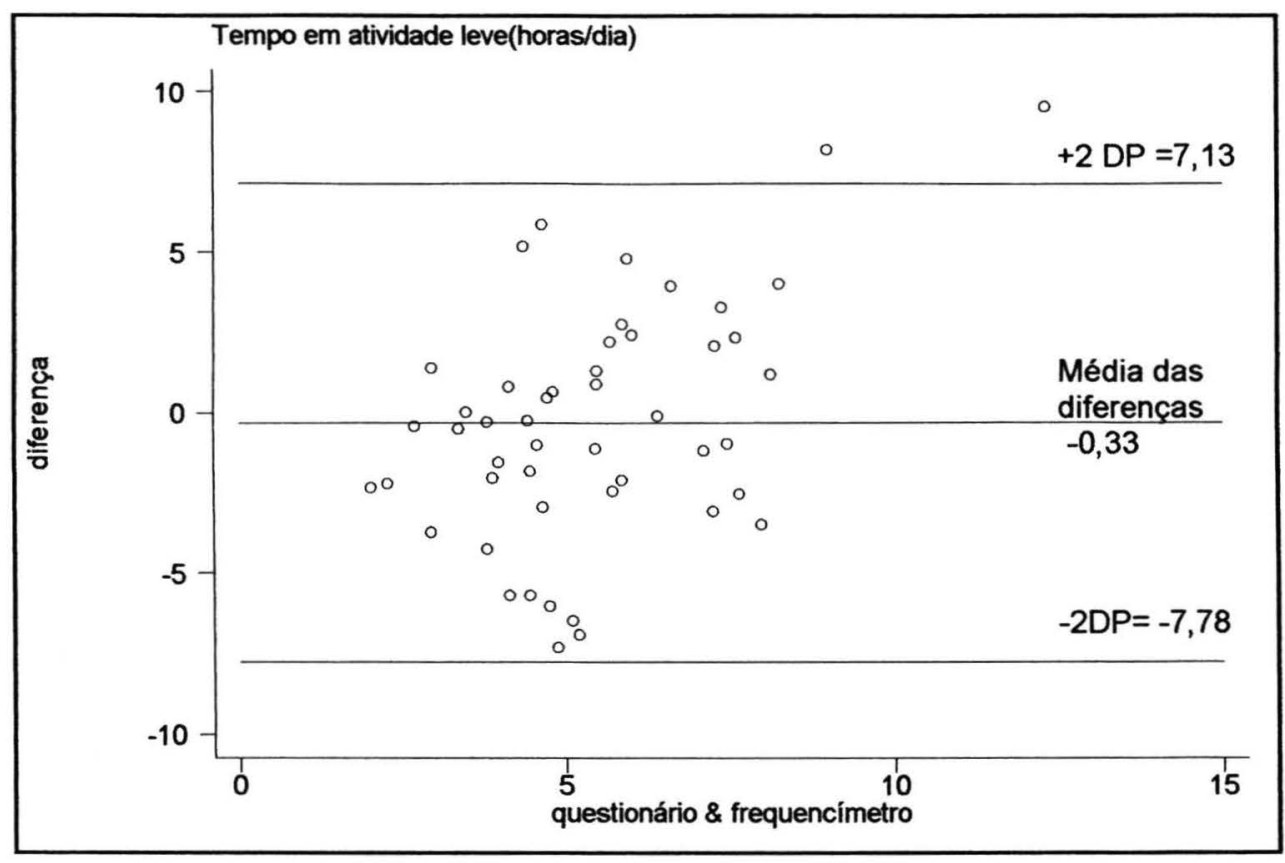

Figura 1. Análise comparativa do tempo em atividades leves entre o questionário e frequencímetro.

A média das diferenças obtidas entre os valores obtidos pelo questionário e pelo freqüencímetro se aproximaram de zero nas atividades leves. Resultado similar foi obtido para a média das diferenças considerando as atividades moderadas com valor próximo de 44 minutos por dia.

Os limites de concordância foram amplos tanto para as atividades leves quanto moderadas, aproximando-se de sete e 11 horas por dia respectivamente. Além desse fator a maior dispersão dos dados das atividades moderadas, com o aumento da magnitude das medidas indica menor precisão para valores mais elevados. Nas atividades leves, observa-se dispersão adequada dos dados. 


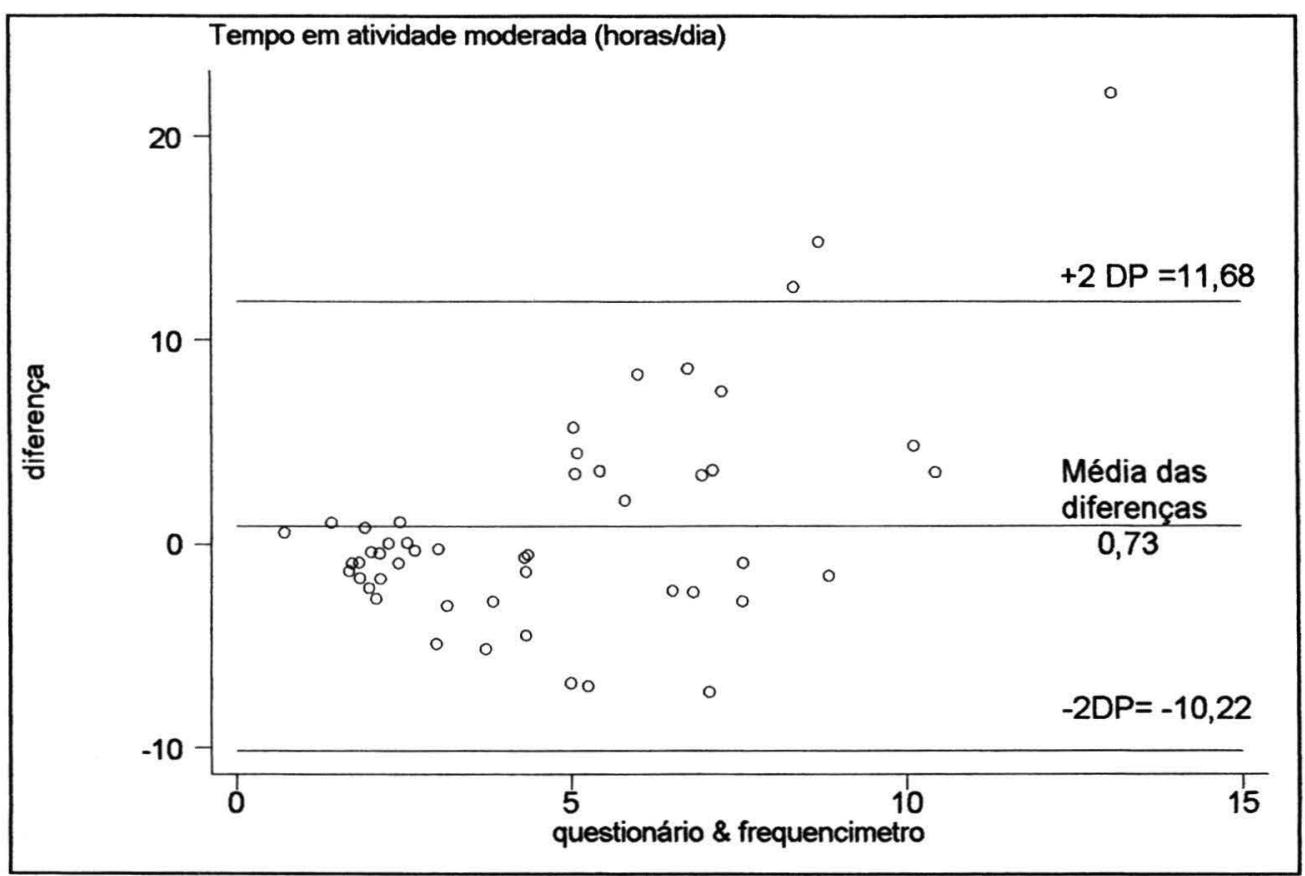

Figura 2. Análise comparativa do tempo em atividades moderadas entre o questionário e freqüencímetro.

\section{DISCUSSÃO}

Os questionários destacam-se como o instrumento mais acessível para avaliação da atividade física habitual, pela facilidade de aplicação em grandes grupos, pelo menor custo e pela possibilidade de coletar informações com relação ao tipo e ao contexto em que são realizadas, sendo instrumentos importantes em estudos epidemiológicos. No entanto, as características das informações que buscam coletar/obter podem sofrer maior variação, pois dependem do relato dos indivíduos e, portanto, da memória e da percepção subjetiva em relação ao esforço e duração da atividade entre outros aspectos. Assim, quando comparado com outros métodos, podem demonstrar maiores problemas quando avaliado quanto à reprodutibilidade e validade de seus resultados.

A utilização de questionários auto-preenchidos tem acurácia reduzida em mulheres de menor nível educacional (SCHMIDT et al. 2006). Para minimizar erros de medida foi elaborado manual de instruções detalhado e realizado treinamento das entrevistadoras visando a correta 
aplicação do questionário. Ainda assim, possivel viés de informação pode ocorrer na aplicação do questionário.

Estudos de validação demandam tempo substancial e cooperação por parte dos participantes, tendo em geral elevado número de recusas. Nesse estudo, o percentual de recusas foi igual a $28 \%$. Deve-se considerar a possibilidade de as mulheres que concordaram em participar diferenciem-se da população em geral com relação à acurácia dos níveis de atividade física reportados. A perda de seguimento foi igual a $18 \%$ não havendo diferenças significativas entre o grupo estudado e as perdas.

Outro fator importante na análise dos resultados é a modificação da atividade física habitual que ocorre nesse período, com três quartos das mulheres referindo alguma modificação, quando questionadas no segundo trimestre de gestação. Esse fato dificulta a mensuração das atividades físicas cotidianas, uma vez que, segundo MISRA et al. (1998) modificações importantes ocorrem nos dois primeiros trimestres de gestação.

Os erros em replicar as estimativas do questionário podem ter diversas fontes. Primeiramente o curto intervalo de tempo entre as aplicações do questionário (cerca de uma semana) pode ter influenciado a memória da mulher e resultar em melhores coeficientes de correlação. Por outro lado, a utilização de equipamento e preenchimento do diário de atividades físicas podem ser fatores modificadores, tanto da percepção da gestante quanto no tocante à modificação das próprias atividades diárias. Para minimizar esses problemas foi também analisado o período pósparto.

É importante mencionar a enorme dificuldade na análise dos diários de atividades físicas, ainda que tenham sido excluídas mulheres não alfabetizadas, devido ao preenchimento incorreto. A listagem de diferentes atividades no mesmo período de tempo foi freqüente. Este fato dificultou a quantificação exata da duração, início e término de cada atividade e impossibilitou a utilização do diário como parâmetro na 
interpretação da frequêencia cardíaca para cada atividade realizada (Anexo 4).

O Compêndio de Atividades Físicas (AINSWORTH et al. 2000), proposto como sistema de classificação e padronização das intensidades segundo o equivalente metabólico de repouso (MET), não foi desenvolvido para determinar com precisão o custo energético individual das atividades físicas. No entanto, verifica-se que muitos profissionais e pesquisadores o utilizam para expressar o gasto energético em relação ao peso corporal e realizar prescrição de exercício. Dentre as críticas quanto à sua utilização para estimativa do gasto energético, encontra-se a superestimação em grupo heterogêneo de indivíduos (BYRNE et al. 2005) ou a subestimação em indivíduos obesos (LEENDERS et al. 2000). Por esse motivo, a presente análise utilizou o Compêndio como uma estratégia de classificação das atividades físicas, apenas para analisar o tempo despendido nas várias dimensões de atividade física.

Os resultados de reprodutibilidade encontrados com relação às questões qualitativas do questionário em três momentos foram satisfatórios somente para três questões: carregar objetos pesados, como percebia seu nível de atividade física durante a gestação e ajuda nos serviços domésticos. Os coeficientes de concordância Kappa entre Q1 e Q2 situaram-se na faixa de classificação médio para bom, de 0,40 a 0,75 (COHEN, 1960). Estes dados estão de acordo com os resultados apresentados por WILDSHUT et al. (1993), exceção feita às questões subjetivas com desempenho insatisfatório em seu estudo.

No tocante às variáveis quantitativas, a análise de correlação intraclasse apresentou bons resultados na reprodutibilidade do questionário. Entretanto atividades agrupadas como permanência em pé apresentaram valores abaixo do esperado. Ainda que a maneira de agrupar as diversas atividades diárias tenha sido diferente, os resultados obtidos por SCHMIDT et al. (2006) nas atividades agrupadas foram semelhantes, variando de 0,76 para atividades habituais a 0,86 para ocupacionais. 
Muitos estudos utilizam inapropriadamente o coeficiente de correlação produto momento como indicador de concordância entre dois instrumentos. Assim o fizeram, os recentes estudos de validação de questionários de atividade física em gestantes, de CHASAN-TABER et al. (2004) e SCHMIDT et al. (2006), os quais apresentam bons coeficientes de correlações de Pearson e Spearman. No entanto, a relação linear não considera e diferencia a inclinação dos pontos, nem diferenças sistemáticas entre os instrumentos que podem afetar substancialmente a concordância (HALLAL e VICTORA 2004). A análise proposta por BLAND e ALTMAN (1986) é mais adequada, pois considera os valores médios obtidos em cada método em relação à diferença obtida entres eles, verificando o grau de concordância entre os dados obtidos.

Pequena diferença foi verificada na comparação entre as médias dos valores do questionário com a freqüência cardíaca, cujos valores se aproximavam de zero, tanto para as atividades leves quanto moderadas. Porém, a verificação dos limites de concordância ( \pm 2 desvios padrão) indica grande variação, mais de 10 horas diárias para atividades moderadas e sete horas para as atividades leves, representando quase um terço do total diário. Ainda que a maioria dos pontos encontre-se dentro dos limites, esses valores apontam para variabilidade individual demasiadamente elevada nas medidas do tempo despendido nas duas dimensões da atividade física entre os instrumentos.

Em relação à disposição gráfica, dispersão adequada dos dados é observada nas atividades leves indicando que as diferenças não variaram de maneira sistemática em toda a faixa de medida. Por outro lado, os dados obtidos nas atividades moderadas sugerem maior variabilidade. Além disso, a inclinação dos pontos indica tendência a aumento da diferença à medida que aumenta o tempo despendido.

Esse resultado discordante entre métodos também foi encontrado por StEIN et al. (2003) ao analisarem 56 mulheres, com o objetivo de descrever padrões de gasto energético durante a gestação e verificar a validade concorrente de três métodos de estimativa. Os autores 
verificaram que a estimativa do gasto energético subestimou os valores obtidos com o sensor de movimentos (acelerômetro) e superestimou os valores baseados no recordatório de atividades físicas quando comparados com a estimativa da frequêencia cardíaca mensurada, em ambos grupos e períodos da gestação. A análise estatística apresentou coeficientes de correlação de Pearson (pairwise) entre 0,07 e 0,81 . Segundo os autores, os três métodos são sensiveis às variações do gasto energético durante cada atividade. $O$ recordatório de atividade física e o sensor de movimento (acelerômetro), bastante utilizados em estudos epidemiológicos para categorizar a atividade física de gestantes, apresentaram diferenças em relação à freqüência cardíaca.

A opção por um método de referência é o ponto crítico na análise das informações para a validação de um instrumento, considerando que esse deverá mensurar com a maior acurácia possível as várias dimensões da atividade física. Os resultados confirmam a falta de um padrão ouro para mensuração da atividade física. Ainda que a mensuração da freqüência cardíaca tenha sido utilizada como uma medida objetiva, ela deve ser considerada medida indireta da atividade física. A comparação das estimativas tanto no freqüêncímetro quanto no questionário são influenciadas por erros de medida. Adicionalmente, alteração da freqüência cardíaca com fatores externos ao esforço físico, tal como situações nas quais o indivíduo é tomado de sobressalto. Bem como, a solicitação de retirada do equipamento em atividades na água e ao dormir somada às falhas de registro do equipamento em decúbito lateral também podem ter afetado os resultados. Outra falha detectada diz respeito à superestimação da medida com a proximidade de motor em funcionamento (carro/ônibus).

Além disso, a freqüência cardíaca em gestantes apresenta significativas alterações fisiológicas inerentes à gestação como o aumento do volume plasmático. Os cuidados tomados no presente estudo incluíram a mensuração no mesmo trimestre da gestação, utilização de equação proposta para gestantes no mesmo período (PIRVANIK et al. 
2002) e seleção de equipamento (Polar) acurado (ACHTEN e JEUKENDRUP 2003).

Ao analisar o questionário proposto por CHASAN-TABER et al (2004), o auto-preenchimento restringe a utilização em mulheres de menor escolaridade, parcela expressiva da nossa população. Diferenças sócioeconômicas podem impossibilitar a sua utilização, visto que as categorias estabelecidas a priori no questionário subestimam a realização, por exemplo, de atividades domésticas pesadas e leves. A categoria mais elevada do questionário corresponde a três ou mais horas por semana, e as gestantes de nosso estudo apresentaram mediana igual a quatro e seis horas por semana.

SCHMIDT et al. (2006) utilizaram o Kaiser Physical Activity Questionnaire, questionário previamente validado para mulheres para avaliar a atividade física total por intermédio de um índice. Essa metodologia reduz a possibilidade de proposições e recomendações específicas para atividade física. Em estudo anterior no qual atividades em pé puderam ser detalhadas, identificou-se associação especifica da atividade de lavar roupa com o peso inadequado ao nascer (TAKITO et al. 2005).

As análises do presente estudo parecem assegurar a reprodutibilidade do questionário de atividade física para gestantes. Entretanto, com relação à validação, a comparação com os resultados obtidos pelo frequencímetro - instrumento disponível na época da coleta de dados - não mostrou graus de concordância adequados. São necessários estudos que utilizem metodologia estatística semelhante à aqui empregada e instrumentos mais adequados de medida de atividade física. É possivel supor que o questionário de atividades físicas proposto por esse estudo possa ter resultados satisfatórios quando comparado a outros métodos de medida mais precisos, tais como acelerômetro triaxial ou água duplamente marcada. Mais estudos são necessários para a identificação de metodologias adequadas de mensuração da atividade física durante a gestação em estudos epidemiológicos. 


\section{Referências Bibliográficas}

ACHTEN J, JeUKENDRUP AE. Heart rate monitoring: applications and limitations. Sports Med 2003; 33 (7): 517-38.

AINSWORTH BE, HASKELL WL, WHITT MC. Compendium of physical activities: an update of activity codes and MET intensities. Med Sci Sports Exerc 2000; 32 (suppl.9): S498-516.

ARTAL R. Exercise and pregnancy. Clin Obst Gynecol 2003; 46(2):377-8.

BLAND JM, ALTMAN DG. Statistical methods for assessing agreement betwen two methods for clinical measurement. Lancet 1986; 8: 30710.

BOREHAM C, RIDDOCH C. The physical activity, fitness and health of children. J Sports Sci 2001; 19(12): 915- 29.

BRASIL. Ministério da Saúde. Secretaria de Vigilância em Saúde. Secretaria de Atenção à Saúde. Instituto Nacional de Câncer. Coordenação de Prevenção e Vigilância. Inquérito domiciliar sobre comportamentos de risco e morbidade referida de doenças e agravos não transmissíveis: Brasil, 15 capitais e Distrito Federal, 2002-2003. Rio de Janeiro: INCA, 2004

Byrne NM, Hills AP, Hunter GR, Weinsier RL, Schutz Y. Metabolic equivalent: one size does not fit all. J Appl Physiol 2005; 99: 1112-9.

Chasan-Taber L, Schmidt MD, Roberts DE, Hosmer D, Markenson G, FREEDSON PS. Development and validation of a pregnancy physical activity questionnaire. Med Sci Sports Exerc 2004; 36(10): 1750-60.

Craig Cl, marshell al, Sjörstrom $M$, Bauman aE, Booth $M L$, ainsworth Be, Ekelund U, YNgVe A, Sallis Jf, OJa P, the IPAQ CONSENSUS GROUP AND THE IPAQ RELIABILITY AND VALIDITY STUDY GROUP. International physical activity questionnaire (IPAQ): 12-country reliability and validity. Med Sci Sports Exerc 2003; 35:1381-95.

FLEISS JL. Statistical methods for rates and proportions. $2^{\text {nd }}$ ed. New York: John Wiley \& Sons, 1981. 
FLORINDO AA, LATORRE MRDO. Validação e reprodutibilidade do questionário Baecke de avaliação da atividade física habitual em homens adultos. Rev Bras Med Esporte 2003; 9 (3): 121-8.

HALLAL PC, VICTORA CG. Reliability and validity of the International Physical Activity Questionnaire (IPAQ). Med Sci Sports Exerc 2004 Mar;36(3):556.

Hatch MC, Shu Xo, Mclean De, Levin B, Begg M, Reuss L, Susser M. Maternal exercise during pregnancy, physical fitness, and fetal growth. Am J Epidemiol 1993; 137(10):1105-14.

HULley SB, CUmmings SR. Designing Clinical Research: an epidemiological approach. Baltimore: Willians \& Wilkins, 1998.

KRAMER MS. Aerobic exercise for women during pregnancy (Cochrane review). The Cochrane Library, Issue 4, 2003. Chichester; UK: John Wiley \& Sons.

Leender NYJM, Sherman WN, Nagaraja HN. Comparisons of four methods of estimating physical activity in adult women. Med Sci Sports Exerc 2000;32(7):1320-6.

Matsudo SM, Matsudo VR, araúJo TL, ANDRAde DR, ANDRAde EL, OliveIRA LC, BRAggion GF. The Agita São Paulo program as a model for using physical activity to promote health. Pan Am J Public Health 2003; 14 (4): $265-72$.

MisRa DP, Strobino DM, Stashinko EE, Nagey DA e Nanda J. Effects of physical activity on preterm birth. Am J Epidemiol 1998; 147: 628-35.

Pardini R, matsudo S, araújo T, matsudo V, Andrade E, Braggion G, ANDRAde D, Oliveira L, Figueira JR A, Raso V. Validação de questionário internacional de nível de atividade física (IPAQ - versão 6): um estudo piloto em adultos jovens brasileiros. Rev Bras Cien Mov 2002; 10 (4): $41-50$.

Pate RR, Pratt M, Blair SN, Haskell WL, macera CA, Bouchard C, Buchner D, Ettinger W, Heath GW, King AC. Physical activity and public health: a recommendation from the Centers for Disease Control 
and Prevention and the American College of Sports Medicine. JAMA 1995; $273(5): 402-7$.

PIRVANIK JM. Potencial effects of maternal physical activity on birth weight: brief review. Med Sci Sports Exerc 1998; 30(3): 400-6.

PiRVANIK JM, Stein AD, Rivera JM. Effect of pregnancy on heart rate/oxygen consumption calibration curves. Med Sci Sports Exerc 2002; 34(5):750-5.

Schmidt MD, Freedson PS, Pekow P, Roberts D, Sternfeld B, ChasanTABER L. Validation of the Kaiser physical activity survey in pregnant women. Med Sci Sports Exerc 2006;38(1):42-50.

SteIN AD, RIVERA JD, PIRVANIK JM. Measuring energy expenditure in habitually active and sedentary pregnant women. Med Sci Sports Exerc 2003;35(8):1441-6.

TAYLOR HL, JACOBS JR DR, SHUCKER B, KNUDESN J, LeON AS E DEBAKER G. A questionnaire for the assessment of leisure-time physical activities. $\mathbf{J}$ Chron Dis 1978; 31: 741-55.

TAKITO MY, BENÍcIO MHDA, LATORRE MRD. Postura materna durante a gestação e sua influência sobre o peso ao nascer. Rev Saude Publica 2005; 39(3): 325-32.

Tremblay MS, Shephard RJ, McKenzie TL, Gledhill N. Physical activity assessment options within the context of the Cannadian physical activity, fitness, and lifestyle appraisal. Can J Appl Physiol 2001; 26 (4): $388-407$.

WASHBuRn RA, FICKeR JL. Physical Activity Scale for the Elderly (PASE): the relation with activity measured by a portable accelerometer. $\mathbf{J}$ Sports Med Phys Fitness 1999; 39 (4): 336 - 40.

Washburn RA, Jacobsen DJ, Sonko BJ, Hill JO, Donnelly JE. The validity of the Stanford seven-day physical activity recall for young adultvs. Med Sci Sports Exerc 2003; 35 (8): 1374 - 80. 
WILDSCHUT HI, HARKER LM, RIDDOCH CJ. The potencial value of a questionnaire for the assessment of habitual physical activity in pregnancy. J Psychosom Obstet Gynaecol 1993; 14(1): 17-29.

WORLD HEALTH ORGANIZATION. 2002 world report: reducing risks, promoting healthy life. Geneva: WHO; 2002. 
Artigo III.

Atividade física durante a gestação e baixo peso ao nascer: um estudo de casos e controles. 


\section{Resumo}

Objetivos: Identificar e medir a magnitude dos riscos de baixo peso ao nascer e prematuridade associados a características da atividade física, abrangendo as diferentes dimensões (ocupacional, doméstica, lazer e locomoção) em gestantes de baixa renda. Métodos: Trata-se de estudo de caso-controle desenvolvido em três hospitais de grande porte do município de São Paulo. Foram estudados 273 recém-nascidos de baixo peso e 546 controles e sub-amostra dos casos $(n=117)$ com idade gestacional inferior a 37 semanas e seus controles não prematuros $(n=234)$. As Informações foram obtidas mediante entrevistas com as puérperas e transcrição de dados dos prontuários. Para detectar o efeito-líquido de cada fator em estudo, realizou-se análise de regressão logística múltipla condicional e hierarquizada. Tais fatores e as possíveis variáveis de confundimento foram agrupados em blocos, ordenados segundo a precedência com que influiriam o peso ao nascer. Adotou-se $p<0,20$ para seleção das variáveis de controle e $p<0,05$ para identificação de associação estatisticamente significativa entre fatores de estudo e desfechos estudados. Resultados: Foi identificada como fator de proteção para baixo peso ao nascer a realização de atividades leves por $31 \frac{1}{2}$ a 7 horas diárias (OR ajustado=0,73; $I_{95 \%}: 0,49-1,11$ ) e mais de 7 horas diárias (OR ajustado=0,64; IC $\mathrm{C}_{95 \%}: 0,42-0,99$ ), para a qual identificou-se relação do tipo dose-resposta ( $p$ de tendência $=0,046$ ). A realização de atividades domésticas associou-se tanto ao baixo peso ao nascer quanto a prematuridade ( $p$ de tendência $=0,007$ e 0,035 , respectivamente). Foi detectado efeito de proteção de prematuridade da caminhada no lazer por menos de 20 minutos diários (OR ajustado=0,44; $I_{95 \%}: 0,21-0,90$ ) e 20 ou mais minutos diários (OR ajustado=0,36; $\left.I_{95 \%}: 0,16-0,78\right)$. Conclusões: Evidenciou-se que a atividade física durante o segundo trimestre de gestação exerce efeito independente sobre o baixo peso ao nascer e a prematuridade.

Descritores: baixo peso ao nascer, prematuridade, atividade física, gestação 


\section{Introdução}

O peso ao nascer representa importante questão de saúde pública, tanto em países desenvolvidos quanto em países em desenvolvimento, sendo o fator que mais exerce influência sobre o estado de saúde, nutrição e as chances de sobrevivência das crianças (MCCoRMıcK 1985). Associa-se também à ocorrência de doenças crônicas na idade adulta (GoDfREY e BARKER 2000).

É importante destacar que nas duas últimas décadas, contrariamente à tendência declinante de vários indicadores de saúde - mortalidade infantil, desnutrição pós-natal e desnutrição em mulheres adultas - o baixo peso ao nascer (BPN), inferior a 2.500 gramas, tem mostrado prevalência estável ou em elevação em municípios da Região Sudeste e Sul do Brasil - como São Paulo, Pelotas e Ribeirão Preto. Elevação na prevalência de BPN foi também registrada em países desenvolvidos, entre eles Canadá e EUA (SILVA et al. 1998; MONTEIRO et al. 2000; BRANUN e SCHOENDORF 2002; BARROs et al. 2005).

Ao analisar os processos que podem ocasionar elevação na incidência de BPN, da restrição do crescimento intrauterino (RCIU) e da prematuridade, BARROS et al. (2005) observaram em Pelotas, nas duas últimas décadas, discreta elevação na prevalência de baixo peso ao nascer e acentuada na prematuridade (6,3\% em 1982 para 16,2\% em 2004). A RCIU manteve-se inalterada.

Segundo KRAMER (1987), a causalidade para o baixo peso ao nascer é multifatorial. Entre seus determinantes destacam-se condições sócioeconômicas desfavoráveis, baixo peso da mãe no início da gestação, baixa estatura materna, doenças como malária, infecção genital, hipertensão arterial, tabagismo, falta ou deficiência da assistência pré-natal, antecedentes reprodutivos desfavoráveis, a ocorrência de gravidez múltipla, uso de drogas ilícitas, estresse, falta de apoio psicossocial e atividade física excessiva durante a gestação (KRAMER 1987; BERKoWITZ e PAPIERNIK 1993; KRAMER et al. 2001; MONAGHAN et al. 2001). 
Em recente estudo de revisão sistemática da literatura sobre atividade física materna durante a gestação e baixo peso ao nascer, prematuridade e restrição de crescimento intra-uterino, TAKITO (2006a) confirmaram os efeitos deletérios do esforço físico excessivo tanto no trabalho (SAUREL-CuBizolles e KAMINSKI 1991; Koeemester et al. 1995; SPINILlo et al. 1996; TUNTISERANEE et al. 1998; WeRGELAND et al. 1998) quanto no lazer (CAMPBEL e Mottola 2001; MAGANN et al. 2002). De forma concomitante, diversos estudos apontaram efeito igualmente prejudicial decorrente de atividade física insuficiente nas atividades de lazer (MAGANN et al. 1996; SCHRAMm et al. 1996, CAMPBel e Mottola 2001) ou mesmo devido ao tempo excessivo despendido assistindo televisão (MISRA et al. 1998). Estes resultados falam a favor da hipótese de uma curva em $U$ relacionando atividade física e os produtos da gestação. Entretanto, a escassez de estudos que considerem simultaneamente todas as dimensões da atividade física (ocupacional, doméstica, no lazer e de locomoção) impedem que a referida hipótese seja devidamente avaliada.

Neste estudo pretende-se avaliar a influência das quatro dimensões da atividade física (ocupacionais, domésticas, no lazer, e de locomoção) em gestantes usuárias de serviços públicos do município de São Paulo sobre o baixo peso ao nascer e a prematuridade.

\section{Métodos}

\section{Tipo de delineamento}

Trata-se de um estudo de casos e controles desenvolvido em três hospitais públicos de grande porte do município de São Paulo (sendo um deles referência para gestações de alto risco). Foram estudados 273 casos (recém-nascidos com peso ao nascer inferior a 2.500 gramas) e 546 controles (peso ao nascer maior ou igual a 2.500 gramas). Este tamanho amostral conferiu ao estudo poder de teste de $80 \%$ para detectar um odds ratio igual ou superior a 1,7 , com nivel de significância de $5 \%$, para uma exposição afetando entre 20 e $50 \%$ dos controles. Uma sub-amostra dos 
recém-nascidos com baixo peso foi selecionada para estudar a prematuridade, totalizando 117 casos (recém-nascidos com peso ao nascer inferior a 2.500 gramas e idade gestacional inferior a 37 semanas) com dois controles não prematuros $(n=234)$. O menor tamanho amostral conferiu a esta análise um poder de teste de $80 \%$ para detectar um odds ratio igual ou superior a 2,2 , com nível de significância de $5 \%$ para uma exposição afetando entre 20 e $50 \%$ dos controles.

Foram critérios de exclusão do estudo: nascimentos gemelares, puérperas com idade inferior a 18 anos, natimortos ou recém-nascidos com malformação congênita aparente ao nascimento.

Os casos foram selecionados nos livros de registro de partos dos centros obstétricos e os dois controles foram identificados dentro do mesmo hospital. Os controles foram sorteados em período de até 48 horas após o nascimento do caso, dentre os nascidos vivos com peso igual ou superior a 2.500 gramas.

As informações foram obtidas mediante entrevistas realizadas com as mães dos casos e dos controles durante sua permanência no hospital, utilizando questionário pré-testado. $O$ questionário de atividades físicas (Anexo 3) proposto por TAKITO (2006b) foi utilizado para aferição das variáveis de exposição. Vale lembrar que a atividade física estudada referese a uma semana típica do segundo trimestre da gestação, momento em que a influência sobre o crescimento fetal é mais expressiva. Informações complementares foram transcritas dos prontuários das gestantes e dos recém-nascidos.

As entrevistas foram conduzidas por seis entrevistadoras treinadas. A coleta de dados foi supervisionada pela autora, que realizou controle de qualidade parcial de $5 \%$ das entrevistas selecionadas de forma aleatória.

\section{Variáveis dependentes}

A informação do peso ao nascer foi coletada junto ao livro de parto do centro obstétrico de cada hospital. A informação da idade gestacional foi obtida a partir da entrevista e dos prontuários clínicos. Houve perda da 
informação em 3,7\% das informações de idade gestacional por falta de plausibilidade biológica quando comparada com o peso ao nascer KRAMER et al. (2001b). A idade gestacional de $83,3 \%$ dos nascimentos foi estimada pela data da última menstruação, $11,4 \%$ por ultrassonografia anterior à $20^{\mathrm{a}}$ semana e 5,2\% por avaliação clínica do recém-nascido. Outra variável de interesse foi a condição de prematuridade, identificada pela: idade gestacional inferior a 37 semanas.

\section{Variáveis independentes estudadas}

Foram também coletadas informações sobre condições que pudessem exercer efeito de confusão sobre as associações investigadas, levando-se em conta variáveis sócio-econômicas (renda per capita, escolaridade materna e presença de companheiro), reprodutivas (idade, paridade), cor da pele, relacionadas à assistência pré-natal (número de consultas), comportamentais (tabagismo, consumo de álcool e drogas ilícitas, planejamento da gravidez, atividade sexual durante a gestação) e doenças e condições de saúde potencialmente associadas à exposição e ao desfecho (hipertensão arterial, infecções não tratadas, sangramento, rotura prematura de membranas, depressão e tristeza, repouso em casa por indicação médica ou não, uso de medicação via oral ou venosa, internação hospitalar). A medida direta da estatura e do peso pós-parto não pode ser efetivada devido à condição física de parte das muheres por ocasião da entrevista. Informações recordatórias de peso pré-gestacional, estatura e ganho ponderal foram coletadas e descartadas da análise por se mostrarem inconsistentes.

\section{Fator de estudo: atividade fisica.}

De início, procurou-se quantificar o tempo despendido em atividades segundo intensidade. Para tanto utilizou-se o compêndio de atividades físicas (AINSWORTH et al. 2000) para verificar o custo energético das atividades e agrupá-las conforme o quadro a seguir. 
Atividades físicas agrupadas segundo a intensidade.

\begin{tabular}{|c|c|c|}
\hline Intensidades & MET & Atividades \\
\hline \multirow[t]{2}{*}{ Sedentárias } & $<1,5$ & Assistir televisão \\
\hline & & Descansar (sentada ou deitada) \\
\hline \multirow[t]{9}{*}{ Leves } & $1,5-2,9$ & Limpeza leve \\
\hline & & Lavar, estender e passar roupa \\
\hline & & Lavar louça \\
\hline & & Cozinhar \\
\hline & & Cuidar e brincar com criança sentada \\
\hline & & Andar devagar, sem inclinação nem peso \\
\hline & & Usar meios de transporte \\
\hline & & Realizar trabalhos manuais \\
\hline & & Trabalhar sentada ou em pé parada \\
\hline \multirow[t]{6}{*}{ Moderadas } & $3,0-6,0$ & Limpeza pesada (faxina) Varrer casa e quintal \\
\hline & & Limpar carpetes e atividades agachadas \\
\hline & & Cuidar, brincar com criança e carregar no colo \\
\hline & & Andar normal ou rapidamente, com inclinação ou com \\
\hline & & peso \\
\hline & & Trabalhar andando ou carregando objetos \\
\hline Vigorosas & $>6,0$ & Subir escadas \\
\hline
\end{tabular}

MET: equivalente metabólico

A seguir, foram apreciadas as atividades desenvolvidas durante a gestação no trabalho doméstico, no trabalho fora de casa, no lazer e para a locomoção. Buscou-se classificar as mulheres segundo nivel de atividade física durante a gestação: sedentárias, pouco ativas, ativas e muito ativas (com atividades vigorosas), através dos múltiplos da taxa metabólica basal (WHO/FAO 2003).

O estudo abrangeu o tempo, obtido através da multiplicação da freqüência e duração das atividades, expresso em minutos ou horas por dia, e apresentado em geral por meio de quartis ou tercis para as seguintes modalidades de atividades:

- Caminhadas: no lazer (passeando ou se exercitando), sem carregar peso (incluindo caminhada para o trabalho, durante o trabalho, levando criança à escola) e carregando peso 
(fazendo compras com peso, no trabalho com peso e com criança no colo).

- Caminhada no lazer (passeando ou se exercitando)

- Atividades domésticas

- Assistir televisão (sentada ou deitada)

Como a gestação é um período de grandes transformações físicas e psicológicas, consideraram-se também alterações no padrão de atividade física durante a gestação, seja por recomendações ou contra-indicações clínicas, seja pela disposição individual. As informações foram obtidas por meio de questionamento feito às mulheres quanto à modificação da atividade física e da freqüência da atividade sexual no decorrer da gestação.

A percepção subjetiva da atividade física da mulher foi verificada com uma questão, que enfocava a comparação com outras mulheres, em cinco categorias. A categoria intermediária "tão ativas quanto as outras gestantes" foi agrupada junto com as categorias "menos" e "muito menos ativas", pois o cruzamento desta questão com os múltiplos da taxa metabólica basal, mostrou que $70 \%$ das mulheres que se referiam "tão ativas quanto as outras" eram classificadas como sedentárias. Dificuldades de compreensão ou o meio ambiente da mulher, tendo um grupo menos ativo como comparação, podem ter ocasionado essa diferença na classificação.

\section{Análise estatística}

Os Odds Ratios brutos e ajustados e seus respectivos intervalos de confiança de $95 \%$ para os desfechos estudados foram estimados mediante análise de regressão logística condicional considerando o pareamento por hospital (SCHLESSELMAN 1982). A condução da análise múltipla ocorreu de maneira hierarquizada seguindo procedimento de VICTORA et al. (1997), com ajuste pelas covariáveis estudadas que mostraram associação com as variáveis resposta com $p<0,20$ na análise univariada. A significância estatística das variáveis incluídas nos modelos foi avaliada pelo teste da razão de máxima verossimilhança (CLAYTON e HILls 1993), com nível crítico 
de $p$ inferior a $5 \%$. Testes de tendência linear foram executados quando apropriados.

O modelo teórico dos determinantes de baixo peso ao nascer desenvolvido por SANTOS (1995) foi adaptado ao presente estudo e orientou a ordem de inclusão dos blocos de variáveis para a modelagem (FIGURA 1). Os fatores do bloco mais distal, sócio-econômico, foram os primeiros a serem incluídos no modelo. Aqueles que guardaram associação $(p<0,20)$ com o desfecho permaneceram como variáveis de ajuste dos blocos hierarquicamente inferiores. Da mesma forma, as variáveis do grupo de características biológicas e reprodutivas maternas que mantiveram associação significativa com a variável resposta para os fatores internos ao bloco e para os fatores do bloco socioeconômico permaneceram e passaram a constituir variáveis de controle das análises subseqüentes. Procedimento análogo foi adotado para os dois blocos mais proximais (variáveis indicadoras de morbidade, comportamento materno e cuidados de prénatal).

O projeto foi aprovado pelos Comitês de Ética em Pesquisa da Faculdade de Saúde Pública e dos hospitais onde foi realizado o estudo (Anexo I). 
Figura 1. Marco teórico da causalidade do baixo peso ao nascer (SANTOS 1995).

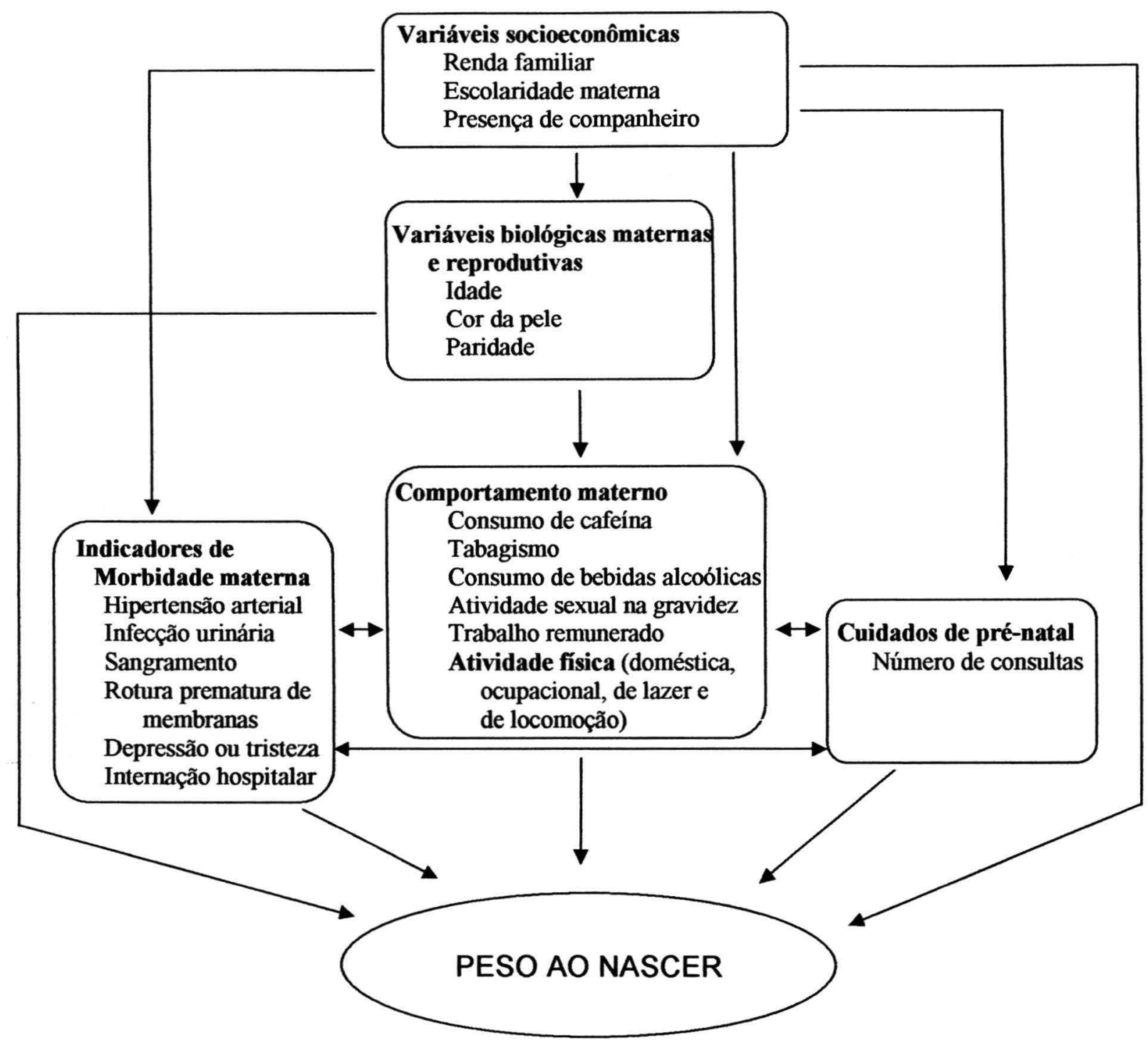

\section{Resultados}

$\mathrm{Na}$ Tabela 1 apresentam-se os resultados das análises univariadas entre cada uma das variáveis de controle e o baixo peso ao nascer. Todas as variáveis socioeconômicas e maternas biológicas e reprodutivas foram selecionadas para as análises múltiplas posteriores, exceção feita à renda familiar per capita e paridade. Foi mais freqüente entre os casos a condição de baixa escolaridade materna, ausência de companheiro, idade superior a 35 anos, cor da pele negra. Entre as variáveis do bloco de comportamento materno, foram selecionadas para as análises múltiplas, o tabagismo e a 
redução da atividade sexual. Também foram selecionadas para as análises múltiplas todas as variáveis do bloco de indicadores de morbidade materna e pré-natal, exceto a realização de repouso em casa. Todas as variáveis indicadoras de morbidade, o tabagismo e a baixa freqüência a pré-natal foram mais freqüentes entre os casos. A redução da atividade sexual ocorreu mais frequentemente nos controles.

$\mathrm{Na}$ Tabela 2 apresentam-se os resultados das análises brutas entre as variáveis de atividade física e o baixo peso ao nascer. As análises ajustadas exibidas na Tabela 3, são apresentadas em dois modelos multivariados diferentes devido à alta colinearidade entre as variáveis atividades leves e atividades domésticas, incluídas nos modelos I e II, respectivamente.

Na Tabela 2, verifica-se efeito de proteção da duração das atividades leves sobre o baixo peso ao nascer. Esta relação é do tipo dose resposta com $p$ de tendência igual a 0,001 . O ajuste pelas variáveis de confundimento, apresentado na Tabela 3 , confirma a tendência do efeito de proteção, mas evidencia redução da significância estatística ( $p$ de tendência linear igual a 0,046). A caminhada no lazer apresenta, na análise univariada, efeito de proteção que não chega a alcançar significância estatística na análise múltipla $(p=0,099)$. Reduzir a atividade física no decorrer da gestação associou-se negativamente ao baixo peso ao nascer na análise univariada, permanecendo no modelo I como variável de ajuste.

$\mathrm{Na}$ análise univariada das variáveis incluídas no modelo II, detectouse associação negativa entre a duração das atividades domésticas e o baixo peso ao nascer a qual se intensificou após ajuste pelas variáveis de confundimento com $p=0,007$ no teste de tendência linear. A percepção subjetiva da atividade física durante a gestação apontou como condição de risco para o baixo peso ao nascer "ser muito mais ativa" ou "ser menos ativa" em relação à categoria de mulheres que se auto-classificavam como ativas. Esta associação foi significativa na análise bruta $(p=0,048)$, mas perdeu significância estatística na análise múltipla $(p=0,131)$, permanecendo como variável de ajuste. As demais variáveis: duração das atividades sedentárias 
e moderadas, assistir televisão, caminhada, percepção subjetiva da atividade física prévia à gestação e a intensidade da atividade física (avaliada por múltiplos da taxa metabólica basal) não se associaram ao baixo peso ao nascer na análise bruta.

As Tabelas 4 e 5 mostram os resultados das análises brutas e ajustadas realizadas em uma sub-amostra de recém-nascidos prematuros ( $n=117)$ extraídos do total de casos de baixo peso $(n=273)$ e respectivos controles não prematuros $(n=234)$. Vale mencionar que as variáveis selecionadas como de ajuste foram as mesmas incluídas na análise múltipla quando o desfecho foi o baixo peso ao nascer para os blocos socioeconômico e variáveis biológicas. No bloco de indicadores de morbidade permaneceram como variáveis de ajuste hipertensão arterial, sangramento, rotura prematura de membranas e internação hospitalar. No bloco de variáveis comportamentais, o trabalho remunerado.

Os resultados vistos na Tabela 5 referem-se aos dois modelos que incluem as variáveis de exposição I e II. Verifica-se na análise univariada associação negativa estatisticamente significativa entre duração das atividades leves e prematuridade, a qual não se mantém após ajuste pelas variáveis de confundimento. $\mathrm{Na}$ análise univariada verifica-se efeito de proteção da realização de caminhada no lazer. Esta relação é do tipo dose resposta com $p$ de tendência igual a 0,018. $O$ ajuste pelas variáveis de confundimento torna ainda mais evidente o efeito de proteção.

Com relação às variáveis do modelo II, detectou-se, na análise univariada, associação negativa entre a duração das atividades domésticas e a prematuridade do tipo dose resposta com $p$ de tendência igual a 0,053 , a qual se mantém após ajuste para as variáveis de confundimento $(p=0,035)$. As demais variáveis de duração das atividades sedentárias, moderadas, assistir televisão, caminhada agrupada, redução da atividade física, percepção subjetiva da atividade física, tanto prévia quanto na gestação, e a intensidade da atividade física não mostraram associação com a prematuridade na análise bruta. 


\section{Discussão}

Serão abordados de início aspectos relacionados à validade do estudo e a seguir os resultados propriamente ditos. Tratando-se de estudo sobre fatores de risco para desfecho reconhecidamente multicausal, impõem-se duas questões cruciais para a validade interna dos resultados obtidos: o controle do efeito dos diversos potenciais de fatores de confusão e a qualidade dos indicadores adotados para expressar a atividade física materna. Com relação à primeira questão foi possível obter algumas informações a respeito dos determinantes clássicos do baixo peso ao nascer. Considerando-se que a identificação das variáveis de controle foi abrangente e a análise estatística realizada por procedimento particularmente indicado para eventos multicausais - análise hierarquizada é pequena a possibilidade de que os odds ratios ajustados obtidos estejam distorcidos por fatores de confundimento não considerados ou impropriamente controlados.

Quanto à questão da validade operacional dos indicadores empregados para expressar a atividade física materna, deve-se lembrar que não existiam, por ocasião do planejamento do estudo, questionários e indicadores referendados. $O$ questionário adotado foi elaborado com base em cuidadosa revisão da literatura, tendo sido realizado estudo que mostrou bons resultados de reprodutibilidade, mas validade inadequada quando comparado ao instrumento de medida objetiva da freqüência cardíaca como parâmetro da atividade física. $\mathrm{O}$ instrumento utilizado, freqüêncimetro (Polar) apresentou problemas como aferidor objetivo da freqüência cardíaca (TAKITO 2006b).

Ainda que diversas medidas tenham sido tomadas para minimizar potenciais erros sistemáticos, deve-se considerar prováveis limitações deste estudo para a interpretação dos resultados. A realização de entrevista no puerpério, buscando informações do segundo trimestre de gestação, pode aumentar o viés de memória, embora as entrevistadoras tenham sido treinadas visando minimizar esta questão. Ainda que, as puérperas não tivessem conhecimento da hipótese do estudo, não foi possível o cegamento 
dos entrevistadores aos desfechos, pois os mesmos selecionavam casos e controles.

Com relação aos resultados do presente estudo, verificou-se influência da atividade física durante a gestação sobre o baixo peso ao nascer e a prematuridade. A tendência à redução do risco à medida que aumenta o tempo despendido em atividades leves é confirmada para o baixo peso ao nascer, com relação do tipo dose-resposta. Realizar sete ou mais horas diárias de atividades leves representa redução de cerca de um terço no risco de baixo peso ao nascer, em relação a despender menos de $31 / 2$ horas. A comparação destes resultados com os da literatura é dificultada pela diversidade de métodos de aferição da exposição e pelo fato de poucos estudos terem avaliado a atividade física de forma global enfocando suas quatro dimensões: tarefas domésticas, lazer, locomoção e ocupacional. 0 estudo de MAGANN et al. (1996), utilizando o gasto energético diário, detectou aumento do risco de prematuridade $\left(\mathrm{OR}=1,61\left[\mathrm{I} \mathrm{C}_{95 \%}\right.\right.$ :1,15-2,26]) para as mulheres menos ativas. BARNES et al. (1991) analisando a idade gestacional de maneira contínua detectaram associação positiva com o gasto energético em atividades ocupacionais e domésticas. KLEBANOFF et al. (1990), estudando uma única dimensão da atividade física também detectaram redução da prematuridade associada ao tempo de trabalho leve, com um efeito do tipo dose-resposta ( $p$ tendência $=0,019$ ). Outros estudos, de qualidade metodológica inferior, não detectaram associação do peso ao nascer com a realização de atividades domésticas de leve intensidade (AGARWAL et al. 2001) e a atividade física auto-classificada (ROSE et al. 1991).

No presente estudo, verifica-se que as atividades leves representam quase a metade (46\%) das atividades físicas diárias das mulheres no grupo de controles, sendo as atividades sedentárias, menos de $27 \%$ e as moderadas, $15 \%$. Dentre as atividades identificadas como de leve intensidade destacam-se: cozinhar e lavar louça (40\%), limpeza leve $(21 \%)$ e cuidados com a roupa (16\%). 
Com relação às atividades domésticas (35\% das atividades diárias), detectou-se proteção de cerca de $50 \%$ para as mulheres que realizavam mais de 4 horas ao dia, em relação às que executavam menos do que 2 horas diárias. Esta proteção foi confirmada tanto para o baixo peso ao nascer quanto para a prematuridade. Tal efeito se manteve após ajuste pelas variáveis de confusão ( $\rho$ de tendência linear $=0,007$ e 0,035 , respectivamente). Estes resultados coincidem com os achados por CAVALLIe TANAKA (2001) em gestantes multiparas. Estes autores detectaram proteção para prematuridade nas mulheres que não contavam com ajuda no trabalho doméstico (OR= 0,23 [IC $95 \%: 0,07 ; 0,74]$ ) e para aquelas que contavam com ajuda parcial, sendo responsável por mais da metade das tarefas domésticas ( $O R=0,31$ [ $\left.\left.I C_{95 \%}: 0,11 ; 0,88\right]\right)$. Utilizando a questão do auxílio nas tarefas domésticas como indicador da atividade doméstica da gestante, LAUNER et al. (1990) identificaram risco de nascimento de crianças pequenas para idade gestacional superior a 1,7 para as mulheres que referiam não ter ajuda em casa. Esta variável, provavelmente se associa negativamente aos desfechos por relacionar-se mais com as atividades vigorosas e extenuantes, das quais as mulheres com ajuda nas tarefas domésticas são provavelmente poupadas. Contrariamente a estes resultados, RABKIN et al. (1990) não detectaram associação das atividades domésticas agrupadas (leves, moderadas e vigorosas) com o peso ao nascer. Esse fato possivelmente deve-se à inadequada mensuração desta atividade.

Conforme observado, em estudo de coorte por nós realizado (TAKITO et al. 2005) no município de São Paulo com 153 gestantes de baixa renda, usuárias de serviço público de pré-natal, a realização de atividades físicas vigorosas consideradas prejudiciais ao bem estar materno e fetal (CLAPP e CAPELESS 1990), foi quase inexistente. No presente estudo, apenas seis mulheres referiram despender mais de 10 minutos por dia em atividades dessa natureza. A comparação com os diversos estudos que detectaram associação de exercício/esforço moderado-vigoroso com a saúde maternofetal ficou comprometida pela não realização de atividades vigorosas pelas mulheres desse estudo. SpINILLo et al. (1996) detectaram risco de quase 
duas vezes e meio associado à $\mathrm{RCIU}(\mathrm{OR}=2,4$ [IC $95 \%: 0,36 ; 4,21])$, ao analisar unicamente a atividade ocupacional das mulheres. KOEMEESTER et al. (1995) identificaram redução da idade gestacional associada a maior duração de tarefas de alta carga de trabalho físico. MAGGAN et al. (2002) detectaram redução do peso ao nascer de 86 gramas, nas mulheres que realizavam exercício vigoroso de maneira obrigatória no treinamento militar. Contrariamente, HATCH et al. (1993) detectaram aumento do peso ao nascer com a realização de exercício moderado e vigoroso igual a 124 [IC $95 \%$ :$6 ;+255]$ e $276 \mathrm{~g}[\mathrm{IC} 95 \% ;+54 ;+497]$ gramas, respectivamente.

As variáveis caminhada no lazer, redução da atividade física durante a gestação e percepção subjetiva da atividade física permaneceram nos modelos finais de baixo peso ao nascer como variáveis de controle. A redução espontânea na duração das atividades físicas perdeu a significância estatística no modelo ajustado, não confirmando o efeito de proteção para o baixo peso ao nascer, conforme já observado na literatura (CLAPP e DiCKENSTEIN 1984; SPINILlo et al. 1996). Em estudo de coorte anterior, foi detectado que a redução das atividades físicas ocorreu especificamente nas atividades moderadas e vigorosas, o que pode explicar a não influência das atividades físicas moderadas no presente estudo (TAKITO et al. 2005).

A variável que agrupa a caminhada em suas diversas dimensões não se mostrou associada aos desfechos estudados. Analisando separadamente a caminhada no lazer (passeando ou exercitando-se) detectou-se proteção para a prematuridade, resultando em redução de mais de $50 \%$ do risco para as mulheres que caminhavam menos de 20 minutos por dia e cerca de dois terços para aquelas que caminhavam diariamente 20 ou mais minutos. A elevação da proteção para a prematuridade com o aumento do tempo de caminhada no lazer apresentou efeito do tipo dose-resposta com $p$ de tendência linear igual a 0,003 . O efeito da caminhada sobre o baixo peso ao nascer não foi significativo na análise ajustada. Diversos estudos, que analisaram a caminhada (intencional ou não) detectaram o mesmo sentido do efeito protetor de caminhar, considerando a duração, até 50 minutos diários, sobre o peso inadequado ao nascer ( $O R=0,44$ [ $\left[\mathrm{C}_{95 \%}: 0,20-0,98\right]$ ) 
(TAKITO et al. 2005), ou sobre a variável contínua com acréscimo de 35 [8;63] gramas para as mulheres que caminhavam de duas a cinco horas por dia (HENRIKSEN et al. 1995). TUntISERANeE et al. (1998), analisando atividade ocupacional, detectaram aumento de risco para prematuridade analisando caminhadas rápidas $\left(\mathrm{OR}=2,4\left[\mathrm{IC}_{95 \%}: 1-5,7\right]\right)$. MISRA et al. (1998) encontraram o dobro de risco de nascimentos prematuros ( $O R=2,10$ [IC $95 \%: 1,38 ; 3,20]$ ), analisando a freqüência de caminhada intencional (não necessariamente no lazer), por quatro ou mais vezes, na semana. Um diferencial entre os resultados da literatura e os apresentados no presente estudo pode ser a menor velocidade de deslocamento, visto que a freqüência de caminhada rápida no grupo de mulheres que caminhavam no lazer foi apenas 5,7 \%.

Melhores níveis de condicionamento físico implicam melhor transporte e aproveitamento de oxigênio e substratos, o que possibilita ao feto melhor suprimento inclusive durante a realização de atividades físicas mais intensas. $O$ fato das mulheres realizarem mais atividades leves possibilita a manutenção do fluxo sangüíneo, ainda que não haja melhoria do condicionamento físico.

No tocante à hipótese de uma curva em $\mathrm{U}$ relacionando atividade física e baixo peso ao nascer e prematuridade, os resultados do presente estudo permitem confirmar o extremo esquerdo da curva, explicitado pelo aumento do risco de baixo peso ao nascer e prematuridade nas mulheres menos ativas, que despendem menos tempo em atividades leves, em atividades domesticas e com caminhada no lazer. O extremo oposto da curva não pode ser testado pelo fato das mulheres estudadas não realizarem atividades vigorosas.

Este estudo mostrou que despender mais tempo em atividades leves durante a gestação representa proteção para o baixo peso ao nascer e que mais tempo em atividades domésticas associa-se a proteção para o baixo peso ao nascer e para a prematuridade. Detectou também efeito de proteção da caminhada no lazer para a prematuridade. Vale destacar que esta prática é pouco freqüente na população estudada. Apenas um quarto das mulheres do grupo controle caminha mais de 20 minutos diários. 
Nossos resultados suportam os esforços realizados em saúde pública para aumentar o nível de atividade física da população em geral. Futuros estudos devem ser realizados para confirmar estes achados e avaliar os riscos e benefícios da atividade física antes e durante a gestação. São particularmente necessários estudos randomizados de intervenção visando à redução do sedentarismo para dar subsídios a programas de promoção da atividade física em gestantes com vistas à melhoria da saúde materno fetal.

\section{Referências Bibliográficas}

Agarwal S, Agarwal A, Agarwal kn Agarwal DK Bansal A. Physical activity and pregnancy outcome in rural undernourished women. Indian Pediatrics 2001;38:1017-22.

AINSWORTH BE., HASKELL WL, WHITT MC. Compendium of physical activities: an update of activity codes and MET intensities. Med Sci Sports Exerc 2000; 32 (suppl.9): S498-516.

BARNES DL, ADAIR LS e POPKIN BM. Women's physical activity and pregnancy outcome: a longitudinal analisys from the Philippines. Int J Epidemiol 1991; 20(1): 162-72.

Barros FC, Victora CG, Barros aJ, Santos is, Albernaz E, Matijasevich A, Domingues MR, Sclowitz IK, Hallal PC, Silveira MF, Vaughan JP. The challenge of reducing neonatal mortality in middle-income countries: findings from three Brazilian birth cohorts in 1982, 1993, and 2004. Lancet 2005;365(9462):847-54.

BERKOWITZ GS e PAPIERNIK E. Epidemiology of preterm birth. Epidemiol Rev 1993; 15(2): 414-43.

BRANUM AM e SCHOENDORF KC. Changing patterns of low birthweight and preterm birth in the United States, 1981-98. Paediatr Perinat Epidemiol 2002; 16: 8-15.

Buekens P e Klebanoff $M$. Preterm birth research: from disillusion to the search for new mechanisms. Paediatr Perinat Epidemiol 2001, 15(suppl 2): 259-61. 
CAMPBELl MK, MOTtOLA MF. Recreational exercise and ocupational activity during pregnancy and birth weight: a case-control study. Am J Obstet Gynecol 2001; 184:403-8.

CAVALLI AS, TANAKA T. Relationship between maternal physical activities and preterm birth. Environmental Health and Preventive Medicine 2001; 6: 74-81.

ClAPP III JF e CAPELESS EL. Neonatal morphometrics after endurance exercise during pregnancy. Am J Obstet Gynecol 1990; 163: 1605-11.

CLAPP III JF e DicksteIN S. Endurance exercise and pregnancy outcome. Med Sci Sports Exerc 1984; 16 (16): 556-62.

Clayton D e HILLS M. Statistical models in epidemiology. Oxford: Oxford University Press. 1993

FORTIER I, MARCOUX S e BRISSON J. Maternal work during pregnancy and the risks of delivering a small-for-gestacional-age or preterm infant. Scand $\mathbf{J}$ Environ Health 1995; 21(6): 412-8.

GODFREY KM e BARKER DJP. Fetal nutrition and adult disease. Am J Clin Nutr 2000; 71(suppl.): 1344S-1352S.

Hatch, M. C.; Shu, X. O.; Mclean, D. E.; Levin, B.; Begg, M.; Reuss, L. e SUSSER, M. Maternal exercise during pregnancy, physical fitness, and fetal growth. Am J Epidemiol 1993; 137(10): 1105-14.

HenRIKSEN TB, HEDEgAARd M, Sechen NJ. Standing and walking at work and birthweight. Acta Obstet Gynecol Scand 1995; 74:509-16.

Klebanoff MA, Shiono PH, CAREy JC. The effect of physical activity during pregnancy on preterm delivery and birth weight. Am J Obstet Gynecol 1990; 163 (5 Pt1):1450-6.

Koemeester AP, Broersen JPJ e Treffers PE. Physical woark load and gestational age at delivery. Occup Environ Med 1995; 52:313-5.

Kramer mS, Goulet L, lydon J, SÉguin L, McNamara H, Dassa C, Platt RW, Chen MF, Gauthier H, Genest JR J, Kahn S, Libman M, Rozen R, masse A, Miner L, Asselin G, Benjamin A, Klein J, Koren G. Socio- 
economic disparities in preterm birth: causal pathways and mechanisms.

Paediatr Perinat Epidemiol 2001, 15(suppl 2): 104-23.

Kramer mS, Platt RW, Wen SW, Joseph KS, allen A, abrahamowicz M,

BLONDEL B, BRÉART G. A new and improved population-based canadian reference for birth weight for gestational age. Pediatrics 2001b, 108(2):1-7.

KRAMER MS. The Epidemiology of Adverse Pregnancy Outcomes: An Overview. J Nutr 2003; 133(suppl):1592-6.

LAUNer LJ, ViLLAR J, KestLer E, De Onis M. The effect of maternal work on fetal growth and duration of pregnancy: a prospective study. Br J Obstet Gynaecol 1990;97:62-70.

Magann E, Evans SF, Weitz B, Newnham JP. Antepartum, intrapartum and neonatal significance of exercise on healthy low-risk pregnant working women. Obstet Gynecol 2002; 99:466-72.

Magann EF, Evans SF, Newnham JP. Employment, exertion, and pregnancy outcome: assessment by kilocalories expended each day. Am J Obstet Gynecol 1996; 175:182-7.

MCCORMICK MC. The contribution of low birth weight to infant mortality and childhood morbidity. N Engl J Med 1985; 312: 82-90.

MisRa DP, StRobino DM, Stashinko EE, NAGEY DA e NANDA J. Effects of physical activity on preterm birth. Am J Epidemiol 1998; 147:628-35.

Monaghan SC, LitTLE PE, Hulchiy O, StRassner H, GLAden BC. Risk factors for spontaneous preterm birth in two urban areas of Ukraine. Paediatr Perinat Epidemiol 2001; 15: 123-30.

Monteiro CA, Benício MHD'A e OrTiz LP. Tendência secular do peso ao nascer na cidade de São Paulo (1976-1988). Rev Saude Pública 2000; 34(supl. 6): 26-40.

Rabkin CS, Anderson HR, Bland JM, Chamberlain G, Peacock JL. Maternal activity and birth weight: a prospective, population-based study. Am J Epidemiol 1990; 131(3):522-31. 
Rose NC, HADDOW JE, PALOMAKI GE, KNIGHT GJ. Self-rated physical activity level during the second trimester and pregnancy outcome. Obstet Gynecol 1991; 78:1078-80.

SaURel-Cubizolles MJ, Kaminski M. Is preterm delivery still related to physical working conditions in pregnancy? J Epidemiol Community Health 1991; 45: 29-34.

SANTOS IS. Consumo de cafeína e baixo peso ao nascer: um estudo de casos e controles de base populacional. [Tese de doutorado] Universidade Federal do Rio Grande do Sul: Porto Alegre (RS), 1995.

Schramm WF, Stockbauer JW, Hoffman HJ. Exercise, employment, other daily activities, and adverse pregnancy outcomes. Am J Epidemiol 1996;143(3):211-8.

SCHLESSELMAN JJ . Case-control studies: design, conduct, analysis. New York: Oxford University Press. 1982.

SILVA AAM, BARBIERI MA, GOMES UA e BETTIOL H. Trends in low birth weight a comparison of two birth cohorts separated by a 15 year interval in Ribeirão Preto, Brasil. Bull World Health Organ 1998; 76(1): 73-84.

Spinillo, A.; Capuzzo, E.; Baltaro, F.; Piazzi, G.; Nicola, S. e iasci, A. The effect of work activity in pregnancy on the risk of fetal growth retardation. Acta. Obstet. Gynecol. Scand 1996; 75:531-6.

Sternfeld B, QUesenberRy JR CP, EskenazI B e NeWman LA. Exercise during pregnancy and pregnancy outcome. Med Sci Sports Exerc 1995; 27(5): 634-40.

TAKITO MY, BenícIo MHDA, LATORRE MRD. Postura materna durante a gestação e sua influência sobre o peso ao nascer. Rev Saude Publica 2005; 39(3)325-32.

TAKITO MY. Atividade física durante a gestação e baixo peso ao nascer, prematuridade e restrição de crescimento intra-uterino: revisão sistemática. São Paulo; 2006a [Tese de Doutorado - Faculdade de Saúde Pública da USP]; p.1-32. 
TAKITO MY. Avaliação da reprodutibilidade e validade de questionário de atividade física para gestantes. São Paulo; 2006b [Tese de Doutorado - Faculdade de Saúde Pública da USP]; p.33-57.

Tuntiseranee $P$, Geater A, Chongsuvivatwong $V$ e Kor-anantakul $O$. Effect of heavy maternal workload on fetal growth retardation and preterm delivery. JOEM 1998; 40(11): 1013-21.

VICTORA CG, HUtTlY SR, FUCHS SC, OLINTO MT. The role of conceptual frameworks in epidemiological analysis: a hierarchical approach. Int $\mathbf{J}$ Epidemiol 1997;26(1):224-7.

Wergeland E. StRAND K, Bordahl PE. Strenuous working conditions and birthweight, Norway 1989. Acta Obstet Gynecol Scand 1998; 77:263271.

WHO/FAO. Diet, Nutrition and the Prevention of Chronic Diseases. Report of the Joint WHO/FAO Expert Consultation. WHO, editor. No. 916 (TRS 916), 1-149. Geneva, Switzerland: WHO, 2003. Technical Report Series 
Tabela 1. Distribuição de recém nascidos de baixo peso (casos) e controles segundo características socioeconômicas, biológicas, reprodutivas, indicadoras de morbidade materna, comportamentais e cuidados de pré-natal. São Paulo, 2005.

\begin{tabular}{|c|c|c|c|c|c|c|c|}
\hline \multirow[t]{2}{*}{ Variáveis } & \multicolumn{2}{|c|}{ CASOS } & \multicolumn{2}{|c|}{ CONTROLES } & \multirow[t]{2}{*}{ OR bruto } & \multirow[t]{2}{*}{$\mathrm{IC}(95 \%)$} & \multirow[t]{2}{*}{$p$} \\
\hline & $\mathrm{n}$ & $\%$ & $\mathrm{n}$ & $\%$ & & & \\
\hline \multicolumn{8}{|c|}{ Socioeconômicas } \\
\hline \multicolumn{8}{|c|}{ Renda per capita (salários mínimos) } \\
\hline$<0.5$ & 62 & 25,62 & 119 & 24,24 & 1,30 & $0,82-2,07$ & 0,612 \\
\hline $0.5-0.9$ & 82 & 33,88 & 153 & 31,16 & 1,30 & $0,84-2,01$ & $0,283^{*}$ \\
\hline $1.0-1.4$ & 47 & 19,42 & 98 & 19,96 & 1,30 & $0,79-2,13$ & \\
\hline$\geq 1.5$ & 51 & 21,07 & 121 & 24,64 & 1 & & \\
\hline \multicolumn{8}{|l|}{ Companheiro } \\
\hline Não & 67 & 24,54 & 108 & 19,78 & 1,34 & $0,95-1,88$ & 0,093 \\
\hline Sim & 206 & 75,46 & 438 & 80,22 & 1 & & \\
\hline \multicolumn{8}{|l|}{ Escolaridade } \\
\hline Até 7 anos & 98 & 35,9 & 158 & 29,21 & 1,40 & $1,03-1,91$ & 0,035 \\
\hline 8 ou mais & 175 & 64,1 & 383 & 70,79 & 1 & & \\
\hline \multirow{2}{*}{\multicolumn{8}{|c|}{$\begin{array}{l}\text { Caracterísicas biológicas e reprodutivas maternas } \\
\text { Idade (anos) }\end{array}$}} \\
\hline & & & & & & & \\
\hline$\geq 35$ & 47 & 17,22 & 51 & 9,36 & 2,08 & $1,35-3,21$ & 0,001 \\
\hline$<35$ & 226 & 82,78 & 494 & 90,64 & 1 & & \\
\hline \multicolumn{8}{|l|}{ Raça/Cor } \\
\hline Negra & 75 & 28,52 & 124 & 23,48 & 1,26 & $0,91-1,76$ & 0,170 \\
\hline Não negra & 188 & 71,48 & 404 & 76,52 & 1 & & \\
\hline \multicolumn{8}{|l|}{ Paridade } \\
\hline Primípara & 61 & 23,11 & 107 & 20,38 & 1,21 & $0,81-1,81$ & 0,355 \\
\hline Multipara & 203 & 76,89 & 418 & 79,62 & 1 & & \\
\hline \multicolumn{8}{|c|}{ Comportamentais maternas } \\
\hline \multicolumn{8}{|c|}{ Tabagismo (número de cigarros por dia) } \\
\hline$\geq 5$ & 50 & 18,32 & 51 & 9,34 & 2,09 & $1,38-3,16$ & 0,002 \\
\hline$<5$ & 23 & 8,42 & 45 & 8,24 & 1,12 & $0,64-1,95$ & $0,038^{*}$ \\
\hline Não & 200 & 73,26 & 450 & 82,42 & 1 & & \\
\hline \multicolumn{8}{|c|}{ Consumo de alcool } \\
\hline Sim & 32 & 11,72 & 59 & 10,81 & 1,10 & $0,68-1,77$ & 0,685 \\
\hline $\begin{array}{l}\text { Não } \\
\text { Trabalha }\end{array}$ & 241 & 88,28 & 487 & 89,19 & 1 & & \\
\hline Sim & 129 & 47,25 & 279 & 51,1 & 1,17 & $0,88-1,57$ & 0,285 \\
\hline Não & 144 & 52,75 & 267 & 48,9 & 1 & & \\
\hline \multicolumn{8}{|l|}{ Atividade sexual } \\
\hline Reduziu & 133 & 48,72 & 312 & 57,14 & 0,70 & $0,49-1,02$ & 0,053 \\
\hline Não realizava & 68 & 24,91 & 115 & 21,06 & 1,01 & $0,67-1,54$ & \\
\hline Não modificou & 72 & 26,37 & 119 & 21,79 & 1 & & \\
\hline
\end{tabular}




\begin{tabular}{|c|c|c|c|c|c|c|c|}
\hline \multirow[t]{2}{*}{ Variáveis } & \multicolumn{2}{|c|}{ CASOS } & \multicolumn{2}{|c|}{ CONTROLES } & \multirow[t]{2}{*}{ OR bruto } & \multirow[t]{2}{*}{ IC(95\%) } & \multirow[t]{2}{*}{$p$} \\
\hline & $\mathrm{n}$ & $\%$ & $\mathrm{n}$ & $\%$ & & & \\
\hline \multicolumn{8}{|c|}{$\begin{array}{l}\text { Indicadoras de morbidade materna } \\
\text { Internação hospitalar }\end{array}$} \\
\hline Sim & 68 & 24,91 & 66 & 12,11 & 2,30 & $1,59-3,34$ & $<0,001$ \\
\hline Não & 205 & 75,09 & 479 & 87,89 & 1 & & \\
\hline \multicolumn{8}{|c|}{ Repouso em casa } \\
\hline Sim & 98 & 35,9 & 212 & 38,97 & 1,13 & $0,84-1,52$ & 0,424 \\
\hline Não & 175 & 64,1 & 332 & 61,03 & 1 & & \\
\hline \multicolumn{8}{|c|}{ Recomendação médica: repouso ou redução da atividade física } \\
\hline Sim & 158 & 57,88 & 284 & 52,21 & 1,30 & $0,96-1,77$ & 0,09 \\
\hline Não & 115 & 42,12 & 260 & 47,79 & 1 & & \\
\hline \multicolumn{8}{|l|}{ Sangramento } \\
\hline Sim & 80 & 29,3 & 102 & 18,72 & 1,85 & $1,31-2,63$ & $<0,001$ \\
\hline Não & 193 & 70,7 & 443 & 81,28 & 1 & & \\
\hline \multicolumn{8}{|c|}{ Infecções não tratadas } \\
\hline Sim & 21 & 7,69 & 20 & 3,66 & 2,25 & $1,18-4,31$ & 0,014 \\
\hline Não & 252 & 92,31 & 526 & 96,34 & 1 & & \\
\hline \multicolumn{8}{|c|}{ Rotura prematura de membrana } \\
\hline Sim & 46 & 16,85 & 36 & 6,59 & 3,11 & $1,89-5,11$ & $<0,001$ \\
\hline Não & 227 & 83,15 & 510 & 93,41 & 1 & & \\
\hline \multicolumn{8}{|c|}{ Hipertensão arterial } \\
\hline Sim & 71 & 26,1 & 99 & 18,2 & 1,68 & $1,17-2,41$ & 0,005 \\
\hline Não & 201 & 73,9 & 445 & 81,8 & 1 & & \\
\hline \multicolumn{8}{|c|}{ Depressão ou tristeza } \\
\hline Sempre & 20 & 7,33 & 12 & 2,2 & 3,69 & $1,74-7,81$ & 0,006 \\
\hline Às vezes & 20 & 7,33 & 35 & 6,41 & 1,24 & $0,71-2,19$ & $0,007^{*}$ \\
\hline Raramente & 88 & 32,23 & 181 & 33,15 & 1,09 & $0,78-1,51$ & \\
\hline Nunca & 145 & 53,11 & 318 & 58,24 & 1 & & \\
\hline \multicolumn{8}{|c|}{ Tomou alguma medicação (durante a gestação) } \\
\hline & 178 & 65,2 & 296 & 54,31 & 1,63 & $1,20-2,21$ & 0,002 \\
\hline Não & 95 & 34,8 & 249 & 45,69 & 1 & & \\
\hline \multicolumn{8}{|c|}{$\begin{array}{l}\text { Cuidados de pré-natal } \\
\text { Número de consultas }\end{array}$} \\
\hline$<6$ & 108 & 39,56 & 124 & 22,71 & 2,26 & $1,63-3,12$ & $<0,001$ \\
\hline$>=6$ & 165 & 60,44 & 422 & 77,29 & 1 & & \\
\hline
\end{tabular}


Tabela 2. Variáveis de atividade física materna e baixo peso ao nascer, análise bruta. São Paulo, 2005.

\begin{tabular}{|c|c|c|c|c|c|c|c|}
\hline VARIAVEL & CASOS & $(n=273)$ & CONTROLE & $S(n=546)$ & OR bruto & IC(95\%) & $p$ \\
\hline \multirow{2}{*}{\multicolumn{4}{|c|}{ Atividades sedentárias ( $\mathrm{min} / \mathrm{dia}$ ) }} & $\%$ & & & \\
\hline$<140$ & 90 & 32,97 & 183 & 31,68 & & & \\
\hline $140-300$ & 95 & 34,8 & 190 & 34,8 & 1,00 & $0,71-1,41$ & $0,865^{*}$ \\
\hline$\geq 300$ & 88 & 32,23 & 173 & 33,52 & 1,03 & $0,72-1,49$ & \\
\hline \multicolumn{8}{|c|}{ Atividades leves (min/dia) } \\
\hline$<210$ & 99 & 41,42 & 140 & 25,64 & 1 & & 0,0045 \\
\hline $210-420$ & 93 & 34,07 & 199 & 36,45 & 0,67 & $0,47-0,95$ & $0,001^{\star}$ \\
\hline$\geq 420$ & 81 & 29,67 & 207 & 37,91 & 0,55 & $0,38-0,79$ & \\
\hline \multicolumn{8}{|c|}{ Atividades moderadas ( $\mathrm{min} / \mathrm{dia}$ ) } \\
\hline$<60$ & 96 & 35,16 & 192 & 35,16 & 1 & & 0,501 \\
\hline $60-150$ & 71 & 26,01 & 163 & 29,85 & 0,88 & $0,60-1,29$ & $0,568^{*}$ \\
\hline$\geq 150$ & 106 & 38,83 & 191 & 34,98 & 1,1 & $0,77-1,56$ & \\
\hline \multicolumn{8}{|c|}{ Assistir televisão (horas/dia) } \\
\hline Até 1,5 & 35 & 29,91 & 66 & 28,21 & 0,93 & $0,54-1,61$ & 0,802 \\
\hline De 1,5 a 4,0 & 40 & 34,19 & 83 & 35,47 & 1 & & \\
\hline Mais de 4,0 & 42 & 35,9 & 85 & 36,32 & 0,9 & $0,51-1,61$ & 0,731 \\
\hline \multicolumn{8}{|c|}{ Caminhada (agrupada) $(\mathrm{min} / \mathrm{dia})$} \\
\hline Não caminha & 37 & 13,55 & 49 & 8,97 & 1 & & \\
\hline$<20$ & 69 & 25,27 & 148 & 27,11 & 0,64 & $0,38-1,06$ & 0,280 \\
\hline $20-50$ & 66 & 24,18 & 137 & 25,09 & 0,64 & $0,38-1,08$ & $0,196^{*}$ \\
\hline$\geq 50$ & 101 & 37 & 212 & 38,83 & 0,63 & $0,39-1,03$ & \\
\hline \multicolumn{8}{|c|}{ Caminhada no lazer_intencional (min/dia) } \\
\hline Não & 146 & 53,48 & 252 & 46,15 & 1 & & 0,1385 \\
\hline$<20 \mathrm{~min} / \mathrm{dia}$ & 69 & 25,27 & 156 & 28,57 & 0,76 & $0,53-1,08$ & $0,086^{*}$ \\
\hline $220 \mathrm{~min} / \mathrm{dia}$ & 58 & 21,25 & 138 & 25,27 & 0,73 & $0,51-1,05$ & \\
\hline \multicolumn{8}{|c|}{ Reduziu a atividade física no decorrer da gestação } \\
\hline Sim & 145 & 53,11 & 252 & 46,24 & 0,76 & $0,57-1,02$ & 0,0669 \\
\hline Não & 128 & 46,89 & 293 & 53,76 & 1 & & \\
\hline \multicolumn{8}{|c|}{ Atividades Domésticas (horas/dia) } \\
\hline$<2$ horas & 77 & 28,21 & 112 & 20,51 & 1 & & 0,1083 \\
\hline $2-3,9$ & 88 & 32,23 & 185 & 33,88 & 0,7 & $0,48-1,03$ & $0,033^{* *}$ \\
\hline $4-5,9$ & 56 & 20,51 & 127 & 23,26 & 0,65 & $0,42-0,99$ & \\
\hline$\geq 6$ & 52 & 19,05 & 122 & 22,34 & 0,63 & $0,41-0,97$ & \\
\hline \multicolumn{8}{|c|}{ Múltiplos da Taxa Metabolica Basal } \\
\hline Sedentária & 187 & 68,5 & 352 & 64,47 & 1,24 & $0,82-1,88$ & 0,412 \\
\hline Pouco ativa e ativa & 38 & 13,92 & 85 & 15,57 & 1 & $0,61-1,70$ & \\
\hline Muito ativa & 48 & 17,58 & 109 & 19,96 & 1,01 & & \\
\hline \multicolumn{8}{|c|}{$\begin{array}{l}\text { Percepção subjetiva da atividade física na gestação } \\
\text { Muito mais ativa }\end{array}$} \\
\hline Ativas & 43 & 16,23 & 67 & 12,45 & 1,69 & $1,03-2,76$ & 0,048 \\
\hline Menos Ativas & 62 & 23,4 & 168 & 31,22 & 1 & & \\
\hline $\begin{array}{l}\text { Percepção subjetiva c } \\
\text { Muito mais ativa }\end{array}$ & 160 & 60,38 & 303 & 56,31 & 1,44 & $1,03-2,02$ & \\
\hline Ativas & 45 & 16,48 & 96 & 17,58 & 0,87 & $0,62-1,24$ & 0,6865 \\
\hline Menos ativas & 80 & 29,3 & 145 & 26,56 & 1 & & \\
\hline
\end{tabular}


Tabela 3. Variáveis de atividade física materna e baixo peso ao nascer, análise ajustada. São Paulo, 2005.

\begin{tabular}{|c|c|c|c|c|c|c|}
\hline VARIÁVEL & OR bruto & $\mathrm{IC}(95 \%)$ & $p$ & OR ajustado & $\mathrm{IC}(95 \%)$ & $p$ \\
\hline \multicolumn{7}{|c|}{$\begin{array}{l}\text { Modelo I } \\
\text { Atividades leves (min/dia) }\end{array}$} \\
\hline$<210$ & 1 & & 0,0045 & 1 & & 0,119 \\
\hline $210-420$ & 0,67 & $0,47-0,95$ & $0,001^{*}$ & 0,73 & $0,49-1,11$ & $0,046^{*}$ \\
\hline$\geq 420$ & 0,55 & $0,38-0,79$ & & 0,64 & $0,42-0,99$ & \\
\hline \multicolumn{7}{|c|}{ Caminhada no lazer_intencional (min/dia) } \\
\hline Não & 1 & & 0,1385 & 1 & & 0,099 \\
\hline$<20 \mathrm{~min} / \mathrm{dia}$ & 0,76 & $0,53-1,08$ & $0,086^{\star}$ & 0,75 & $0,55-1,06$ & \\
\hline$\geq 20 \mathrm{~min} / \mathrm{dia}$ & 0,73 & $0,51-1,05$ & & & & \\
\hline \multicolumn{7}{|c|}{ Reduziu a atividade física no decorrer da gestação } \\
\hline Sim & 0,76 & $0,57-1,02$ & 0,0669 & 0,78 & $0,56-1,09$ & 0,154 \\
\hline Não & 1 & & & 1 & & \\
\hline \multirow{2}{*}{\multicolumn{7}{|c|}{$\begin{array}{l}\text { Modelo II } \\
\text { Atividades Domésticas (horas/dia) }\end{array}$}} \\
\hline & & & & & & \\
\hline$<2$ horas & 1 & & 0,1083 & 1 & & 0,041 \\
\hline $2-3,9$ & 0,7 & $0,48-1,03$ & $0,033^{* *}$ & 0,66 & $0,42-1,05$ & $0,007^{*}$ \\
\hline $4-5,9$ & 0,65 & $0,42-0,99$ & & 0,58 & $0,35-0,96$ & \\
\hline$\geq 6$ & 0,63 & $0,41-0,97$ & & 0,5 & $0,29-0,84$ & \\
\hline \multicolumn{7}{|c|}{ Percepção subjetiva da atividade física na gestação } \\
\hline Muito mais ativa & 1,79 & $1,03-2,76$ & 0,048 & 1,76 & $0,97-3,19$ & 0,131 \\
\hline Ativas & 1 & & & 1 & & \\
\hline Menos Ativas & 1,44 & $1,03-2,02$ & & 1,37 & $0,92-2,03$ & \\
\hline
\end{tabular}

ajustados pelas variáveis dos blocos anteriores: presença de companheiro, escolaridade (socioeconômico), idade, cor da pele (biológica materna); e do mesmo nível: tabagismo (comportamental), hipertensao arterial, sangramento, infecção não tratada, rotura prematura de membranas, internação hospitalar, uso de medicamentos (variáveis indicadoras de morbidade), consultas de pré-natal (assistência pré-natal) e pelas variáveis do próprio bloco que participam do modelo final (que constam na tabela)

$p$ Teste de razão de maximoverossimilhança

* $p$ para tendência linear 
Tabela 4. Variáveis de atividade física materna e prematuridade, análise bruta. São Paulo, 2005.

\begin{tabular}{|c|c|c|c|c|c|c|c|}
\hline \multirow{2}{*}{ VARIÁVEL } & \multicolumn{2}{|c|}{ CASOS $(n=117)$} & \multicolumn{2}{|c|}{ CONTROLES $(n=234)$} & \multirow[t]{2}{*}{ OR bruto } & \multirow[t]{2}{*}{$\mathrm{IC}(95 \%)$} & \multirow[t]{2}{*}{$p$} \\
\hline & $\mathbf{n}$ & $\%$ & $\mathrm{n}$ & $\%$ & & & \\
\hline \multicolumn{8}{|c|}{ Atividades sedentárias (min/dia) } \\
\hline$<140$ & 38 & 32,48 & 78 & 33,33 & 0,91 & $0,52-1,57$ & 0,654 \\
\hline $140-300$ & 42 & 35,90 & 73 & 31,20 & 1,16 & $0,69-1,95$ & $0,747^{\star}$ \\
\hline$>300$ & 37 & 31,62 & 83 & 35,47 & 1 & & \\
\hline \multicolumn{8}{|l|}{ Atividades leves (min/dia) } \\
\hline$<210$ & 42 & 35,90 & 58 & 24,79 & 1 & & 0,049 \\
\hline $210-420$ & 41 & 35,04 & 82 & 35,04 & 0,71 & $0,42-1,19$ & $0,014^{\star}$ \\
\hline$\geq 420$ & 34 & 29,06 & 94 & 40,17 & 0,5 & $0,28-0,87$ & \\
\hline \multicolumn{8}{|c|}{ Atividades moderadas ( $\mathrm{min} / \mathrm{dia}$ ) } \\
\hline$<60$ & 41 & 35,04 & 90 & 38,46 & 1 & & 0,46 \\
\hline $60-150$ & 26 & 22,22 & 60 & 25,64 & 0,96 & $0,52-1,77$ & $0,287^{\star}$ \\
\hline$\geq 150$ & 50 & 42,74 & 84 & 35,90 & 1,31 & $0,78-2,21$ & \\
\hline \multicolumn{8}{|c|}{ Assistir televisão (horas/dia) } \\
\hline Até 1,5 & 35 & 29,91 & 66 & 28,21 & 0,93 & $0,54-1,61$ & 0,94 \\
\hline De 1,5 a 4,0 & 40 & 34,19 & 83 & 35,47 & 1 & & \\
\hline Mais de 4,0 & 42 & 35,90 & 85 & 36,32 & 0,9 & $0,51-1,61$ & \\
\hline \multicolumn{8}{|c|}{ Caminhada (agrupada) (min/dia) } \\
\hline Não caminha & 14 & 11,97 & 20 & 8,55 & 1,37 & $0,61-3,07$ & 0,763 \\
\hline$<20$ & 28 & 23,93 & 62 & 26,50 & 0,88 & $0,46-1,68$ & \\
\hline $20-50$ & 32 & 27,35 & 63 & 26,92 & 1 & & \\
\hline$\geq 50$ & 43 & 36,75 & 89 & 38,03 & 0,95 & $0,54-1,67$ & \\
\hline \multicolumn{8}{|c|}{ Caminhada (intencional) (min/dia) } \\
\hline Não & 70 & 59,83 & 111 & 47,44 & 1 & & 0,068 \\
\hline$<20 \mathrm{~min} / \mathrm{dia}$ & 28 & 23,93 & 64 & 27,35 & 0,71 & $0,42-1,21$ & $0,023^{*}$ \\
\hline$\geq 20 \mathrm{~min} / \mathrm{dia}$ & 19 & 16,24 & 59 & 25,21 & 0,52 & $0,29-0,95$ & \\
\hline \multicolumn{8}{|c|}{ Reduziu a atividade fisica no decorrer da gestação } \\
\hline Sim & 69 & 58,97 & 118 & 50,43 & 0,71 & $0,45-1,11$ & 0,132 \\
\hline Não & 48 & 41,03 & 116 & 49,57 & 1 & & \\
\hline \multicolumn{8}{|c|}{ Atividades Domésticas (horas/dia) } \\
\hline$<2$ horas & 37 & 31,62 & 44 & 18,80 & 1 & & 0,075 \\
\hline $2-3,9$ & 34 & 29,06 & 83 & 35,47 & 0,5 & $0,27-0,90$ & $0,053^{\star}$ \\
\hline $4-5,9$ & 24 & 20,51 & 53 & 22,65 & 0,54 & $0,28-1,04$ & \\
\hline$\geq 6$ & 22 & 18,80 & 54 & 23,08 & 0,51 & $0,27-0,97$ & \\
\hline \multicolumn{8}{|c|}{ Multiplos da Taxa Metabolica Basal } \\
\hline Sedentária & 80 & 68,38 & 155 & 66,24 & 1,06 & $00,58-1,94$ & 0,906 \\
\hline Pouco ativa e ativa & 19 & 16,24 & 42 & 17,95 & 1 & $0,43-2,01$ & \\
\hline Muito ativa & 18 & 15,38 & 37 & 15,81 & 0,92 & $0,48-2,06$ & \\
\hline \multicolumn{8}{|c|}{ Percepção subjetiva da atividade física na gestação } \\
\hline Muito mais ativa & 16 & 13,68 & 25 & 10,68 & 1,46 & $0,69-3,10$ & 0,615 \\
\hline Ativas & 32 & 27,35 & 73 & 31,20 & 1 & & \\
\hline Menos ativas & 69 & 55,97 & 136 & 58,12 & 1,15 & $0,71-1,86$ & \\
\hline \multicolumn{8}{|c|}{ Percepção subjetiva da atividade física prévia a gestação } \\
\hline Muito mais ativa & 22 & 18,80 & 47 & 20,09 & 0,95 & $0,49-1,84$ & 0,943 \\
\hline Ativas & 34 & 29,06 & 69 & 29,49 & 1 & & \\
\hline Menos ativas & 61 & 52,14 & 118 & 50,43 & 1,05 & $0,62-1,77$ & \\
\hline
\end{tabular}

p Teste de razão de maximoverossimilhança

* p para tendência linear 
Tabela 5. Variáveis de atividade física materna e prematuridade, análise ajustada. São Paulo, 2005.

\begin{tabular}{|c|c|c|c|c|c|c|}
\hline VARIÁVEL & OR bruto & $\mathrm{IC}(95 \%)$ & $p$ & OR ajustado & $\mathrm{IC}(95 \%)$ & $p$ \\
\hline \multicolumn{7}{|c|}{$\begin{array}{l}\text { Modelo I } \\
\text { Caminhada (intencional) (min/dia) }\end{array}$} \\
\hline Não & 1 & & 0,068 & 1 & & 0,0073 \\
\hline$<20 \mathrm{~min} / \mathrm{dia}$ & 0,71 & $0,42-1,21$ & $0,023^{*}$ & 0,44 & $0,21-0,90$ & $0,003^{*}$ \\
\hline$\geq 20 \mathrm{~min} / \mathrm{dia}$ & 0,52 & $0,29-0,95$ & & 0,36 & $0,16-0,78$ & \\
\hline \multicolumn{7}{|c|}{ Atividades leves (min/dia) } \\
\hline$<210$ & 1 & & 0,049 & 1 & & 0,422 \\
\hline $210-420$ & 0,71 & $0,42-1,19$ & $0,014^{*}$ & 0,78 & $0,40-1,54$ & $0,192^{*}$ \\
\hline$\geq 420$ & 0,5 & $0,28-0,87$ & & 0,61 & $0,29-1,29$ & \\
\hline \multicolumn{7}{|c|}{$\begin{array}{l}\text { Modelo II } \\
\text { Atividades Domésticas (horas/dia) }\end{array}$} \\
\hline$<2$ horas & 1 & & 0,0754 & 1 & & 0,114 \\
\hline $2-3,9$ & 0,5 & $0,27-0,90$ & $0,053^{*}$ & 0,5 & $0,23-1,09$ & $0,035^{\star}$ \\
\hline $4-5,9$ & 0,54 & $0,28-1,04$ & & 0,56 & $0,25-1,27$ & \\
\hline$\geq 6$ & 0,51 & $0,27-0,97$ & & 0,38 & $0,17-0,89$ & \\
\hline
\end{tabular}

ajustado por escolaridade materna, presença de companheiro (bloco de variáveis socioeconômicas), idade materna (bloco de variaveis biologicas maternas), hipertensão arterial, sangramento, rotura prematura de membranas e internação hospitalar (indicadores de morbidade) e consultas de prénatal.

p Teste de razão de maximoverossimilhança

* $\mathrm{p}$ para tendência linear 


\section{RELATÓRIO TÉCNICO}

Relatório do trabalho de campo. 


\section{Introdução}

Inicialmente será enfocado o trabalho de campo realizado com vistas à validação do questionário de atividades físicas durante a gestação, visando a aplicação no puerpério imediato, bem como durante toda a gestação. Posteriormente, seguir-se-á descrição dos procedimentos para seleção e treinamento da equipe, estudo piloto, e logística do estudo de casos e controles propriamente dito.

\section{Confecção do instrumento}

O questionário de atividades físicas foi elaborado e validado, descrito anteriormente. Para caracterização da amostra foram incluídas questōes sócio-econômicas, reprodutivas, biológicas maternas, entre outras. As entrevistas foram realizadas por duas entrevistadoras treinadas.

Para tanto, inicialmente, o estudo obteve autorização do Comitê de ética do "Hospital e Maternidade Leonor Mendes de Souza". Dada a necessidade do preenchimento de diário de atividades excluiu-se as gestantes não alfabetizadas. A maternidade é um centro de referência a gestaçōes de alto risco e, por este motivo dois meses de coleta foram infrutiferos, com diversas recusas das poucas gestantes que cumpriam os critérios para inclusão no estudo (estar no $2^{\circ}$ trimestre de gestação, idade superior a 18 anos e sem morbidade potencialmente associada à alteração da atividade física habitual). Por conta disso, buscou-se unidades básicas de saúde que atendessem a gestantes de baixo risco (anexo parecer).

Constatou-se que diversas mulheres referiam dificuldade de retornar ao serviço de saúde para devolução dos aparelhos. Visando minimizar as perdas, optou-se por visitas domiciliares para realização dos questionários. Mesmo com a exclusão de mulheres não alfabetizadas, diversas mulheres apresentaram grandes dificuldades na utilização dos equipamentos e correto preenchimento do diário de atividades físicas, foram então realizadas também visitas domiciliares de monitoração do uso dos aparelhos, minimizando assim, falhas na coleta de dados. 
Foram adquiridos 3 equipamentos e contava-se com um equipamento da pesquisadora, entretanto tal equipamento apresentou defeitos na vedação do relógio, e entrada de água, não sendo possível conserto. Outro fator complicador foi o furto de um equipamento e a interrupção do tratamento pré-natal da gestante. Ainda que a aquisição de novo equipamento tenha sido efetivada rapidamente, no período de 2 meses, tal fato diminuiu a possibilidade de captação.

O diagrama abaixo apresenta o plano de ações realizado para a coleta de dados de validação do questionário: 
Informação dos procedimentos e concordância em participar (TCLE).

$1^{\text {a }}$ Entrevista

- Questionário de Atividades Físicas (QAF1)

- Explicação do uso do freqüencímetro e pedômetro

- Explicação e início do preenchimento do Diário de Atividades Físicas (DAF)

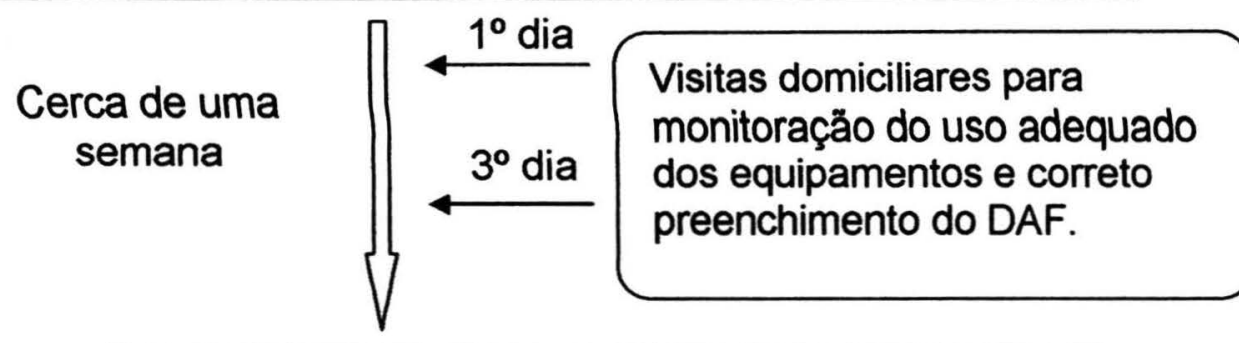

$2^{\mathrm{a}}$ Entrevista

- Reteste QAF2

- Devolução dos equipamentos e do DAF

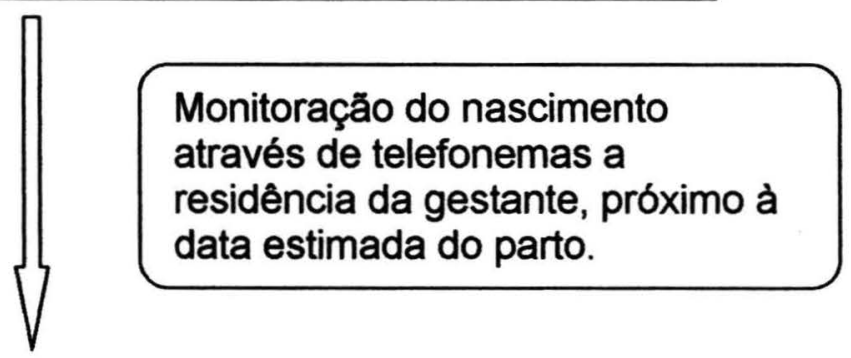

$3^{\mathrm{a}}$ Entrevista - Puerpério

- QAF3

- $M A Q$ adaptado

Após a entrevista a gestante foi instruída quanto ao preenchimento do diário de atividades físicas e a utilizaçăo dos aparelhos frequencímetro Polar $\circledast$, e Pedômetro Techline $\AA$

O pedômetro, posicionado na lateral do quadril, mede o comportamento de caminhada do indivíduo através de sensor de movimento horizontal. Os dados de quantidade de passos foram anotados pelas gestantes no diário de atividades. Entretanto, este equipamento demonstrou 
ineficiência na mensuração da caminhada, visto que diversos problemas foram relatados pelas próprias gestantes. O movimento de deslocamento do meio de condução (ônibus, trem, carro entre outros) ocasiona contagem de passos, com a mulher sentada, principalmente no banco do ônibus. Estudo anterior, AINSLIE ET AL. (2003) verificaram erros de mensuração em indivíduos obesos, nas gestantes o aumento do volume abdominal pode ocasionar tal efeito, dificultando o posicionamento e a adequada colocação do equipamento. $O$ preenchimento deste dado no diário de atividades físicas foi verificado em apenas 21 mulheres. Tendo resultados de correlação muito baixos com o diário de atividades físicas e questionário, $r=0,19$ e 0,35, respectivamente. Dados não apresentados nos resultados.

A previsão no planejamento do estudo de realizar a validação com 3040 mulheres no período de 2 a 3 meses, contando com 4 equipamentos e não prevendo tantas recusas e exclusões, não se concretizou. Foram necessários 13 meses para alcançar 34 gestantes com dados completos de questionário (teste e reteste), diário de atividades físicas e freqüência cardíaca armazenada durante o tempo solicitado (4 dias).

No puerpério testou-se também o "MAQ modificado", questionário inicialmente proposto para uma análise conjunta, que foi descartado nos primeiros testes dos questionários devido ao grande volume de questões do QAF e da quantidade de informações/instruções dadas à gestante por ocasião da entrega dos equipamentos e DAF. Verificou-se também que as mulheres apresentaram muita dificuldade para relatar as principais atividades realizadas e ao serem questionadas dos 4 períodos solicitados ( 3 meses antes da gestação, $1^{\circ}, 2^{\circ}$ e $3^{\circ}$ trimestres) e na maioria das vezes informaram que as atividades eram semelhantes e não havia modificado.

O término do estudo de validação do QAF possibilitou a montagem do questionário do estudo de casos e controles, que incluía questões de identificação da puérpera, dados sócio-econômicos, reprodutivos, morbidades e comportamentais.

Seguindo assim para a elaboração dos instrumentos para transcrição de dados dos prontuários da puérpera e do recém nascido e cartão de pré- 
natal. Cada hospital disponibilizou os referidos prontuários em branco, no período de realização pré-teste do questionário foram selecionadas as informaçōes parciais a serem transcritas dos prontuários hospitalares e cartão de pré-natal.

Concomitantemente foi re-elaborado Manual de instruções visando a adequação ao estudo, incluindo seleção de casos e controles, procedimentos na detecção das puérperas e efetivação das entrevistas.

\section{Seleção e treinamento da equipe.}

A equipe foi constituída pela pesquisadora principal, a qual teve a seu cargo a coordenação e supervisão do projeto e das entrevistadoras, por 7 entrevistadoras, as quais realizavam também a primeira digitação dos dados, e por 4 digitadores para realizar a $2^{\mathrm{a}}$ digitação dos dados.

O treinamento capacitou as entrevistadoras nas técnicas de entrevista, aplicação do questionário e busca de informações nos prontuários. $O$ treinamento envolveu apresentação do projeto global (sem detalhar a hipótese principal) e dos instrumentos. Realizou-se a leitura do questionário, questão por questão, e estudo do manual de instruções. A seguir ensaio de técnicas de entrevistas com simulaçöes de situações reais. Foi enfatizada no treinamento a adequada abordagem das puérperas no início e decorrer da entrevista a fim de não extenuar a puérpera.

As rotinas de detecção dos casos e sorteio de controles junto ao livro de parto dos centros obstétricos a localização das puérperas e recém nascidos, nos diferentes hospitais, bem como a extração de informações junto aos prontuários e cartão de pré-natal foram realizadas no período de realização das entrevistas supervisionadas.

Após o treinamento, a compreensão do manual de orientação, o desempenho nas entrevistas supervisionadas (aproximação no início da entrevista, correta argüição, e percepção do ambiente e da mulher) e a qualidade do preenchimento do questionário (saber interpretar as respostas da puérpera marcando corretamente as respostas) foram considerados na seleção das entrevistadoras. 


\section{Estudo piloto}

No período de 14 de fevereiro a 12 de março 2005, foi realizado o estudo piloto. Foram entrevistadas 51 puérperas (17 casos e 34 controles). Todas as entrevistas foram supervisionadas pela coordenadora.

A adequação do questionário, fichas de transcrição dos prontuários I cartão de pré-natal e a qualidade de treinamento das entrevistadoras foram avaliadas, resultando em algumas modificações no questionário, em questões da história reprodutiva que nem sempre estavam preenchidas nos prontuários, e na simplificação das fichas de transcrição. Devido a estas alteraçōes, o estudo piloto, que inicialmente, estava previsto para durar duas semanas se estendeu por um mês. A logística de detecção de casos e controles então se mostrou adequada após as correções.

\section{Logística do estudo de caso-controle}

A coleta de dados se realizou no período vespertino, de terça a sábado, devido ao menor volume de cuidados por parte do serviço médicohospitalar neste período, e ao fato de haverem sido realizadas as visitas de rotina tanto às puérperas quanto aos recém nascidos. Entretanto, em dois hospitais, a coleta de dados ocorria no período matutino nas segundas feiras, visando minimizar a perda por alta hospitalar das puéperas que dessem a luz no sábado à tarde ou domingo pela manhã, dia em que não eram realizadas entrevistas. Em um dos hospitais, Amparo Maternal, não foi autorizada realização das entrevistas no período matutino, devido a realização dos procedimentos e visitas hospitalares, ocorrendo perda dos nascimentos ocorridos no final da tarde de sexta feira e no sábado.

\section{Identificação dos casos}

Todos os nascimentos ocorridos no dia anterior foram verificados junto ao Livro de Partos, sendo transcritas as principais informaçōes para localizar as puérperas nas enfermarias. Após a transcrição foram assinalados os nascimentos de recém nascido vivos, com peso inferior a 2500 gramas, de mulheres com 18 anos ou mais. 
Informações de análise de hemocultura dos recém nascidos, que indicariam infecção materna não tratada, foram coletadas 15 dias após o nascimento.

\section{Identificação dos controles}

No Hospital e Maternidade Leonor Mendes de Barros, no qual o padrão de internação previa no mínimo 48 horas de permanência da parturiente no hospital, foi possível o sorteio de controles dentro do mesmo dia de nascimento do caso. Nos outros dois hospitais, Amparo Maternal e Santa Marcelina, onde em partos normais, sem intercorrências, ocorria a alta em 24 horas após o parto alterou-se a seleção de controles para o sorteio dos nascimentos ocorridos no período de 12 horas anteriores e posteriores ao nascimento do caso.

Nascimentos ocorridos em cada maternidade durante o período de coleta de dados. São Paulo, 2005.

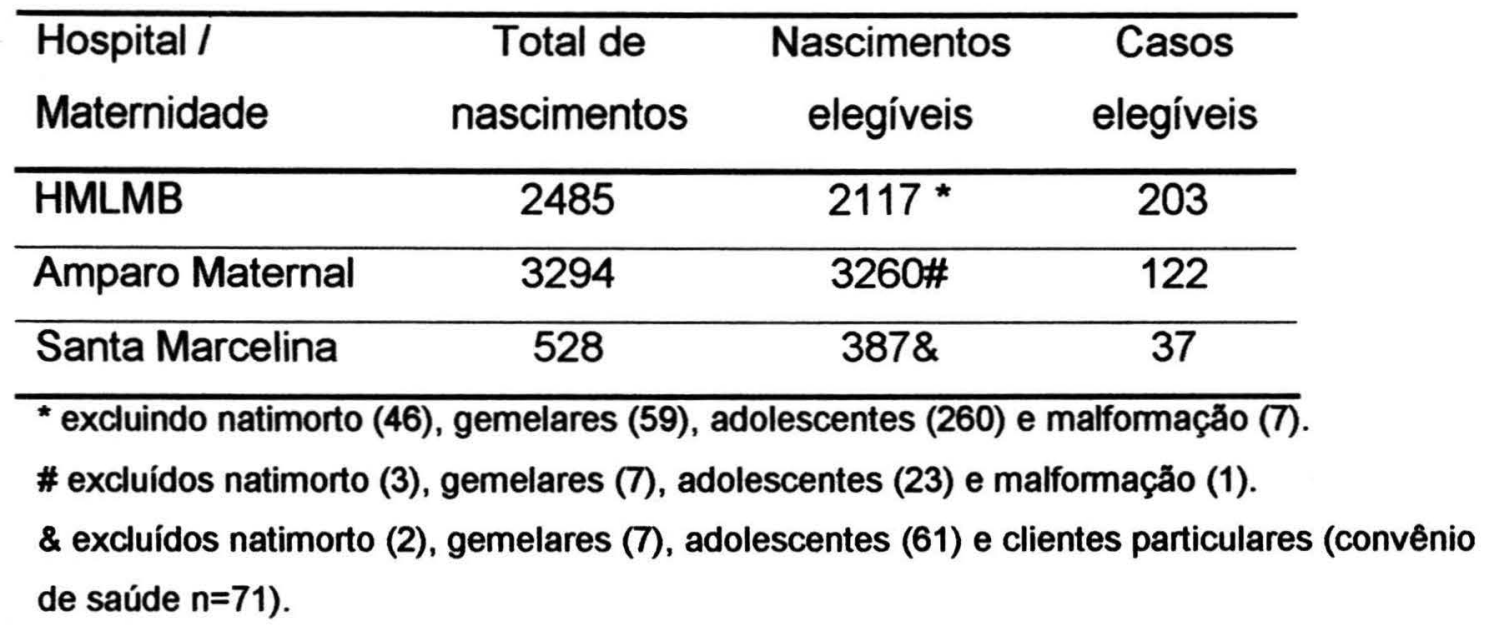

\section{Fluxo de entrevistadoras}

$\mathrm{O}$ treinamento foi realizado em três momentos, antes do estudo piloto, com 5 candidatas, sendo iniciado o estudo piloto e coleta de dados no Hospital Leonor Mendes de Barros, com três entrevistadoras. Após adequadamente encaminhada a coleta de dados neste hospital, foi realizado novo treinamento, duas entrevistadoras iniciaram as coletas na Maternidade Amparo Maternal. Devido ao volume de casos inferior ao esperado foi 
incluído um terceiro hospital de grande porte Hospital e Maternidade Santa Marcelina, com a inclusão de 2 entrevistadoras.

No primeiro mês de coleta em cada hospital, as entrevistadoras informavam, diariamente, à supervisora a freqüência de nascimentos com baixo peso, o número de entrevistas realizadas, as causas de não inclusão (para os casos) e os problemas surgidos durante o trabalho de campo.

Reunião com todas as entrevistadoras implicava em redução de um dia de coleta de dados, assim foram realizadas apenas 3 após o início da coleta de dados. Para abordar dúvidas a respeito do questionário, da logística do estudo e dificuldades encontradas foram realizadas reuniões semanais, com parte das entrevistadoras e as informações eram repassadas para as que estavam em campo. Nestes momentos era reforçado o uso do manual de orientação, era verificado o seguimento rigoroso da metodologia da pesquisa e entregues os questionários realizados no período. Sempre que necessário, havia o contato por telefone ou em reuniōes extras para eventuais dificuldades encontradas. Os questionários eram revisados quinzenalmente e codificados, dúvidas de preenchimento e inconsistência eram discutidas com cada entrevistadora.

\section{Coleta de dados}

A coleta de dados iniciou-se em 14 de março de 2005 no Hospital e Maternidade Leonor Mendes de Barros (HMLMB), 2 de maio de 2005 no Amparo Maternal (AM) e 25 de Julho de 2005 no Hospital e Maternidade Santa Marcelina (HMSM). 0 encerramento ocorreu em 29 de agosto de 2005 no HMLMB, e 30 de setembro no AM. Previa-se encerramento no mesmo período no HMSM, porém devido às dificuldades encontradas, tais como o reduzido número de casos (a seleção deste hospital baseou-se nos dados do SINASC do ano anterior, e não foram compatíveis com os nascimentos efetivamente ocorridos), fraude de entrevistas detectada no controle de qualidade e não permanência de outra entrevistadora encerrouse a coleta no dia 6 de setembro de 2005 . 
A maioria das entrevistas foi realizada no período de 24 horas após o parto, entretanto dois casos foram entrevistados em período superior (48 horas), devido a mudança de enfermaria para o setor "mãe-canguru", não detectada pela entrevistadora. Os controles destas por sua vez foram sorteados dentre os nascimentos ocorridos no dia da realização da entrevista dos casos, visto que as mulheres saudáveis já teriam tido alta hospitalar.

Um possivel viés de seleção foi a não realização de entrevista, quando ocorreu morte neonatal no período inferior a 24 horas, momento em que a mulher estava em um período difícil de pós-parto, muito triste por ter perdido o bebê. Este desenlace ocorreu em 9 nascimentos de casos.

O estudo teve 40 recusas registradas (19 casos e 21 controles), 2 entrevistadas estrangeiras que não compreendiam a língua portuguesa $e$ não tinham acompanhante, 6 mulheres que não souberam responder ao questionário (2 com distúrbio psiquiátrico relatado no prontuário), 12 casos por alta hospitalar e 15 casos por coleta de controle inadequado (período de tempo superior a 72 horas do nascimento do caso).

\section{Controle de qualidade}

Ainda que tenha sido buscada qualidade dos dados pela criteriosa seleção de entrevistadoras, preparação, e pré-testagem do questionário e manual de orientação, treinamento intensivo e acompanhamento da coordenadora do trabalho de campo, detectou-se problemas no momento de realização do controle de qualidade. Inicialmente, uma amostra aleatória de $5 \%$ das entrevistas foi selecionada e as mães foram contatadas e reentrevistadas pela supervisora do projeto. Foram repetidas algumas perguntas relacionadas a atividade física, visando verificar a repetibilidade de variáveis que não mudassem com o tempo. Este procedimento foi realizado para as mães com telefone. Esta estratégia permitiu detectar a não realização de uma entrevista, na $3^{\text {a }}$ semana de uma entrevistadora. Tentouse então entrar em contato com todas as entrevistadas naquela semana e detectou-se mais mulheres que afirmavam não ter participado da pesquisa, 
não recordavam da entrevistadora, nem de responder a um questionário longo sobre atividades diárias. Devido a impossibilidade de identificar quais entrevistas foram fraudadas os 14 casos e respectivos controles desta entrevistadora foram descartados do presente estudo. Para as demais 49 entrevistas, repetidas para controle de qualidade, obteve-se coeficientes kappa entre 0,08 a 0,38 e percentual de concordância variando de 44,9 a $89,8 \%$.

\section{Codificação e digitação dos dados}

As variáveis de atividade física foram digitadas em vezes por semana e minutos despendidos por dia, conforme o quadro de freqüência de atividade física. Entretanto, quando a atividade ocupacional de mulher estava relacionada ao trabalho doméstico, durante o questionamento tornava-se mais fácil anotar os dados separadamente. Desta maneira, foram computados em vezes por semana o maior valor, e o tempo total em minuto era redistribuído nesta freqüência.

A digitação dos questionários teve início no segundo mês de trabalho de campo. Estes foram digitados pelas próprias entrevistadoras e uma segunda digitação foi realizada por 4 estudantes de nível universitário. $O$ programa Epi-info versão 6.02 permitiu a comparação dos bancos de dados e a correção dos erros de digitação. Todos os questionários com diferenças nas digitações foram revisados, tendo sido corrigidos todos os erros identificados.

\section{Referências Bibliográficas}

Ainslie PN, ReILly T, Westerterp KR. Estimating Human Energy expenditure: A review of techniques with particular reference to doubly labelled water. Sports Med 2003;33(9):683-98.

AINSWORTH BE., HASKELL WL, WHITT MC. Compendium of physical activities: na update of activity codes and MET intensities. Med Sci Sports Exerc 2000; 32 (suppl.9): S498-516. 
Anexo I.

Comitê de Ética em Pesquisa da Faculdade de Saúde Pública 


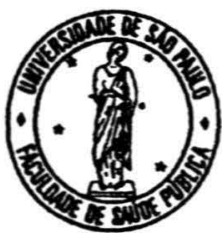

\section{Universidade de São Paulo}

\section{Faculdade de Saúde Pública}

COMITÊ DE ÉTICA-COEP

Av. Dr. Arnaldo, 715 - CEP 01246-904 - São Paulo - Brasil

Telefones: (55-11) 3066- 7734 - fone/fax (55-11) 3064 -7314-e-mail: mdgracas@usp.br

\section{Of.COEP/258/02}

09 de outubro de 2002

Pelo presente, informo que o Comitê de Ética em Pesquisa da Faculdade de Saúde Pública da Universidade de São Paulo-COEP, analisou e aprovou, em sua $8 .{ }^{a} / 02$ Sessão Ordinária realizada em 08.10 .02 , de acordo com os requisitos da Resolução CNS/196/96, o Protocolo de Pesquisa n. ${ }^{\circ}$ 863, intitulado: "ATIVIDADE FÍSICA DURANTE A GESTAÇÃO E PREMATURIDADE: UM ESTUDO DE CASOS E CONTROLES", apresentado pela pesquisadora Monica Yuri Takito.

Atenciosamente,

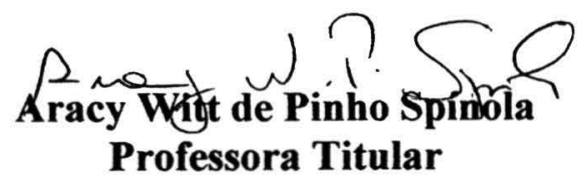

Vice-Coordenadora do Comitê de Ética em Pesquisa da FSP-COEP 


\section{UNIVERSIDADE DE SATO PAULO/FACULDADE DE SAÚDE} PÚBLICA

DEPARTAMENTO DE NUTRIÇÃO

Av. Dr. Arnaldo, 715 - Cerqueira Cesar

CEP: 01246-904 São Paulo/SP

Tel.JFAX: (011) 3066-7705/ 7771/7762

Tel.: (011) 3062.6748

e-mail.hnt@\}sp.usp.br

23 de junho de 2005 .

\section{Prof. Dra. Eunice Aparecida Bianchi Galati}

Coordenadora do Comitê de Ética em Pesquisa da Faculdade de Saúde Pública.

Venho por meio desta informar que o Protocolo de Pesquisa $n^{\circ} 863$ intitulado "Atividade física durante a gestação e prematuridade: um estudo de casos e controles" apresentado por minha orientanda de doutorado Monica Yuri Takito e aprovado pelo Comitê de Ética desta Faculdade em 9 de outubro de 2002 sofreu a seguinte e única modificação: substitui-se a medida da variável resposta: "prematuridade" (idade gestacional $\leq 37$ semanas) por baixo peso ao nascer (peso ao nascer $<2500$ gramas). Esta alteração justificou-se pela dificuldade de se obter medida fidedigna da idade gestacional em estudos epidemiológicos do tipo caso controle não aninhados em estudo prévio de coorte, que inclua avaliação ultrassonográfica precoce (anterior a $20^{\mathrm{a}}$ semana). Fomos alertadas para este fato em reunião com o Prof. César Victora, em Pelotas, na qual foi discutida a experiência recente de estudos epidemiológicos sobre a prematuridade.

Solicito aprovação pelo Comitê de Ética da mencionada modificação no protocolo de pesquisa agora intitulado: “Atividade física durante a gestação e baixo peso ao nascer: um estudo de casos e controles".

\section{Atenciosamente}

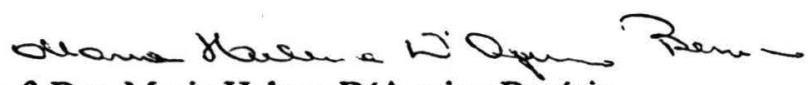

Prof. Dra. Maria Helena D'Aquino Benício

Orientadora da aluna de doutorado Monica Yuri Takito. 


\section{Universidade de São Paulo \\ Faculdade de Saúde Pública \\ COMITÊ DE ÉTICA - COEP}

Av. Dr. Arnaldo, 715 - Assessoria Acadêmica - CEP 01246-904 - São Paulo - Brasil Telefones: (55-11) 3066-7779 - e-mail: coepaitsp.usp.br

\section{Of.COEP/156/05}

30 de junho de 2005

Pelo presente, informo que o Comitê de Ética em Pesquisa da Faculdade de Saúde Pública da Universidade de São Paulo-COEP homologou de acordo com os requisitos da Resolução CNS/196/96 e suas complementares, a emenda sobre a alteração da medida da variável resposta prematuridade por baixo peso ao nascer, do Protocolo de Pesquisa n." 863, intitulado: "ATIVIDADE FÍSICA DURANTE A GESTAÇÃO E PREMATURIDADE: UM ESTUDO DE CASOS E CONTROLES", apresentado pela pesquisadora Mônica Yuri Takito, e portanto o título do projeto passa a ser "ATIVIDADE FÍSICA DURANTE A GESTAÇÃO E BAIXO PESO AO NASCER: UM ESTUDO DE CASOS E CONTROLES".

Atenciosamente,

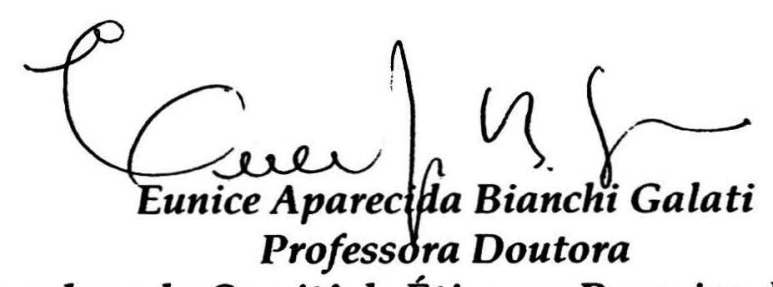

Coordenadora do Comitê de Ética em Pesquisa da FSP-COEP 
Anexo II.

Termo de Consentimento Livre e Esclarecido 


\section{Termo de Consentimento}

Eu, concordo em participar do estudo "Atividade física durante a gestação e baixo peso ao nascer: um estudo de casos e controles". Declaro estar ciente que este estudo será desenvolvido pela Faculdade de Saúde Pública junto ao com o objetivo de estudar a relação entre a atividade física durante a gestação e o baixo peso ao nascer.

Estou consciente que:

(1) os procedimentos citados serão realizados no hospital, no periodo posterior ao parto;

(2) serão obtidas informações junto ao meu prontuário clinico e do meu bebê;

(3) todos os dados obtidos na pesquisa serão utilizados exclusivamente para fins acadêmicos e científicos, incluindo publicação em revistas e livros especializados;

(4) em nenhum momento serei identificada;

(5) tenho liberdade para desistir da minha participação no estudo em qualquer fase sem penalidade alguma e sem prejuizo em meu cuidado, bastando para isso informar minha desistência.

Sei ainda que qualquer dúvida em relação à metodologia poderá ser esclarecida a qualquer momento.

São Paulo, de de

Participante

Nome completo:

Assinatura:

Nome e assinatura do pesquisador que obteve o consentimento:

Pesquisadores responsáveis: Monica Yuri Takito e Profa. Dra. Maria Helena D’Aquino Benício (Depto. Nutrição da Faculdade de Saúde Pública -USP) Telefone: 30667701 
Anexo III

Questionário 


\section{IDENTIFICAÇÃO DA PUÉRPERA}

SERVIÇO DE SAÚDE: (1) Hosp. e Mat. Leonor Mendes de Barros

(2) Amparo Maternal

( )

n.` do prontuário:

\section{Código}

NOME:

ENDEREÇO:

TELEFONE PARA CONTATO:

ENTREVISTADOR:

DATA:

hora início:

hora término:

D.U.M.

1

Primeira US

Data 1 I

IG semanas

Laboratório

( ) referida

( ) não sabe

( )exame US

( ) cartão pré-natal 
PARTE 1 - MULHER

Q1. Qual raca a Sra. se considera?

[raca]

branca 1

negra 2

mulata 3

amarela 4

não sabe 9

Q2. Atualmente mora com o seu marido/companheiro?

$S E N \tilde{A O} \rightarrow Q^{9}$

$\operatorname{sim} 1$

กลัก 2

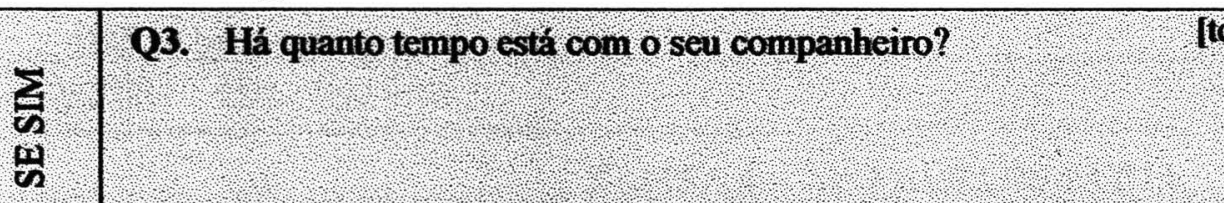

[tcomp]

menos de 3 meses 1

de 3 a 5 meses 2

de 6 a 11 meses 3

de 1 a 2 anos 4

Q4. Ele é o pai do bebê?

[pai]

mais de 2 anos 5

Q5. Seu companheiro/marido frequentou escola?

$S E \mathrm{NAO}=08$

$\sin 1$

nio 2

Q6. Até que anolsérie cursou?

$\sin 1$

[esccomp]

กลั० 2

07. De que grau?

[anocomp]

anolsérie

nto sabe 9

gcompl

$1^{1}$ graw 1

$2^{\circ}$ gran 2

$3^{\circ}$ grau/ superior 3

outro

Q8. Ele fez supletivo?

nab sabe 9

กล้อ T

$1^{\circ}$ gran 2

$2^{\circ}$ gran 3

Somente para as mulheres sem companheiro

Q9. Com quem mora?

[s_comp]

com pais/familiares 1

sozinha 2

com amigos 3

com os filhos 4

no local de trabalho 5

Q10. A Sra. freqüentou escola?

SE NAOO $\rightarrow Q 14$ outro

\begin{tabular}{|c|c|c|}
\hline Q11. Até que anolsérie curson? & [anoescol] & $\begin{array}{r}\text { anolsérie } \\
\text { uło sabe } 9\end{array}$ \\
\hline 012. De que grau? & [gescol] & $\begin{array}{r}\mathcal{P}^{\mathrm{g}} \text { grau } 1 \\
2^{\mathrm{O}} \text { grau } 2 \\
3^{\circ} \text { grau/ superior } 3\end{array}$ \\
\hline & & nsto sabe 9 \\
\hline M13. A Sra fez supletivo? & [supescol] & $\begin{array}{l}\text { nato } 1 \\
1^{\circ} \text { grau } 2 \\
2^{\circ} \text { grau } 3\end{array}$ \\
\hline
\end{tabular}

Apenas para quem tem menos de 4 anos de escolaridade ou nunca freqüentou escola

Q14. A Sr $^{2}$ sabe ler e escrever?

[ler]

\section{PARTE 2 - MORBIDADE}

Durante a gravidez.....

1 sim, não tratado 2 tratado 3 não 9ns

Q15. A Sra teve infecção urinária?

Q16. $\mathrm{A} \mathrm{Sr}^{2}$ teve outro tipo de infecção?

Q17. $\mathrm{A} \mathrm{Sr}^{2}$ teve corrimento?

Q18. A Sr ${ }^{2}$ teve pressão alta? 1=antes da gestaçao $2=$ durante

[infec] 112013

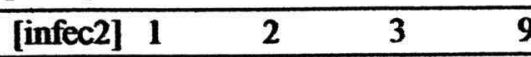

[corrim] 1 201309

Q19. A Sr $^{2}$ teve diabetes? $\quad 1=$ antes da gestaçao $2=$ durante

[has] 1

Q20. A Sr ${ }^{2}$ teve Depressão ou tristeza?

$1=$ sempre $\quad 2=a$ maior parte do tempo $3=$ às vezes $\quad 4=$ nunca

Q21. A $\mathrm{Sr}^{\mathrm{a}}$ teve outra doença?

Qual?

Quando?

[doença] 123




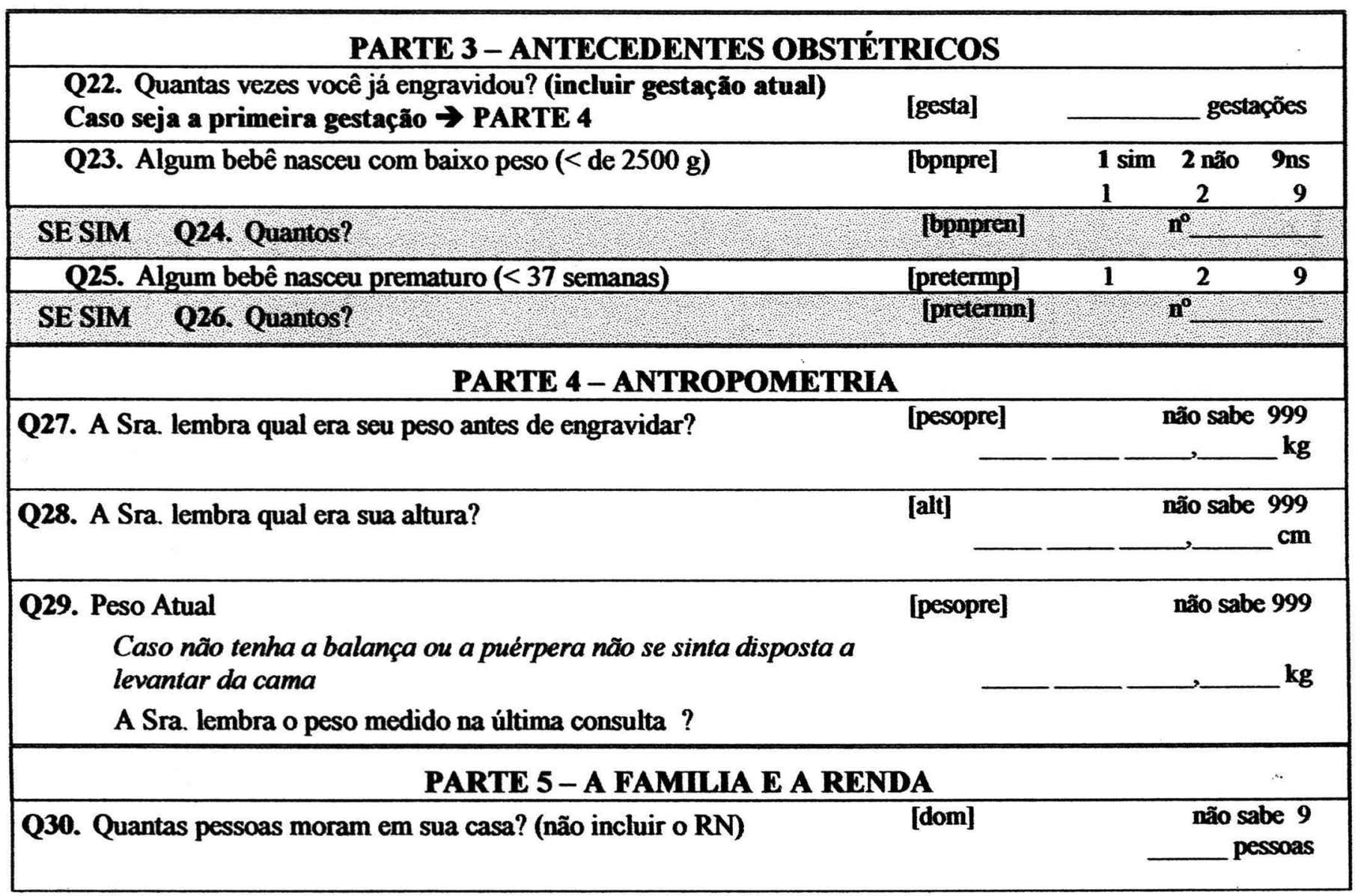

QUADRO 1 - Descrição das pessoas no domicilio

\begin{tabular}{|c|c|c|c|}
\hline \multicolumn{3}{|c|}{ Q31. Enumerar as pessoas que moram no domicilio: } \\
\hline Pessoa & Idade & Parentesco em relação a Sra. & Renda individual no mês anterior \\
\hline 1 & & & \\
\hline 2 & & & \\
\hline 3 & & & \\
\hline 4 & & & \\
\hline 5 & & & \\
\hline 6 & & & \\
\hline 7 & & & \\
\hline 8 & & & \\
\hline
\end{tabular}

Q32. A familia tem outro ganho que contribui para renda familiar? (pensão, aluguel e etc) SE NÃO $\rightarrow Q 27$

[outrend]

$\operatorname{sim} 1$

กล̃o 2

\begin{tabular}{|c|c|c|c|}
\hline \multirow[b]{2}{*}{ 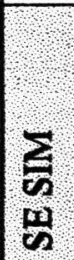 } & $\begin{array}{l}\text { Q33. A Sra lembra qual o valor mensal aproximado de outr } \\
\text { rendas? }\end{array}$ & [Voutrend] & nfio sabe 999 \\
\hline & $\begin{array}{l}\text { Q34. A Sra poderia informar a renda mensal total familiar? } \\
\text { Entrevistador: calcular ao término da cntrevista salá }\end{array}$ & & nojo sabe 999 \\
\hline
\end{tabular}


PARTE 6 - CIGARRO E OUTRAS DROGAS

Q35. A Sra fuma?

[fuma]

$\sin 1$

กลัก 2

$S E N A O O \rightarrow Q 32$

antes de engravidar 3

Q36. Se parou, há quanto tempo ? (especificar tempo-dia, mês, ano) [tfuma]

\begin{tabular}{|c|c|c|c|c|c|}
\hline & & $\begin{array}{l}\text { Antes da } \\
\text { gestação }\end{array}$ & $\begin{array}{c}\text { Nos } 3 \\
\text { primeiros } \\
\text { meses }\end{array}$ & $\begin{array}{l}\text { Dos } 4 \text { aos } \\
6 \text { meses }\end{array}$ & $\begin{array}{c}\text { Dos } 7 \\
\text { meses } \\
\text { até o } \\
\text { final }\end{array}$ \\
\hline$\sum$ & $\begin{array}{l}\text { Q37. Fumava todos os dias? } \\
(0-\text { ndo, }(-\operatorname{sim})\end{array}$ & [fumal] & [fume] & [fuma3] & {$[$ [finz+] } \\
\hline$\sqrt{2}$ & $\begin{array}{l}\text { Q38. Quantos cigarros fumava por dia? } \\
(99-\text { nao sabe) }\end{array}$ & [funas] & 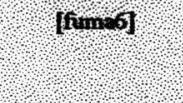 & [fumn] & [f:me8] \\
\hline
\end{tabular}

Agora vamos falar um pouco sobre o hábito de tomar bebidas (alcoólicas, café e outras drogas)

Q39.A Sra. costumava beber bebida de álcool durante a gravidez?

SE NATO $\rightarrow Q 36$

[alcool]

กล̃o 0

$\operatorname{sim} 1$

nẫo sabe 9

Durante a gravidez, a Sra..

UTILVARR $0=$ - ido I-sin, no quadro abaiko

\begin{tabular}{|c|c|c|c|}
\hline & $\begin{array}{l}\text { Nos } 3 \\
\text { primeiros } \\
\text { meses }\end{array}$ & $\begin{array}{l}\text { Dos } 4 \text { aos } \\
6 \text { meses }\end{array}$ & $\begin{array}{l}\text { Dos } 7 \\
\text { meses ate } \\
\text { o final }\end{array}$ \\
\hline
\end{tabular}

Q40. Tomou qual(is) bebida(s) alcoolica(s)?

1 . Quantos dias por semana?

5ै

Quanto tomava por dia? (especificar recipiente)

Q41. A Sra costumava tomar café durante a

gravidez?

$(0=$ não; $1=$ sim $)$ SE NÃO $\rightarrow Q 38$

$\rightarrow$ Quantos dias por semana a Sra tomava café?

\%) Quanto tomava por dia? (especificar recipiente)

A Sra. já fez uso de alguma destas drogas?

Q42. maconha

Q43. crack

Q44. cocaína

Q45. LSD

Q46. heroina

Q47. Utilizou algum medicamento?

Quais?

PARTE 7 - TRABALHO

Q48. Durante a gestação a Sra. trabalhou fora de casa? SE NÃO $\rightarrow$ SIGA PARA PARTE 8

[trab]

$\operatorname{sim} 1$

กลีว 2

Q49. Quantos meses a Sra trabalhou?

[trab1]

meses

Q50. O que fazia no trabalho?

[trab2]

Q51. Quantos dias a Sra. trabalhava na semana?

[trab3]

dias

Q52. Quantas horas por dia?

[trab4]

loras

Q53. Qual o meio de transporte a Sra. utilizava para ir e voltar do trabalho?. [trabcond] 
Q54. A Sra. permanecia muito sentada no trabalho?

[trabsent]

não sabe 9

Q55. A Sra se abaixava lagachava muito? A Sra se curvava muito?

[trabagac]

Q56. A Sra. permanecia em pé parada muito tempo?

nร̌̄o sabe 9

SE SIM Q57. Quanto tempo?

[trabpet]

Q58. A Sra. se cansava muito no trabalho (físicamente)? horas

[trabcans]

\section{PARTE 8 - ATIVIDADE FISICA}

Q59. Comparando com outras gestantes da sua idade [ativa] quanto ativa a Sra. é?

Muito mais ativa 1

Mais Ativa 2

Tão ativa quanto 3

Pouco ativa 4

Muito pouco ativa 5

Não sabe referir 9

Q60. No momento que soube que estava grávida queria ter um filho?

SE NAO Q61. Por que?

Q62. A Sra. praticava esportes?

[desejfil]

$\operatorname{sim} 1$

กอีด 2

[naodes]

[esporte]

$\operatorname{sim} 1$

ก⿺辶่ 2

SE SIM 063. Qual?

[esportq]

Q64. A Sra. praticava alguma atividade fisica que fazia a Sra. transpirar? [ativfis]

Q65. A Sra. levantava ou carregava objetos pesados (mais de $10 \mathrm{~kg}$ )? [ativfis]

Q66. A Sra. praticava regularmente atividades fisicas vigorosas que [afvig] necessitam de um grande esforço físico e fazem respirar muito mais forte do que o normal?

$\operatorname{sim} 1$ não 2

$\operatorname{sim} 1$

กมีว 2

$\operatorname{sim} 1$

กลิ์ 2

não sabe 9

SE Q67. Qual?

SIM Q68. Quanto tempo?

[afvigq] [afvigd]

dias da semana

[afvigh]

horas pordia

Q69. A Sra praticava regularmente atividades fisicas moderadas que [afmod] necessitam de um algum esforço físico e fazem respirar um pouco mais forte do que o normal?

$\operatorname{sim} 1$

não 2

กมิ์ sabe 9

SE Q70. Qual?

SIM Q71. Quanto tempo?

[afinodq]

[afmodd]

[afimodh]

[ativapre]

Q72. Comparando com outras mulheres da sua idade quanto ativa a Sra. era antes de engravidar?

dias da semana horas por dia

Muito mais ativa 1

Mais Ativa 2

Tão ativa quanto 3

Pouco ativa 4

Muito pouco ativa 5

Não sabe referir 9

sim, diminui 1 sim, aumentei 2 não modifiquei 3

não sabe referir 9

Q73. A Sra. acha que modificou suas atividades fisicas depois que ficou [modifi] sabendo que estava grávida?

SE Q74. Quando?

[modifq]

SIM Q75. Por que?

[modifp]

Q76. Nas suas atividades de casa (lavar, passar, varrer, limpar, etc.) a [ajuda]

Sra tinha alguém que a ajudasse regularmente?

$\operatorname{sim} 1$

กล๊ก 2

SESIM 077. Quem?

[ajudq] 
Q78. Com que frequêencia, em uma semana típica do segundo trimestre de sua gestação, a Sra. realizou as seguintes atividades (incluir o tempo $e$ as atividades de trabalho fora quando este estiver relacionado com atividades domésticas como: faxineira, empregada doméstica, babá e entre outras)?

Localizar com a mulher o periodo da gestação e também meses do ano.

No item Modifica incluir modificação da atividade física durante a gestação e utilizar a seguinte classificação: diminuiu (1), aumentou (2), não modificou (3), não sabe referir (9). Caso a gestante refira alteração (respostas $1 \mathrm{e}$ 2), especificar mês gestacional.

\begin{tabular}{|c|c|c|c|c|}
\hline ATIVIDADE & $\begin{array}{l}\text { Vezes por } \\
\text { Semana }\end{array}$ & $\begin{array}{l}\text { Tempo dispendido } \\
\text { por vez (minutos) }\end{array}$ & Modifica & $\begin{array}{c}\text { Mês } \\
\text { gestacional }\end{array}$ \\
\hline \multicolumn{5}{|l|}{ limpar casa } \\
\hline \multicolumn{5}{|l|}{ ( ) limpeza leve } \\
\hline \multicolumn{5}{|l|}{ ( ) faxina pesada } \\
\hline \multicolumn{5}{|l|}{ varrer casa } \\
\hline \multicolumn{5}{|l|}{ varrer quintal } \\
\hline \multicolumn{5}{|l|}{ limpar carpetes } \\
\hline \multicolumn{5}{|l|}{$\begin{array}{l}\text { Atividades agachada } \\
\text { Quais? }\end{array}$} \\
\hline \multicolumn{5}{|l|}{ lavar roupa } \\
\hline \multicolumn{5}{|l|}{ estender roupa no varal } \\
\hline \multicolumn{5}{|l|}{ passar roupa } \\
\hline \multicolumn{5}{|l|}{ cozinhar } \\
\hline \multicolumn{5}{|l|}{ lavar louça } \\
\hline \multicolumn{5}{|l|}{$\begin{array}{l}\text { Cuidar de criança ( }<5 \text { anos) } \\
\text { Quantas?___ Idade / peso? }\end{array}$} \\
\hline \multicolumn{5}{|l|}{$\begin{array}{l}\text { Dar banho / vestir / Alimentar / } \\
\text { Amamentar } \\
\text { ( ) sentada ( ) em pé } \\
\text { Brincar com a criança: } \\
\text { De quê? }\end{array}$} \\
\hline \multicolumn{5}{|l|}{$\begin{array}{l}\text { ( ) sentada ( ) em pé } \\
\text { Esforço: ( ) Leve } \\
\text { ( ) Moderado ( ) Intenso }\end{array}$} \\
\hline \multicolumn{5}{|l|}{$\begin{array}{l}\text { Carregar no colo } \\
\text { Outras atividades }\end{array}$} \\
\hline Atividade sexual & & & & \\
\hline
\end{tabular}


NOME

COD

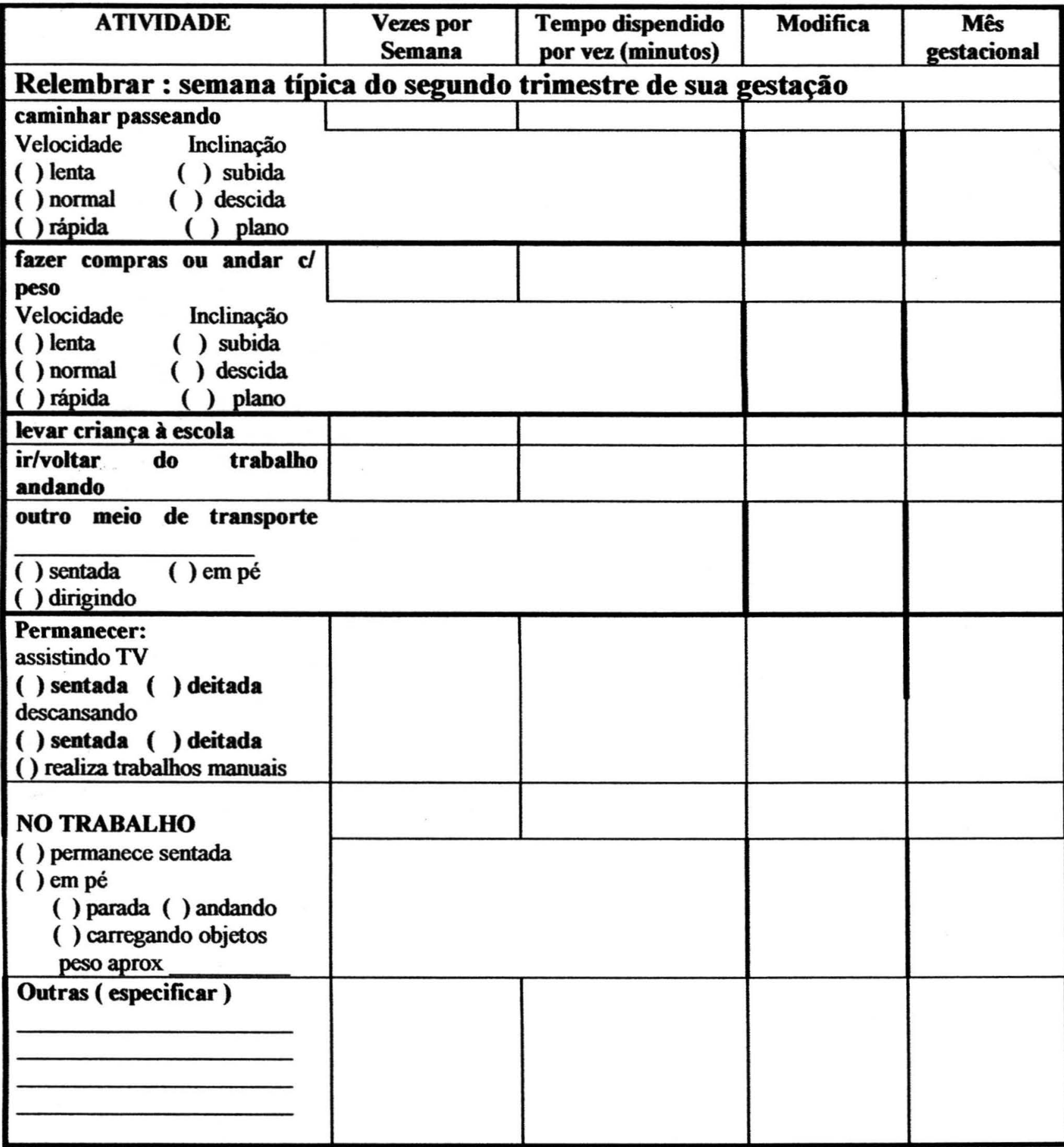

Q79. Quantas horas, a Sra. dormia normalmente? (incluir horas de sono [sonoh] horas durante o dia)

Q80. A Sra. em geral tinha um sono tranqüilo?

ou das

às $\mathbf{h}$ [sono]

\section{PARTE 9 - PRÉ-NATAL}

\section{Agora vamos conversar sobre sua gravidez}

Q81. A Sra. planejou ter esse filho ou engravidou sem querer?

[plan]

planejou 1

sem querer 2

mais ou menos 3

não sabe 9

Q82. A Sra. fez alguma consulta de pré-natal durante a gravidez?

[apn]

กลัก 0

$\operatorname{sim} 1$

SE NÄO FEZ PRÉ-NATAL $\rightarrow$ ENCERRAR A ENTREVISTA

não sabe 9 
Q83. Qual o local onde a Sra. fez o seu Pré-Natal?

Posto de Saíde (nome):

[apni]

posto de saúde 1

Endereco (ou referencial):

outro 7

Outro local - qual?

näo sabe 9

$\rightarrow$ Se for convênio Qual o convênio?

Q84. A Sra foi atendida pelo mesmo médico ou enfermeira durante as [apn2] consultas do pré-natal ou eram profissionais diferentes a cada consulta? profissionais diferentes 2 nä̀ sabe 9

085. Quantas consultas de pré-natal a Sra fez? (náo sabe = 99) lapn3 consultas

Q86. Em que mês da gravidez a Sra. fez a primeira consulta de pré-natal? (não sabe -99 )

Q87. A Sra. fez exames de sangue durante a gravidez? Se fez, quantas coletas? 100 -não fez; 99 -não sabe)

Q88. A Sra fez exames de urina durante a gravidez? Se fez, quantas coletas? ( 00 - nāo fez, 99 -não sabe)

[apn4]

mês

Q89. A Sra fez ultra-sonografias durante o pré-natal? Se fez, quantos? (00-não fez; 99-não sabe)

Q90. Para quando foi marcada a sua última consulta de pré-natal?

Caso a última consulta agendada tenha sido antes da internaçăo

Q91. A Sra sabe por que não foi marcada outra consulta?

[apn5]

Outro

[apn6]

4. exames

Durante as consultas de pré- natal o médico ou a enfermeira alguma vez..

Q2. Mediu a sua barriga?

[apn10]

-. exames

[apn7]

[ap8] Data exames

mês gestacional

[apn9] alia de pré natal 1

faltou na consulta anterior 2

marcou procedimento no hospital 3

$\leftarrow$ outro 4

nầ sabe 9

Q93. Mediu sua pressão?

[apn11]

$\sin 1$

ñ̃o sabe 9

กล้อ 0

$\sin 1$

ñ̃o sabe 9

Q94. Fez exame ginecológico?

(Se nao entender, usar o termo "exame por baixo".)

năo 0

$\sin 1$

não sabe 9

Q95. Receitou remédio para anemia?

[apn12]

$\sin 1$

näo sabe 9

Q96. Receitou vitaminas?

[apn14] กล์จด 0

$\sin 1$

nồ sabe 9

Q97. Orientou sobre exercícios físicos, como caminhada, por exemplo?

[apni5]

năo 0

SEE NAO $\rightarrow 0100$

$\sin 1$

não sabe 9

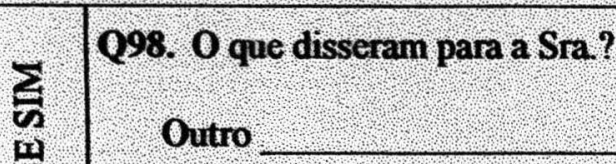

[apn16] que deveria fazer 1 que deveria reduzir ou mudar 2 que nå̄o deveria fazer 3

outro 4

näo sabe 9

Q99. Examinou seus seios?

[apn17] กริด 0

$\operatorname{sim} 1$

não sabe 9

Q100. Fez exame de prevenfão do câncer de colo de útero?

[apn18]

$\operatorname{sim} 1$

fez antes de engravidar 2

niso sabe 9

Q101. Durante o pré-natal, a Sra fez a vacina contra o tétano?

[apn19]

กล้อ 0

$\sin 1$

já estava vacinada 2

näo sabe 9

Q102. Você ficou satisfeita com o seu pré-natal?

nมี० 0

$\sin 1$

SE NĀO $\rightarrow$ Por que?

não sabe 9 
Anexo IV.

Diário 
Endereço:

Telefone:

$$
\begin{aligned}
& \text { Data e horário de início do diário: } \\
& \text { Data e horário de entrega do diário: }
\end{aligned}
$$

\section{Instruçōes}

$\star$ Este teste irá gravar durante todo o período seus batimentos cardíacos.

$\star$ Caso o equipamento desligue ou pare de funcionar, favor entrar em

contato assim que possível.

$\star$ Caso queira desistir da pesquisa favor entrar em contato para devolução

do aparelho, com urgência.

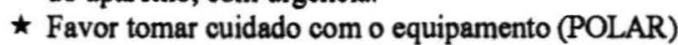

$\star$ Este teste não deverá modificar a sua rotina diária, pelo contrário precisamos conhecer sua rotina de atividades fisicas. Para isso junte este diário.

$\star$ Continue realizando suas atividades mais importantes, por exemplo: andar, assistir TV, almoçar, trabalhar, dormir, etc. Sempre colocando o horário de início e fim de cada atividade, por mais breve ou leve que tenha sido. Favor preencher todas as suas atividades diárias e coloque 0 horário de INICIO e FIM de cada atividade, conforme o exemplo

Dia Horário Atividade

\begin{tabular}{|c|c|c|c|}
\hline & De & Até & \\
\hline \multirow[t]{6}{*}{$1^{0}$} & 7:00 & 7:15 & 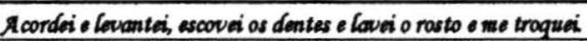 \\
\hline & 7:15 & $7: 30$ & Fiz o caf e esquentei o pdo. Tomei cafe. \\
\hline & $7: 30$ & $8: 00$ & Lavei a loupa \\
\hline & $8: 00$ & $8: 15$ & Cominhiei atte o ponto de Onibus \\
\hline & $\cdots$ & & ..... \\
\hline & $22: 00$ & 7:00 & Donuindo \\
\hline \multirow[t]{2}{*}{$2^{\circ}$} & $7: 00$ & $7: 15$ & Acorder e levanten, escovvei os dentes e lavei o rosto e me troquen \\
\hline & 7:15 & 7:30 & Fiz o cafi e esquentei o pdo. Tomei cafk. \\
\hline
\end{tabular}

TELEFONES PARA CONTATO (11) 9811-7872/(11) 9421-4274

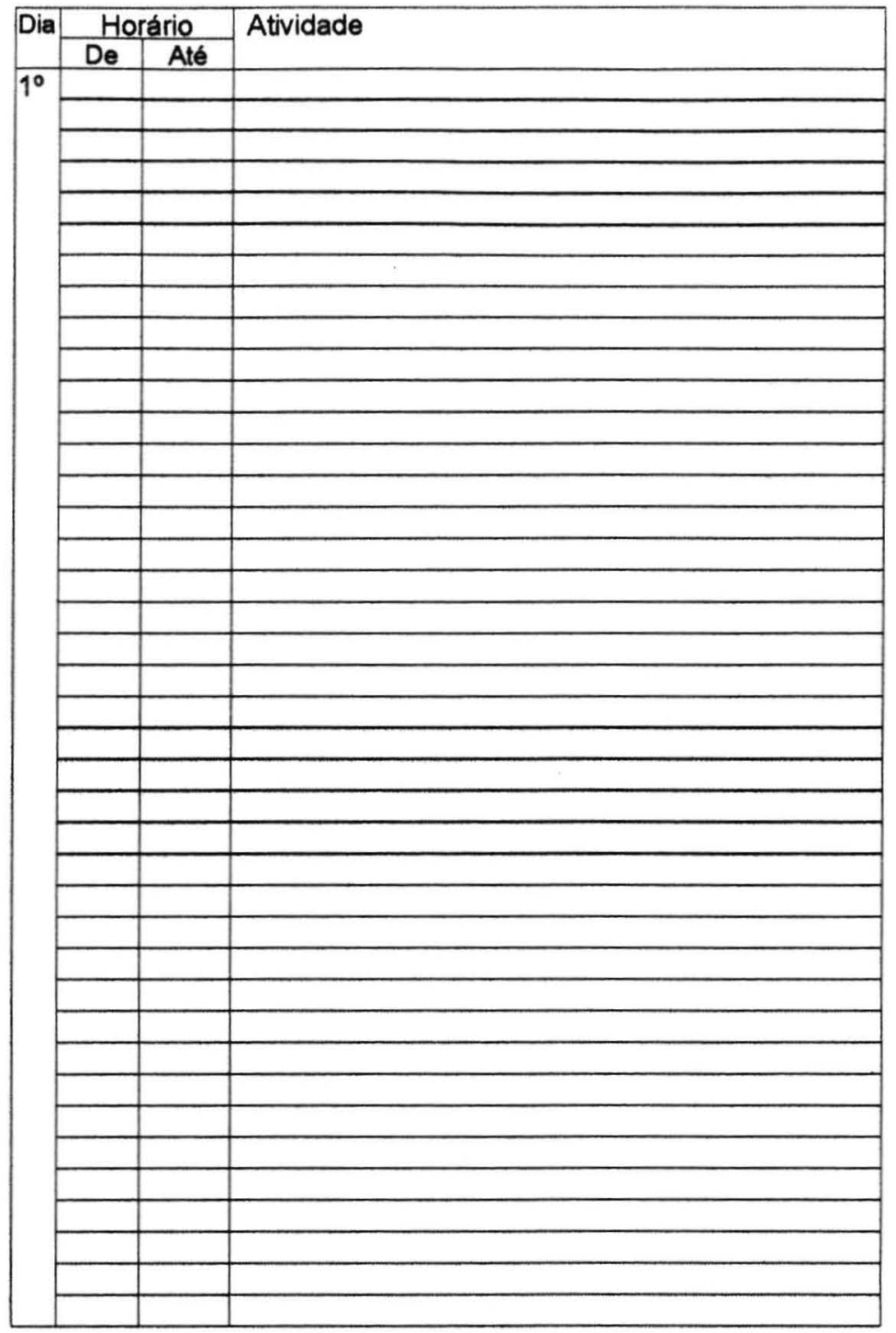

